\title{
The effect of the probiotic L.plantarum 299v on the intestinal flora : methodological studies in health and disease
}

Citation for published version (APA):

Goossens, D. A. M. (2006). The effect of the probiotic L.plantarum 299v on the intestinal flora : methodological studies in health and disease. [Doctoral Thesis, Maastricht University]. Universiteit Maastricht. https://doi.org/10.26481/dis.20060518dg

Document status and date:

Published: 01/01/2006

DOI:

$10.26481 /$ dis.20060518dg

Document Version:

Publisher's PDF, also known as Version of record

\section{Please check the document version of this publication:}

- A submitted manuscript is the version of the article upon submission and before peer-review. There can be important differences between the submitted version and the official published version of record. People interested in the research are advised to contact the author for the final version of the publication, or visit the DOI to the publisher's website.

- The final author version and the galley proof are versions of the publication after peer review.

- The final published version features the final layout of the paper including the volume, issue and page numbers.

Link to publication

\footnotetext{
General rights rights.

- You may freely distribute the URL identifying the publication in the public portal. please follow below link for the End User Agreement:

www.umlib.nl/taverne-license

Take down policy

If you believe that this document breaches copyright please contact us at:

repository@maastrichtuniversity.nl

providing details and we will investigate your claim.
}

Copyright and moral rights for the publications made accessible in the public portal are retained by the authors and/or other copyright owners and it is a condition of accessing publications that users recognise and abide by the legal requirements associated with these

- Users may download and print one copy of any publication from the public portal for the purpose of private study or research.

- You may not further distribute the material or use it for any profit-making activity or commercial gain

If the publication is distributed under the terms of Article $25 \mathrm{fa}$ of the Dutch Copyright Act, indicated by the "Taverne" license above, 


\section{The effect of the probiotic L. plantarum $299 \mathrm{v}$ on the intestinal flora}

Methodological studies in health and disease 
- Dominique Goossens, Maastricht 2006

ISBN-10: 90-6464-008-4

ISBN-13: 978-906464-008-7

Coverdesign: Studio Rebel, www.studiorebel.nl

Layout: Tiny Wouters

Printed by: Ponsen \& Looijen B.V., Wageningen, The Netherlands.

This thesis was financially supported by ALTANA Pharma bv, Probi $A B$ and Numico Research B.V.

Titrin The studies presented in this thesis were performed at the IU (III] Nutrition and Toxicology Research Institute Maastricht (NUTRIM), which participates in the Graduate School VLAG (Food Technology, Agrobiotechnology, Nutrition, and Health Sciences), accredited by the Royal Netherlands Academy of Arts and Sciences (KNAW). 


\title{
The effect of the probiotic L. plantarum $299 \mathrm{v}$ on the intestinal flora
}

\section{Methodological studies in health and disease}

\author{
PROEFSCHRIFT \\ ter verkrijging van de graad van doctor \\ aan de Universiteit Maastricht, \\ op gezag van de Rector Magnificus, \\ Prof. mr. G.P.M.F. Mols, \\ volgens het besluit van het College van Decanen, \\ in het openbaar te verdedigen \\ op donderdag 18 mei 2006 om 16.00 uur
}

door

Dominique Anne Marie Goossens

geboren op 5 januari 1976 te Eindhoven 
Promotor:

Prof dr. R.W. Stockbrügger

Co-promotores:

Dr. D.M.A.E. Jonkers

Dr. M.G.V.M. Russel

Beoordelingscommissie:

Prof. dr. A. Schols (voorzitter)

Prof. dr. C. I. Baeten

Prof. dr. C. A. Bruggeman

Prof. dr. R-J.M. Brummer

Prof. dr. G. Molin (Lund University, Lund, Sweden) 


\section{Contents}

$\begin{array}{lll}\text { Chapter } 1 \text { Introduction } & 7\end{array}$

Chapter 2 The effect of L.plantarum $299 \mathrm{v}$ on the bacterial composition 35 and metabolic activity in faeces of healthy volunteers:

a placebo-controlled study on the onset and duration of effects

Chapter 3 Survival of the probiotic, L. plantarum $299 \mathrm{v}$ and its effects on 53 the faecal bacterial flora, with and without gastric acid inhibition

Chapter 4 Can L. plantarum 299v change the faecal flora after bowel cleansing for colonoscopy?

Chapter 5 The effect of a probiotic drink with L. plantarum $299 \mathrm{~V}$ on the bacterial composition in faeces and mucosal biopsies of rectum and ascending colon

Chapter 6 The faecal and mucosal bacterial composition of patients with inactive UC: can it be changed by L. plantarum 299v?

Chapter 7 General discussion and conclusions

Chapter 8 Summary

Samenvatting

Dankwoord 
काष

s.

is

_. $\quad$ - येग 


\section{Chapter 1}

\section{Introduction}

This chapter has been adapted from the article entitled:

"Probiotics in Gastroenterology: Indications and Future Perspectives" D. Goossens, D. Jonkers, E. Stobberingh, A. van den Bogaard, M. Russel, R. Stockbrügger. 
Chapter 1 


\section{Human microflora}

The human microflora comprises a complex ecosystem with high concentrations and variety of bacterial species that can have an influence on the physiology of the host. The human body contains approximately $10^{14}$ aerobic and anaerobic bacteria that outnumber the total cells of the human body by a factor ten. These bacteria can be found on the skin, and on the mucosa of the oral cavity, upper respiratory tract, urinary tract and vagina, but the largest population inhabits the gastrointestinal tract $t^{1,2}$. This intestinal bacterial flora is not equally distributed in the gastrointestinal tract. The stomach contains relatively small numbers of bacteria $\left(0-10^{3}\right.$ colony forming units (CFU) per ml gastric content) because of the gastric acidity. In the lower gastrointestinal tract, there is a higher $\mathrm{pH}$, lower transit time and a higher amount of carbohydrates, resulting in gradually increased numbers and variety of intestinal bacteria. The highest bacterial numbers $\left(10^{11}-10^{12}\right.$ CFU per $\mathrm{ml}$ intestinal content) and the largest diversity are found in the colon that contains mainly obligatory anaerobic species $(99.9 \%)$ such as Bacteroides spp., Clostridium spp., bifidobacteria, fusobacteria and eubacteria ${ }^{1-4}$. More than 100 different species have been identified in faecal samples from healthy individuals, but at least $400-500$ different species are thought to be present in the colonic microflora ${ }^{5}$.

The composition of the human intestinall flora is influenced by host factors (such as $\mathrm{pH}$, transit time, bile acids, pancreatic enzymes and the mucus composition), non-host factors (such as nutrients, medication, environmental factors) and bacterial factors (such as adhesion capacity, enzymes and metabolic capacities). The intestinal bacteria can interact and these interactions could be either positive or negative by metabolic cooperation or competition, by changes in environmental $\mathrm{pH}$, availability of $\mathrm{O}_{2}$ or by the production of metabolites such as short chain fatty acids (SCFA) and antimicrobial substances ${ }^{6-8}$.

The gastrointestinal tract is sterile at the time of birth but the intestinal flora will be developed during and after birth by exposure to bacteria from the external world. The way of giving birth (naturally or via Caesarean section), the type of feeding (breast-fed versus bottle-fed) and contact with bacteria from the mother are examples of factors determining the composition of the intestinal flora of meonates $^{9 \cdot 11}$. The intestinal tract of breast-fed children is considered to be mainly colonised by bifidobacteria while in bottle-fed children the numbers of bifidobacteria are lower and the numbers of enterobacteriaceae, Bacteroides spp. and clostridia are higher ${ }^{9}$. After weaning, each individual develops an own unique but complex intestinal flora (i.e., a bacterial 'fingerprint') ${ }^{12}$. This intestinal flora is thought to be relatively stable over time: Zoetendal et al. reported that the faecal flora of each of four individuals was stable over a four months' time period based on molecular analyses but showed inter-individual differences in its bacterial 'fingerprints' ${ }^{13}$. On the other hand, Goldin et al. demonstrated that changing the diet (i.e., removal of red meat and adding fibres to a 'Western- 
type' diet) influenced the metabolic activity of the intestinal flora, while influences on the bacterial composition have not been studied ${ }^{14}$. Moreover, the faecal intestinal composition might be affected by the physiology associated with aging ${ }^{15}$ and by the intake of medication such as antibiotics and 5aminosalicyclic acid ${ }^{16-18}$. These findings indicate that also environmental factors may influence the composition and/or metabolic activity of the intestinal flora.

Important functions of the intestinal flora for the host comprise the synthesis of vitamins $(B$ and $K)$ and the metabolism of nutrients, e.g. the production of SCFA such as acetate and butyrate by fermentation of non-digested polysaccharides. Butyrate, for example, is an important energy source for colonocytes and can change cell functioning by influencing lipogenesis, cell membrane assembly, DNA/RNA turnover and crypt cell proliferation ${ }^{19,20}$. Acetate improves the microcirculation and will facilitate the growth of the small intestinal mucosa ${ }^{21}$. Faecal concentrations of SCFA can be influenced by changes in the composition of the intestinal flora for instance by the intake of probiotics $^{22,23}$.

In addition, intestinal bacteria can convert primary bile acids into mutagenic secondary ones. Bacterial enzymes such as $\beta$-glucosidase and $\beta$-glucuronidase can hydrolyse a large number of different glucosides and glucuronides, forming carcinogenic and toxic substances ${ }^{24}$. These bacterial enzyme activities can be influenced by dietary factors. Goldin et al. demonstrated, for example, that rats, fed a high meat diet, showed a significant increase in the $\beta$-glucuronidase activity. Finally, intestinal bacteria can influence the immune system such as the maturation of regulatory $T$ cells and antigen presenting cells changing the T-helper $1 / T$-helper 2 balance ${ }^{25}$. Intestinal bacteria can also play a role in the defence against the invasion of unwanted exogenous bacteria ${ }^{12,26}$ by colonisation resistance ${ }^{27}$.

\section{Probiotics}

During the past few years there is growing interest in changing the intestinal bacterial flora towards a more 'beneficial' and 'healthier' composition by probiotics, characterised by high concentrations of lactobacilli and bifidobacteria and low concentrations of pathogenic bacteria such as Bacteroides spp. 'Probiotics' are defined by Havenaar et al. (1992) as "mono- or mixed cultures of live micro-organisms which, when applied to animal or man, beneficially affect the host by improving the properties of the indigenous microflora" ${ }^{28}$. Both Lactobacilli spp. and Bifidobacterium spp. are frequently applied as probiotics, mostly given in fermented milk products or in a freezedried form ${ }^{2}$. Lactobacillus casei Shirota, Lactobacillus GG, Escherichia coli and Saccharomyces boulardii are examples of probiotic strains frequently investigated in animal and human studies. 
Next to probiotics, prebiotics and synbiotics (combinations of pre- and probiotics) are also often used. 'Prebiotics' are food components that are not digested by the host and therefore reach the colon in intact form, where they stimulate the growth of bifidobacteria and lactobacilli ${ }^{29}$.

Probiotics should be of human origin, genetically stable and it is very important that they are able to survive passage through the gastrointestinal tract (such as low gastric $\mathrm{pH}$ and high intestinal bile acid concentrations). They should preferably be able to adhere to the intestinal mucosa so that they can colonise the host ${ }^{30}$. Probiotics are considered to be safe as the strains are isolated from humans and have long been used in food fermentation ${ }^{31}$. The beneficial effects of probiotics are postulated to be due to modulation of the composition of the intestinal bacterial flora, adherence to the mucosa thereby competing with pathogens, changes of enzyme activities in the colon contents, influences on the immune system of the host, and changes in the availability of metabolic products such as SCFA ${ }^{2,32-34}$.

Potential beneficial effects of probiotics can be expected in clinical conditions where the intestinal bacterial composition is thought to be disturbed. Although the mode of action of probiotics is still not exactly known, several clinical studies focused on the effects of probiotics in gastrointestinal disorders such as diarrhoea (rotavirus-associated and antibiotic-associated), inflammatory bowel disease, pouchitis, irritable bowel syndrome, colorectal cancer, lactose absorption, Helicobacter pylori infection and constipation. The following paragraphs review the main findings of clinical trials performed with probiotics in the field of gastroenterology.

\section{Probiotics and diarrhoea}

Diarrhoea can occur as a consequence of amongst others acute viral or bacterial infections or as a side effect of antibiotics. In patients with acute or antibiotic-associated diarrhoea, a disturbance of the intestinal flora has been observed $^{18}$. The role of probiotics in the prevention or treatment of acute viral or bacterial and antibiotic-associated diarrhoea has been studied extensively as they may restore a balance in the composition of the intestinal flora, stimulate the immune system, and may compete with pathogens.

\section{Acute viral or bacterial diarrhoea}

A major group of interest for probiotic use is acute diarrhoea caused by rotavirus infections, which is the most common cause of acute gastro-enteritis in children. In several placebo-controlled studies an improvement of rotavirusassociated diarrhoea in children has been reported after treatment with $L$. $G G$, measured as reduction in duration of diarrhoea or decrease in number of bowel movements per day ${ }^{35-39}$. The beneficial effects were accompanied by an 
increase of serum IgA antibody levels in these patients ${ }^{37,40}$ and a decrease in rotavirus shedding in the faeces ${ }^{35,41}$. One study on the prophylactic effect of L. GG in 204 undernourished Peruvian children reported a decrease in the incidence of acute diarrhoea ${ }^{42}$.

The positive results of $L, G G$ in acute diarrhoea cannot be extrapolated to other probiotic strains or to other causes of acute diarrhoea of viral or bacterial origin. On the other hand, beneficial effects have been reported for $S$. boulardii in the treatment of acute diarrhoea in children or adults ${ }^{43,44}$ and for Lactobacillus reuter in children with rotavirus-associated diarrhoea ${ }^{39}$. Maiamaa et $a l^{40}$ have also compared several probiotic strains and found a beneficial effect of $L$. GG in rotavirus gastro-enteritis but not of Lactobacillus rhamnosis, Lactobacillus delbrueckif and Saccharomyces thermophilus. In addition, placebo-controlled trials in children with acute diarrhoea could not demonstrate a beneficial effect of Lactobacillus acidophilus ${ }^{45,46}$, and inconsistent results were reported for Enterococcus SF68 in adults with acute diarrhoea ${ }^{47-49}$.

The therapeutic effects of especially $L$. GG in rotavirus-associated diarrhoea are well established. Benefits comprise a reduction in duration of diarrhoea by one or two days compared to a median duration of diarrhoea of three days.

\section{Antibiotic-associated diarrhoea}

Diarrhoea can also occur as an adverse effect of antibiotic therapy with clinical symptoms ranging from mild diarrhoea to severe pseudomembranous colitis. The use of antibiotics can disturb the intestinal microflora and modulate the immune system directly and indirectly, thereby resulting in diarrhoea ${ }^{18,50}$. Probiotics can potentially treat or prevent antibiotic-associated diarrhoea by restoring the intestinal bacterial balance and/or by modulating the immune system. Several placebo-controlled studies have demonstrated a decrease in the incidence of diarrhoea or a change in stool frequency and consistency in patients treated with probiotics in addition to the antibiotic therapy ${ }^{52-58}$. Frequently applied probiotic strains in these studies are L. GG, L. acidophilus and $S$. boulardii. In contrast, some others could not demonstrate a decrease in the incidence of diarrhoe ${ }^{59-61}$. Most studies on probiotics in antibioticassociated diarrhoea are placebo-controlled and performed with reasonable numbers of patients. Recently, two meta-analyses regarding the effect of probiotics in the prevention of antibiotic-associated diarrhoea have been published $^{62,63}$. These included nine and seven randomised placebo-controlled double-blind trials and reported an odds ratio of 0.37 ( $95 \%$ confidence interval, $0.26-0.53$ ) and a relative risk of 0.40 (95\% confidence interval, $0.27-0.57$ ), respectively, in favour of probiotic over placebo treatment.

In contrast to prevention studies, a few studies have focused on the treatment of antibiotic-associated diarrhoea. In nine such patients participating in an uncontrolled study, a faecal enema of colonic bacteria resulted in normalisation of the metabolic activity of the colonic microflora and disappearance of diarrhoea within four days ${ }^{64}$. A study enrolling 45 antibiotic-associated diarrhoea patients from 10 different centres found a significant resolution of 
diarrhoea within one week in $91 \%$ of the patients treated with $E$. coli SF 68 versus $73 \%$ in the placebo group ${ }^{49}$. Also in patients with Clostridium difficileassociated diarrhoea, beneficial effects of probiotics on the duration or resolution of diarrhoea ${ }^{65,66}$ and a decrease in recurrence rate ${ }^{67,68}$ have been observed. However, the studies investigating the treatment of antibioticassociated diarrhoea with probiotics were generally performed with limited numbers of patients and mostly not placebo-controlled.

The role of probiotics in the prevention of traveller's diarrhoea has also been studied extensively, but results are conflicting and vary with the probiotic strain used and with the travel destination ${ }^{69,70}$.

Most studies on probiotics and diarrhoea focus on outcome parameters such as the incidence or duration of diarrhoea or stool frequency. Sometimes the presence of Clostridium toxins or rotavirus shedding in stool has been investigated without studying possible modes of action of probiotics such as influences on the composition and metabolic activity of the intestinal flora.

\section{Probiotics and inflammatory bowel disease}

Possible pathogenic mechanisms associated with inflammatory bowel disease (IBD), mainly ulcerative colitis (UC) and Crohn's disease (CD), are an imbalance of the intestinal bacterial flora, a defective suppressive immune response and an increased gut permeability ${ }^{71,72}$. Animal models of colitis have shown that inflammation will not develop without the presence of intestinal bacteria $^{73-75}$. Clinical studies also support a role of the intestinal flora in the pathogenesis of IBD: disease activity of $C D$ and $U C$ has been found to improve by faecal diversion ${ }^{76}$, bowel rest ${ }^{77,78}$, intestinal lavage ${ }^{26,77}$, and antibiotics ${ }^{6,79,80}$. Metronidazole, for instance, is a frequently used antibiotic in $C D$ patients that significantly decreased the concentration of Bacteroides spp. ${ }^{B \dagger}$.

Although the composition of the bacterial flora seems to play a role in IBD, bacteriological findings with regard to the bacterial composition are inconsistent. Decreased numbers of lactobacilli and increased numbers of anaerobes have been found in faecal and mucosal samples of CD patients ${ }^{82-84}$, whille Giaffer et al. found an increase in the number of faecal aerobes ${ }^{35}$. In UC patients, increased numbers of Bacteroides spp. but decreased numbers of lactobacilli were observed in faecal samples and colonic mucosa ${ }^{83,86}$. Furthermore, in some studies a decrease in the total number of obligatory anaerobic bacteria in UC patients was found, while others reported an increase in both CD and UC patients ${ }^{83,86}$.

As probiotics are able to influence the intestinal flora, they are likely to have beneficial effects in IBD patients. In colitis models with genetically modified or chemically treated animals, intake of lactobacilli reduced the severity of the 
colitis $^{74,87,88}$. Administration of $L$. GG to children with CD increased mucosal $\lg A$ levels ${ }^{89}$, improved intestinal permeability and lowered the disease activity ${ }^{90}$. In adults with inactive $\mathrm{CD}$, the relapse rate was reduced to $6 \%$ after treatment with $S$. boulardif in combination with mesalazine versus $38 \%$ by mesalazine alone $^{91}$. A reduced relapse rate was also found in active $C D$ patients treated with prednisolon in combination with $E$. coli versus placebo ( $33 \%$ versus $64 \%$, respectively) ${ }^{92}$. Administration of Lactobacillus salivarius for ten days to ten adults with active disease caused no remission, but an improvement in quality of life was reported ${ }^{93}$. In contrast to the beneficial findings, no positive results were found in a placebo-controlled study in which $32 \mathrm{CD}$ patients were treated with $L$. $G G$ for 12 months after curative resection. $L$. $G G$ did not prevent relapses and even more severe endoscopic findings were reported in the L. GG treated group 94 .

A case report of a UC patient with active disease showed that antibiotic use followed by implantation of a 'normal colonic flora' via a faecal enema induced remission within one week ${ }^{95}$. Other studies investigated the effect of $E$. coli Nissle versus mesalazine in the maintenance of 120,357 and 116 inactive UC patients during twelve weeks and twelve months, respectively. All studies found a similar relapse rate in $E$. coli Nissle treated and the mesalazine treated groups and concluded that $E$. coli Nissle could be an alternative maintenance therapy ${ }^{96-98}$. A multispecies probiotic preparation (VSL\#3) was also found to have potential as maintenance therapy: in an uncontrolled study, 15 of $20 \mathrm{UC}$ patients remained in remission during a twelve months treatment with VSL\#3 while four patients relapsed. One patient was lost to follow up ${ }^{99}$.

So far, results of probiotic trials are encouraging although the trials mostly included limited numbers of IBD patients and a placebo group is often missing. Moreover, the influence of other medication was frequently not taken into account, and studies have often been performed with patients in remission and during a limited study period.

\section{Probiotics and pouchitis}

Pouchitis is a complication of ileal pouch reconstruction after subtotal colectomy, developing in $10-50 \%$ of the patients and most frequently observed in UC patients ${ }^{100}$. In many patients, pouchitis responds to oral antibiotics such as metronidazole. In patients with pouchitis a decrease in the number of lactobacilli and bifidobacteria and an increase in the number of clostridia and aerobes has been found in faecal samples ${ }^{\dagger 01}$. Furthermore, in patients with pouchitis an increase in bile acids and a decrease in SCFA can be measured in faecal samples with subsequent increase in $\mathrm{pH}^{101,102}$.

Probiotics can change the intestinal bacterial balance in patients with pouchitis:

$L$. $G G$ has been shown to increase the concentration of lactobacilli in faecal 
samples of 20 pouchitis patients after three months treatment ${ }^{103}$. Howewer, in this placebo-controlled study no clinical benefit could be found, as the pouchitis disease activity index did not change significantly ${ }^{103}$. In contrast, Laake et al. showed a beneficial effect on the pouchitis disease activity index after four weeks treatment with $L$. $G G$ while no effect on the histological parameters could be seen ${ }^{104,105}$. Two placebo-controlled studies demonstrated that in 40 and 36 patients with chronic relapsing pouchitis, relapses occurred less frequently after nine months and one year treatment, respectively, with the multispecies probiotic VSL\#3 (15\% probiotic versus $100 \%$ placebo and $15 \%$ probiotic versus $94 \%$ placebo) ${ }^{106.107}$. Moreover, VSL\#3 has been shown to prevent the occurrence of pouchitis if taken during one year immediately after ileostomy ( $10 \%$ probiotic versus $40 \%$ placebo) ${ }^{408}$. This delay in the first onset of pouchitis could also be seen after 3 years of $L$. GG treatment $(7 \%$ probiotic versus $29 \%$ pllacebo) $)^{109}$.

Other studies in ileal-anal pouch patients have been performed with prebiotics. For example, three weeks treatment with inulin in twenty patients, resulted in less Bacteroides spp. and an increase in butyrate concentration measured in faecall samples ${ }^{110}$.

The beneficial effects of prebiotics and probiotics suggest that these can play a role in the prevention of pouchitis. However, more placebo-controlled studies investigating clinical and bacteriological parameters are warranted to get further insight in the efficiency of probiotics as therapeutic option in pouchitis.

\section{Probiotics and irritable bowel syndrome}

Irritable bowel syndrome (IBS) is a functional gastrointestinal disorder with a heterogeneous pathophysiology; varying clinical symptoms such as abdominal pain, diarrhoea or constipation can be experienced. The pathophysiology remains largely unknown although abdominal motility, prior enteric infection, visceral hypersensitivity and psychosociall factors have been associated with $\mathrm{IBS}^{111.112}$. Furthermore, alterations in the composition of the faecal intestinal flora have been reported compared to healthy volunteers ${ }^{113-115}$ : a decrease of numbers of faecal $E$. coli, lactobacilli and bifidobacteria and an increase of other faecal aerobes ${ }^{113,114}$. Moreover, an abnormal colonic fermentation, particularly an increased hydrogen production, has been found ${ }^{116,117}$. Modifications of the intestinal flora of IBS patients by probiotics may improve clinicall symptoms.

The therapeutic effects of $L$. acidophilus, characterised by an improvement of for instance physical state, abdominal pain and daily numbers of stool, were demonstrated in a cross-over trial with 18 IBS patients ${ }^{118}$. Symptomatic improvement was also found in 19 of 28 patients in an uncontrolled study after the administration of Enterococcus faecium PR88 ${ }^{119}$. The administration of 
Lactobacillus plantarum $299 \mathrm{v}$ versus placebo during four weeks decreased pain and flatulence and showed overall clinical improvement in patients with $\mathrm{IBS}^{120,121}$. A recent study also demonstrated a reduction in symptoms scores such as abdominal pain, bloating and bowel motions after eight weeks treatment with Biffolobacterium infantis 35624 compared to treatment with $L$. salivarius UCC $4331^{122}$. Moreover; $B$. infantis 35624 normalized the abnormal $\mathrm{IL}-10 / \mathrm{LL}-12$ ratio in IBS patients ${ }^{122}$. In contrast, no improvement with respect to pain, urgency to defaecation and bloating was reported after the consumption of $L$. $G G$ for eight weeks in bloating-predominant IBS patients ${ }^{123.124}$.

Most studies about the efficiency of probiotics in IBS patients were double-blind and placebo-controlled. However, the inclusion criteria with regard to diarrhoea-predominant or constipation-predominant IBS differed among the studies and the patient groups were rather heterogenous. In addition, the influence of concurrent other medical treatments was mostly not taken into account and the placebo-response in these studies was found to be relatively high. So far, no conclusions can be drawn whether probiotics may benefit in certain subgroups of IBS patients like diarrhoea-predominant or constipationpredominant IBS.

\section{Probiotics and lactose malabsorption}

The prevalence of lactose malabsorption in Northern Europe is $5-20 \%$, but in Asia the prevalence can be as high as $90-100 \%{ }^{125}$. Lactose malabsorption is characterised by the absence or decreased production of the lactose-cleaving enzyme ß-galactosidase (lactase) in the mucosa of the small intestine, so that unsplitted and non-absorbed lactose reaches the colon. Lactose is a fermentable substrate for the colonic flora and causes bloating, flatulence, bowel cramps, and diarrhoea as clinical symptoms possibly on the basis of dysbacteriosis. Lactose absorption may be improved by the consumption of probiotic bacteria due to microbial B-galactosidase activity, changes in colonic bacterial flora and delayed transit time in the small bowel ${ }^{126,127}$.

In placebo-controlled studies, it has been shown that milk containing L. acidophilus improved the clinical symptoms of lactose malabsorption in lactose intolerant patients ${ }^{128,129}$. However, some other studies have demonstrated that $L$. acidophilus did not improve clinical symptoms or lactose absorption according to hydrogen breath test ${ }^{130-132}$. A recent review article concluded that probiotic bacteria may alleviate clinical symptoms caused by malabsorbed lactose ${ }^{133}$ although more well-designed studies are warranted. 


\section{Probiotics and Helicobacter pylori}

H. pylori infection is associated with gastritis, gastric and duodenal ulcers, and gastric malignancies. In vitro, antibacterial activities of probiotic bacterial strains such as $L$. acidophilus against $H$. pylori have been demonstrated ${ }^{134,135}$. In animals infected with $H$. pylori, L. salivarius suppressed the colonisation and growth of this bacterium and reduced the inflammatory response in gastric epithelial cells ${ }^{136,137}$. Reduction of the severity of gastritis and the $H$. pylori density in the gastric mucosa as well as decreased $H$. pyloribreath test values have been observed in infected volunteers treated with probiotics such as $L$. acidophilus johnsonii and Lactobacillus gasseri OLL 2716 ${ }^{134,138,139}$, but these results could not be confirmed by others ${ }^{140,141}$. Placebo-controlled studies found a reduction of the unwanted side effects of the standard triple eradication therapy for $H$. pylori infections (containing two antibiotics) if concurrently with this therapy probiotics such as $L$. GG and $S$. boulardii were given ${ }^{141,142}$. Canducci et al. have described an improved efficacy of eradication when the standard treatment regimen was combined with a daily intake of inactivated $L$. acidophilus ${ }^{143}$.

The results of this limited number of studies indicate a possible supporting role for probiotics when added to standard $H$. pylori eradication therapies, but no evidence is available that they can replace standard eradication therapy.

\section{Probiotics and constipation}

Probiotics may have a positive effect on intestinal transit time in constipated patients by modulating the colonic microflora. Several studies investigated the treatment of constipation with prebiotics such as inulin, oligofructose and lactulose. In addition to an improvement of constipation, these studies report an increase in numbers of faecal bifidobacteria and/or lactobacilli ${ }^{144-146}$.

A limited number of studies has been published about the effects of probiotics on constipation. An increase in defaecation frequency in constipated patients treated with lactobacilli has been observed ${ }^{129,147,148}$. One group studied the combination of lactulose with $L$. acidophilus in 21 elderly patients with chronic constipation and found a significant increase in weekly bowel motion frequency ${ }^{149}$, while a study including children did not see a clinical improvement of constipation after treatment with lactulose plus $L$. $G G^{150}$. A major drawback of these studies was that they were all open except one by Banaszkiewicz et $a l^{150}$. In contrast to the beneficial effects reported, Ling et al. did not find any significant effects on bowel function in constipated elderly patients treated with $L$. GG in a blinded placebo-controlled study ${ }^{15}$. 


\section{Probiotics and colorectal cancer}

Colorectal cancer is one of the leading causes of cancer mortality in Western countries $^{152}$. In women, colorectal cancer is the second most common cancer after breast cancer and in men, colorectal cancer is the third most common cancer after lung and prostate cancer ${ }^{153}$. Epidemiological studies in for instance Finland, the Netherlands and California have demonstrated low cancer incidences in populations that consume regularly large quantities of yoghurt and/or other fermented milk products. These lower incidences were also found after adjustment for potential confounding variables such as fat and caloric intake ${ }^{154-15}$. These observations indicate that intake of lactic acid bacteria might lower the risk of colon cancer. Mechanisms by which probiotics may exert an anti-carcinogenic effect include binding of mutagenic compounds, deactivation of carcinogens, decreasing the amounts of bacterial enzymes that convert procarcinogens into carcinogens, and enhancing the host's immune response. These mechanisms have been studied in vitro ${ }^{158-160}$ and in experimental animals. In animals, in which colon cancer was induced by chemical carcinogens, administration of lactic acid bacteria showed a suppression in DNA damage, in the formation of aberrant crypt foci, and in tumour formation and growth ${ }^{1611166}$.

Despite these encouraging results in animal models, there is no prospective evidence that probiotics reduce the colon cancer incidence in humans. So far, trials in humans only have shown that probiotics affect biomarkers for colon cancer risk such as short chain fatty acids and bacterial enzymes. Lactic acid bacteria, for example, significantly decreased faecal bacterial enzyme activities such as $\beta$-glucosidase and $\beta$-glucuronidase, involved in carcinogenesis, in healthy volunteers consuming a 'Western-type' diet ${ }^{8,14,23,167.168}$. However, other studies in healthy volunteers failed to demonstrate an effect of lactic acid bacteria on these bacterial enzyme profiles ${ }^{169.170}$.

\section{Critical focus on probiotic studies}

In the past decade, the interest in probiotics has grown extensively. They are commercially available, but are also increasingly used for both research and clinical purposes. Probiotics are becoming an adjuvant or alternative therapy in gastrointestinal disorders as they are considered to be safe, have minimal pathogenic potential for the host and are without side effects.

Because of their postulated modes of action it is supposed that probiotics might be especially beneficial in gastrointestinal disorders where the composition of the intestinal bacterial flora has been disturbed. However, the role of the intestinal bacterial flora in gastrointestinal disorders such as IBD, pouchitis and IBS is still not completely understood and should be investigated in controlled 
trials that take into account stage and activity of the disease and side effects of concurrent medication.

An overview of the outcome of probiotic studies in gastrointestinal disorders is shown in table 1.1. The most conclusive evidence exists for the prevention and treatment of diarrhoea by $L . G G, L$. reuteriand $S$. boulardii. Two meta-analyses concluded that probiotics can reduce the risk of developing antibioticassociated diarrhoea and significant benefits have also been shown in acute (rotavirus-associated) diarrhoea. A second group of patients who could benefit from probiotics are IBD patients. Animal studies have shown that probiotics decrease the severity of colitis. Lactobacilli, E. coli Nissle and $S$. boulardii seem to reduce relapse rates in $U C$ and $C D$ patients, but studies showing these effects are mostly not placebo-controlled and/or have other methodological limitations. Reduced relapse rates have also been demonstrated in pouchitis patients treated with multi-, and monospecies probiotics in placebo-controlled studies.

Furthermore, probiotic treatment may have potential in the therapy of IBS patients associated with previous enteric infections and/or a change in the intestinal flora. Although some beneficial effects of probiotic therapy have been described in these patients, also negative results have been reported and possible benefits for subgroups need to be studied. Furthermore, probiotics may have beneficial effects in the treatment of lactose malabsorption, constipation and as adjuvant in $H$. pylori eradication. Finally, probiotics can reduce the amounts of genotoxic compounds and biomarkers of colon cancer risk in the colon contents of humans. However, despite some effectiveness in the prevention of colorectal cancer in animal models, their value in preventing colorectal cancer in humans still has to be elucidated.

In general, results of studies on the effects of probiotics in gastrointestinal disorders are encouraging. However, before recommendations for therapy and/or prevention can be given, the results of well-designed blinded placebocontrolled studies with sufficient numbers of clinically well defined (sub)groups of patients have to be awaited.

Many other issues still have to be resolved including dose and duration of probiotic treatment and the onset and duration of effects after start and cessation of probiotics. It is unlikely that one single probiotic strain will be effective in all clinical indications. Differences between bacterial strains as well as the effects of multispecies versus monospecies probiotics warrant further research although so far multispecies probiotics seem to be more effective in treating gastrointestinal disorders, probably due to synergistic effects of the bacterial strains ${ }^{179}$. In addition, the survival of probiotic strains through the gastrointestinal tract is one of the selection criteria of probiotics, but for many probiotic strains the resistance to gastric acidity, bile acids and pancreatic acids still has to be tested. 
More attention should especially be paid to the modes of action by which probiotics may exert beneficial effects. It is thought that one of the possible modes of action is a change in the intestinal bacterial composition.

Also in healthy volunteers, the modes of action of probiotics on the intestinal flora have been itttle investigated. Studies including healthy volunteers demonstrated a faecal increase in the number of lactobacilli after $L$. plantarum $299 \mathrm{v}$. L. casei Shirota, L. rhamnosus and L. acidophilus consumption, respectively ${ }^{23,172-174}$. However, most studies have focused on the effects of probiotics on the intestinal flora in faecal samples while it is unknown if faecal samples are representative for the bacterial composition in the mucosa. Furthermore, the composition of the intestinal flora may differ between the distal and proximal colon and rectum. Faecal samples may reflect the bacterial composition of the distal colon but will not necessarily give information of the proximal colon. Measuring the effects of probiotics in biopsy samples from different intestinal locations can be of additional value.

Moreover, the intestinal flora can also be considered as a metabolic entity and studying the influence of probiotics on the metabolic activities such as on enzyme activities and the production of SCFAs will be interesting. Changes in bacterial metabolites have been observed after probiotic consumption with L. plantarum 299v, L. acidophilus and L. casei Shirota in healthy volunteers such as an increase in the acetic and propionic acid concentrations and a decrease in the $\beta$-glucuronidase activity ${ }^{14,22,23}$. However, these parameters have not been studied in the majority of previous studies with healthy volunteers $^{23,173,175}$. Measuring the effects of probiotics on the intestinal bacterial concentrations as well as on the metabolic activities would be important to get further insight in the possible working mechanism of probiotics. These effects can be studied in healthy volunteers with a 'normal' intestinal bacterial balance, as well as in gastrointestinal patients with changes in the intestinal bacterial balance.

\section{L. plantarum $299 \mathrm{v}$}

A potential probiotic strain is L. plantarum 229v (DSM 9843), which is a Grampositive facultative anaerobic rod and a facultative hetero-fermentative lactobacillus, able to ferment carbohydrates to for instance lactic acid, acetic acid, ethanol and $\mathrm{CO}_{2}$. L. plantarum $299 \mathrm{v}$ has been found in meat, fish and vegetables and is the dominant species in a range of fermented foods, including sourdough, sauerkraut, green olives, natural wines and beers". L. plantarum $299 \mathrm{v}$ has originally been isolated from the human intestinal mucosa of Swedish subjects ${ }^{176}$. 


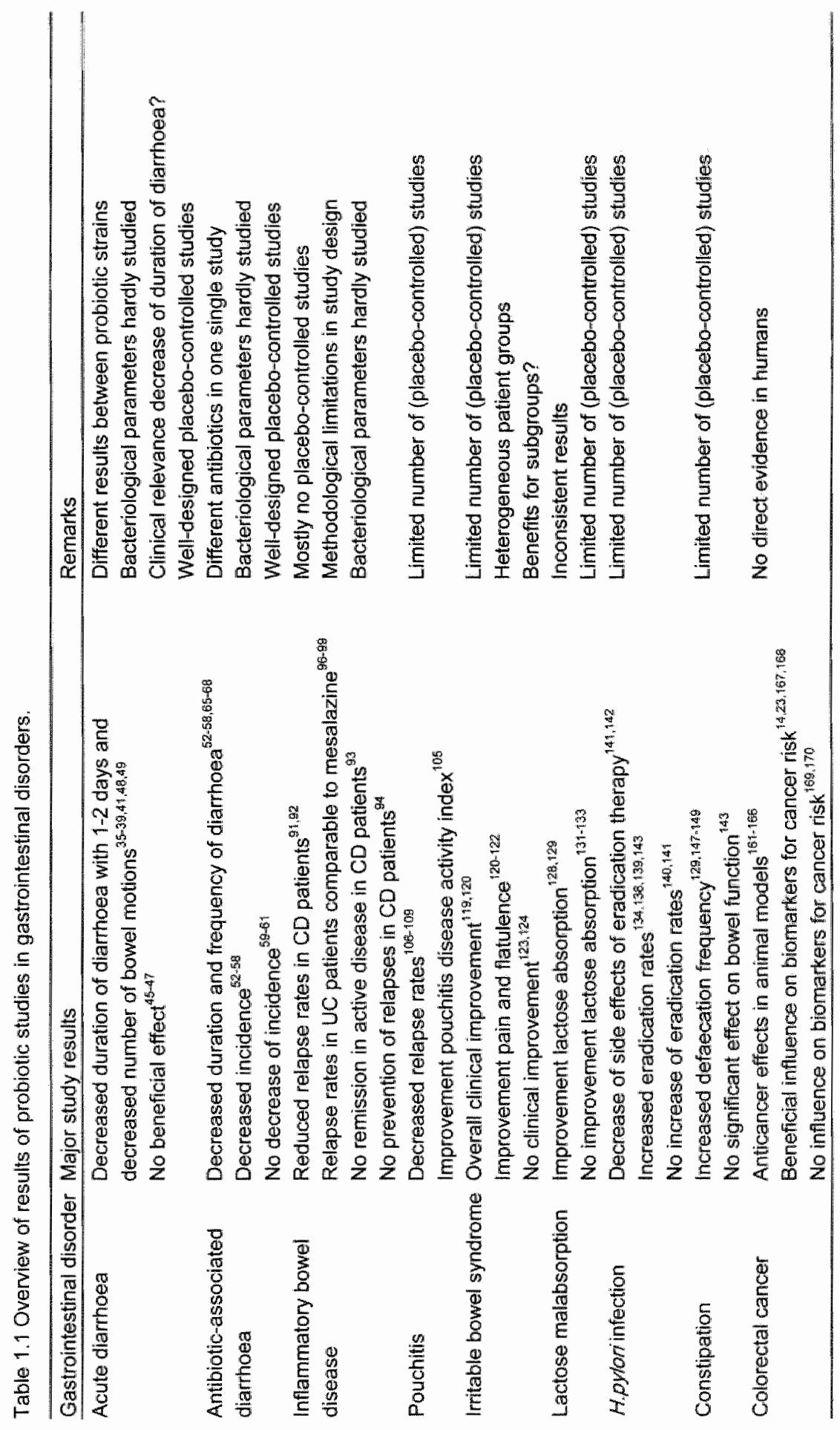


In a healthy volunteer study performed in Sweden, L. plantarum 299v was shown to survive passage through the gastrointestinal tract and was recovered from jejunum and rectum biopsy samples in 8 of 13 healthy volunteers 11 days after cessation of probiotic consumption ${ }^{172}$. Another Swedish study demonstrated the recovery of $L$. plantarum $299 \mathrm{v}$ from faeces in all of the 26 healthy volunteers after three weeks' administration and an increase in the faecal numbers of lactobacilli2,172. However, these studies used a nonsellective agar plate, Rogosa agar, for the culture of lactobacilli.

In vitro, L. plantarum $299 \mathrm{v}$ binds via a mannose-rich adhesion receptor and thereby can compete with $E$. coli for colonisation ${ }^{177}$. Furthermore, the oral administration of $L$. plantarum $299 \mathrm{~V}$ significantly increased the SCFA concentrations such as acetic and propionic acids in healthy volunteers after three weeks treatment ${ }^{22}$.

L. plantarum $299 \mathrm{v}$ has been tested in several clinical trials performed with different patient groups. Forty and 60 IBS patients received $L$. plantarum $299 \mathrm{v}$ or placebo during four weeks, and reported a significant improvement in abdominal pain, defaecation frequency and other IBS symptoms compared to patients treated with the placebo or inactive $L$. plantarum $299 \mathrm{v}^{120,121}$. These clinical improvements could be due to an increase in colonic fermentation influencing the hydrogen production during probiotic consumption. However, no changes in gas or hydrogen production have been measured in 12 IBS patients after L. plantarum $299 \mathrm{v}^{\text {intake }}{ }^{124}$.

The ability of L. plantarum $299 \mathrm{v}$ to prevent Clostridium difficileassociated diarrhoea was also tested in a placebo-controlled trial. The patients treated with the probiotic showed less clinical symptoms defined as the recurrence of diarrhoea within five to ten days after initiating treatment compared to the placebo group ( 4 of 11 versus 6 of 9 ) but the groups were too small to draw a definite conclusion $^{178}$. In contrast, no beneficial effect was seen in a study performed with elective surgical patients: L. plantarum $299 \mathrm{v}$ did not influence the rate of bacterial translocation, gastric colonisation or the incidence of postoperative septic morbidity ${ }^{179}$. L. plantarum $299 \mathrm{~V}$ was also found to be an useful protective agent in atherosclerosis of smokers as a reduction in systolic blood pressure, leptin and fibrinogen was observed after 6 weeks probiotic intake ${ }^{\text {tigo }}$.

The effects of $L$. plantarum $299 \mathrm{v}$ on colitis, gut permeability and the immune system as well as on the competition of $L$. plantarum $299 \mathrm{v}$ with $E$. coli have been tested in several animal studies. In these experiments, $L$. plantarum $299 \mathrm{v}$ was found to reduce the severity of methotrexate-induced colitis in rats and in IL-10 deficient mice ${ }^{88,181}$. Colonisation of germfree $1 \mathrm{~L}-10$ deficient mice with L. plantarum 299v followed by the colonisation of specific bacteria, attenuated the development of colitis ${ }^{162}$. Moreover, the competition for colonisation between $L$. plantarum $299 \mathrm{v}$ and $E$. coli has been studied in an experiment with germ-free rats, showing lower amounts of $E$. coli in the small intestine and caecum if $L$. plantarum was given in addition to $E$. coli during five weeks ${ }^{183}$. 
Furthermore, pre-treatment of $L$. plantarum $299 \mathrm{v}$ protected against an $E$ coli induced increase in gut wall permeability but had no influence on the intestinal permeability if given alone ${ }^{184}$.

Five weeks treatment with $L$. plantarum $299 \mathrm{v}$ influenced the systemic immune system beneficially by increasing the $\lg A$ antibody levels against $E$ coli in gnotobiotic rats ${ }^{183}$. The beneficial immunomodulatory activity of $L$. plantarum $299 \mathrm{v}$ was also shown in an in vitro study demonstrating an increase in IL-10 synthesis and secretion by macrophages and T-cells derived from the inflamed colon of UC patients and incubated with $L$. plantarum $299 v^{185}$. Finally, L. plantarum $299 \mathrm{v}$ with an oatmeal base was more effective in reducing intestinal pathogens in methotrexate-induced enterocolitis in rats than without oats $^{88}$. For this reason, $L$. plantarum $299 \mathrm{v}$ was combined in a commercial available probiotic drink with an oatmeal fermented component.

L. plantarum $299 \mathrm{v}$ has been demonstrated to be one of the dominant lactobacillus species in humans, to survive passage through the gastrointestinal tract, to be able to adhere to the epithelium via mannosespecific receptors, to increase the faecal numbers of lactobacilli during consumption and to reduce colitis in animal models. Moreover, L. plantarum $299 \mathrm{v}$ is a probiotic strain easy to handle in the laboratory and to use in probiotic products which makes it a good candidate to study its effects on the bacterial composition and metabolic activities in healthy volunteers and in patients with gastrointestinal diseases such as $U \mathrm{C}, \mathrm{CD}$ and IBS. 


\section{Aims of the studies}

The main goal of this project was to investigate the effects of the probiotic $L$. plantarum $299 \mathrm{v}$ on the composition of the faecal and mucosal intestinal flora and metabolic activities in healthy volunteers as well as in persons with intestinal disorders. Special attention was paid to the onset and duration of the effects and to the survival of L.plantarum $299 \mathrm{v}$ through the gastrointestinal tract.

In chapter 2 the effect of L. plantarum $299 \mathrm{v}$ on the faecal bacterial composition and metabolitic activities was studied in healthy volunteers by measuring short chain fatty acids, endotoxins and enzyme activities. In this study the onset and duration of the effects after start and cessation of L. plantarum 299v intake have been studied.

Lowering gastric acidity may result in a better survival of the probiotic bacteria during passage through the gastrointestinal tract; a study investigating the recovery of $L$. plantarum $299 \mathrm{v}$ in faecal samples with and without gastric acid inhibition was performed (chapter 3 ).

As the effects of $L$. plantarum $299 \mathrm{v}$ are thought to be different in persons with a 'disturbed" intestinal bacterial balance, the next study focused on the effects of L. plantarum $299 \mathrm{v}$ on the faecal bacterial composition after a bowel cleansing procedure for colonoscopy. Bowel cleansing will wash out the luminal bacteria and probiotics could have a beneficial effect in the recolonisation phase after bowel cleansing. The bacterial composition has been studied using conventional culture techniques as well as the molecular technique, 16S rDNA based PCR followed by denaturation gradient gel electrophoresis. This study is presented in chapter 4.

The influence of $L$. plantarum $299 \mathrm{v}$ on the faecal as well as on the mucosal flora was studied and discussed in chapter 5. A secondary aim of this study was the comparison of the intestinal flora between rectal and colon ascendens biopsy samples. Therefore, patients undergoing a colonoscopy as control for colorectal polyps were included in this study.

In UC patients the intestinal flora might also be disturbed. Differences in bacterial composition between inactive UC patients and healthy volunteers. were compared in chapter 6. Moreover, the effects of L. plantarum $299 \mathrm{v}$ on the intestinal flora in faecal and mucosal samples as well as on faecal metabolic activities were studied in inactive UC patients (chapter 6).

The general discussion in chapter 7 focuses on the effects of L. plantarum $299 \mathrm{v}$ found in the healthy volunteers as well as in the patients and compares the results of the studies performed in more detail. 


\section{References}

1. Savage DC. Microbial ecology of the gastrointestinal tract. Annu Rev Microbiol $1977 ; 31: 107-33$

2. Holzapfel WH, Haberer $P$. Snel J, Schillinger U, Huis in 't Veld J. Overview of gutt flora and probiotics. Int J Food Microbiology 2001;41:85-101.

3. Simon GL, Gorbach SL. The human intestinal microflara. Dig Dis Sci 1986,31 : 147-62.

4. Marteau $P$, Pochart $P$, Dore J, Bera-Maillet $C$, Bernalier $A$, Corthier $G$. Comparative study of bacterial groups within the human cecal and fecal microbiota. Appl Environ Microbiol 2001;67:4939-42.

5. Gorbach SL, Nahas L, Lerner PI, Weinstein L. Studies of intestinall microflora. Effects of diet, age, and periodic sampling an numbers of fecal microorganisms in man. Gastroenterology 1967:53:845-55.

6. Bengmark S. Ecological control of the gastrointestinal tract. The role of probiotic flora. Gut 1998;42:2-7.

7. Farthing MJ. Bugs and the gut: an unstable marriage. Best Pract Res Clin Gastroenterol 2004;18:233-9.

8. Goldin B, Gorbach SL. Alterations in fecal microflora enzymes related to diet, age, lactobacillus supplements, and dimethylhydrazine. Cancer 1977;40:24:21-6.

9. Bullen JJ. Human milk and gut infection in the newborn. $\mathrm{Br} J$ Hosp Med 1977;18:220-31.

10. Rotimi $\mathrm{VO}$, Duerden $\mathrm{BI}$. The development of the bacterial flora in normal neonates. $J$ Med Microbiol 1981;14:51-62.

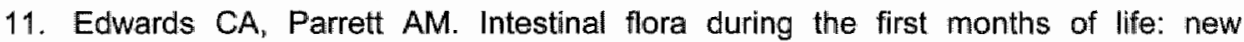
perspectives. Br J Nutr 2002;88 Supp\|1:S11-8.

12. Simon GL, Gorbach SL. Intestinal flora in health and disease. Gastroenterology 1984;86:174-93.

13. Zoetendal $E G$, Akkermans ADL, Akkermans-van Vliet WM, Visser de $A G M$, Vos de WM. The host genotype affects the bacterial community in the human gastrointestinal tract. Microb Ecol in Health and Dis 2001:13:129-34.

14. Goldin BR, Swenson L, Dwyer J, Sexton M, Gorbach SL. Effect of diet and Lactobacillus acidophilus supplements on human fecal bacterial enzymes. J Nall Cancer Inst 1980;64:255-61.

15. Mitsuoka T. Intestinal flora and aging. Nutr Rev 1992;50:438-46.

16. Krook $A$, Danielsson $D$, Kjellander $J$, Jarnerot $G$. Changes in the fecal flora of patients with Crohn's disease during treatment with metronidazole. A preliminary report. Scand J Gastroenterol 1979;14:705-10.

17. Kroak $A_{n}$ Jarnerot $G$, Danielsson D. Clinical effect of metronidazole and sulfasalazine on Crohn's disease in relation to changes in the fecall flora. Scand $\mathrm{J}$ Gastroenterol 1981;16:569-75.

18. Levy $J$. The effects of antibiotic use on gastrointestinal function. Am J Gastroenterol 2000;95:\$8-10.

19. Roediger WE. Oxidative and synthetic functions of n-Butyrate in colonocytes. Dis Colon Rectum 1992;35:511-12.

20. Scheppach W, Muller JG, Boxberger $F$, et al. Histological changes in the colonic mucosa following irrigation with short-chain fatty acids. Eur J Gastroenterol Hepatol $1997 ; 9: 163-8$. 
21. Mortensen FV, Nielsen $H_{*}$ Aalkjaer $C_{\text {s }}$ Mulvany MJ , Hessov 1 . Short chain fatty acids relax isolated resistance arteries from the human ileum by a mechanism dependent on anion-exchange. Pharmacol Toxicol 1994;75:181-5.

22. Johansson $M$, Nobaek $S$, Berggren $A$, et al. Survival of Lactobacillus plantarum DSM 9843 (299v), and effect on the short-chain fatty acid content of faeces after ingestion of a rose-hip drink with fermented oats. Int J Food Microbiol 1998;42: 29-38.

23. Spanhaak $S$. Havenaar $R$, Schaafsma $G$. The effect of consumption of milk fermented by Lactobacillus casei strain Shirota on the intestinal microflora and immune parameters in humans. Eur J Clin Nutr 1998;52:899-907.

24. Gorbach SL. Function of the normal human microflora. Scand $J$ Infect Dis 1986;49:17-30.

25. Rook GA, Brunet LR. Microbes, immunoregulation, and the gut. Gut $2005 ; 54$ : $317-20$.

26. Lennard-Jones JE. Inflammatory bowel disease: medical therapy revisited. Scand J Gastroenterol Suppl 1992;192:110-6.

27. Vollaard EJ, Clasener HA. Colonization resistance. Antimicrob Agents Chemother 1994;38:409-14.

28. Hevenaar $R$, Ten Brink $B$, Huis in 't Veld $\mathrm{J}$. Selection of strains for probiotic use. In: Hall Ca, ed. Probiotics, The scientific basis. London, 1992:209-24.

29. Schrezenmeir J, de Vrese MM. Probiotics, prebiotics, and synbiotics-approaching a definition. Am J Clin Nutr 2001;73:361S-4S.

30. Salminen $S$, Laine $M$, Wright von A, Vuopio-Varkila J, Korhonen $T$, MatillaSandholm $T$. Development of selection criteria for probiotic strains to assess their potential in functional foods: a Nordic and European approach. Biosci Microflora 1996;15:61-7.

31. Bengmark S. Immunonutrition: role of biosurfactants, fiber, and probiotic bacteria. Nutrition 1998;14:585-94.

32. Fuller R. Probiotics in human medicine. Gut 1991;32:439-42.

33. Shanahan F. Probiotics in inflammatory bowel disease. Gut 2001;48:609.

34. Isolauri E. Probiotics in human disease. Am J Clin Nutr 2001;73:1142S-6S.

35. Guarino A, Canani RB, Spagnuolo MI. Albano F, Di Benedetto L. Oral bacterial therapy reduces the duration of symptoms and of viral excretion in children with mild diarthea. J Pediatr Gastroenterol Nutr 1997;25:516-9.

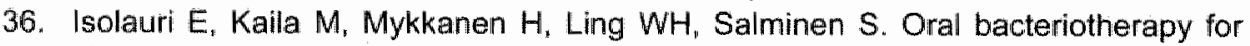
viral gastroenteritis. Dig Dis Sci 1994;39:2595-2600.

37. Kaila $M_{3}$ Isolauri $E_{\text {, Soppi }} E_{\text {, Virtanen }}$, Laine $S$, Arvillommi $H$. Enhancement of the circulating antibody secreting cell response in human diarrhea by a human Lactobacillus strain. Pediatr Res 1992;32:141-4.

38. Pant AR, Graham SM, Allen SJ, et al. Lactobacillus GG and acute diarrhoea in young children in the tropics. J Trop Pediatr 1996;42:162-5.

39. Shomikova AV, Isolauri $E$, Burkanova $L$, Lukovnikova $S$, Vesikari $T$. A trial in the Karelian Republic of oral rehydration and Lactobacillus GG for treatment of acute diarrhoea. Acta Paediatr 1997;86:460-5.

40. Majamaa $H_{\text {, Isolauri }} \mathrm{E}_{\text {, Saxelin }} \mathrm{M}$, Vesikari $T$. Lactic acid bacteria in the treatment of acute rotavirus gastroenteritis. J Pediatr Gastroenterol Nutr 1995;20:333-8.

41. Isolauri $E$, Juntunen $M$, Rautanen $T$, Sillanaukee $P$, Koivulla $T$. A human Lactobacillus strain (Lactobacillus casei spp strain GG) promotes recovery from acute diarrhea in children. Pediatrics 1991;88:90-7. 
42. Oberhelman RA, Gilman RH, Sheen $P_{i}$ et al. A placebo-controlled Irial of Lactobacillus GG to prevent diarrhea in undernourished Peruvian children. J Pediatr 1999;134:15-20.

43. Chapoy P. Treatment of acute infantile diarrhea: controlled trial of Saccharomyces boulardii. Ann Pediatr (Paris) 1985;32:561-3.

44. Hochter $W$, Chase $D$, Hagenhoff $G$. Saccharomyces boulardii bei akuter Erwachsenendairrhoe: Wirksamkeit und Vertraglichkeit der Behandlung. Munchen Medzinische Wochenschr 1990;32:188-92.

45. Bin LX. Controlled clinical trial in infants and children comparing Lacteol Fort sachets with two antidiarrheal reference drugs. Ann Pediatr (Paris) 1995;42: 396-401.

46. Boulloche J, Mouterde $O$, Mallet $E$. Management of actute diarrhea in infants and toddlers. Ann Pediatr (Paris) 1994;41:457-63.

47. Mitra AK, Rabbani GH. A double-blind, controlled trial of bioflorin (Streptococcus faecium SF68) in adults with acute diarrhea due to Vibrio cholerae and enterotoxigenic Escherichia coli. Gastroenterology 1990;99:1149-52.

48. Buydens $P$, Debeuckelaere $S$. Efficacy of SF 68 in the treatment of acute diarrhea. A placebo- controlled trial. Scand J Gastroenterol 1996;31:887-91.

49. Wunderlich PF, Braun L, Fumagalli l, et all. Double-blind report on the efficacy of lactic acid-producing Enterococcus SF68 in the prevention of antibiotic-associated diarrhoea and in the treatment of acute diarrhoea. J Int Med Res 1989;17:333-8.

50. Van Vlem B, Vanholder $R$, De Paepe $P$, Vogelaers $D$, Ringoir $S$. Immunomodulating effects of antibiotics: literature review. Infection 1996;24: $275-91$.

51. Sullivan $A$, Edlund $C$, Nord $C E$. Effect of antimicrobial agents on the ecological balance of human microflora. Lancet Infect Dis 2001;1:101-14.

52. Gotz V, Romankiewicz JA, Moss $J$, Murray HW. Prophylaxis against ampicillinassociated diarrhea with a lactobacillus preparation. Am $J$ Hosp Pharm $4979 ; 36: 754-7$.

53. Siitonen $S$, Vapaatalo $H$, Salminen $S$, et al. Effect of Lactobacillus GG yoghurt in prevention of antibilotic associated diarrhoea. Ann Med 1990;22:57-9.

54. Arvola T, Laiho $K$, Torkkell $S$, et al. Prophylactic Lactobacillus GG reduces antibiotic-associated diarrhea in children with respiratory infections: a randomized study. Pediatrics 1999;104:e64.

55. McFarland LV, Surawicz CM, Greenberg RN, et al. Prevention of beta-lactamassociated diarrhea by Saccharomyces boulardii compared with placebo. Am J Gastroenterol 1995;90;439-48.

56. Vanderhoof JA, Whitney DB, Antonson DL, Hanner TL. Lupo JV, Young RJ. Lactobacillus GG in the prevention of antibiotic-associated diarrhea in children. $J$ Pediatr 1999; 135:564-8.

57. Adam $₫$. Barret $A$, Barret-Bellet $C$. Esais cliniques controles en doubles insu de $I^{\prime}$ ultra-leur lyophyilisee. Etude multi-centrique par 25 medecins de 38 cas. Gaz Med Francaise 1977;84:2072-8.

58. Borgia M, Sepe N, Brancaro $V$, Simone P, Borgia R. A controlled clinical study on Streptococcus faecium preparation for the prevention of sidle reactions during longterm antibiotic treatments. Curr Ther Res 1982;31:265-71.

59. Thomas $M R$, Litin SC, Osmon DR, Corr AP, Weaver AL, Lohse CM. Lack of effect of Lactobacillus GG on antibiotic-associated diarrhea: a randomized, placebocontrolled trial. Mayo Clin Proc 2001;76:883-9. 
60. Lewis $S$ J, Potts LF. Barry RE. The lack of therapeutic effect of Saccharomyces boulardili in the prevention of antibiotic-related diarrhoea in elderly patients. I Infect $1998 ; 36: 171-4$.

61. Tankanow RM, Ross MB, Ertel IJ "Dickinson DG, McCormick LS, Garfinkel JF. A double-blind, placebo-controlled study of the efficacy of Lactinex in the prophylaxis of amoxicillin induced diarrhea. DICP 1990;24:382-4.

62. Cremonini F, Di Caro S, Nista EC, et al. Meta-analysis: the effect of probiotic administration on antibiotic- associated diarrhoea. Aliment Pharmacol Ther $2002 ; 16: 1461-7$.

63. D'Souza AL, Rajkumar C, Cooke J, Bulpitt C.J. Probiotics in prevention of antibiotic associated diarrhoea: meta- analysis. BMJ 2002;324:1361.

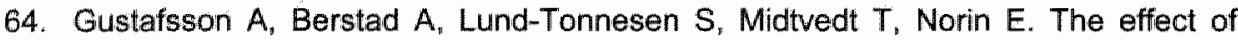
faecal enema on five microflora-associated characteristics in patients with antibiotic-associated diarrhoea. Scand J Gastroenterol 1999;34:580-6.

65. Buts JP, Corthier G, Delmee M. Saccharomyces boulardii for Clostridium difficileassociated enteropathies in infants. J Pediatr Gastroenterol Nutr 1993;16:419-25.

66. Schellenberg $D$, Bonington $A$, Champion $C M$, Lancaster $R$, Webb $S$, Main J. Treatment of Clostridium difficile diarrhoea with brewer's yeast. Lancet 1994;343:171-2.

67. Ellmer GW. Probiotics: "living drugs". Am J Health Syst Pharm 2001;58:1101-1109.

68. Pochapin $M$. The effect of probiotics on Clostridium difficille diarrhea. Am J Gastroenterol 2000;95:S11-3.

69. Lewis SJ, Freedman AR. Review article: the use of biotherapeutic agents in the prevention and treatment of gastrointestinal disease. Aliment Pharmacol Ther $1998 ; 12: 807-22$.

70. de Roos NM, Katan MB. Effects of probiotic bacteria on diarrhea, lipid metabolism, and carcinogenesis: a review of papers published between 1988 and 1998 . Am J Clin Nutr 2000;71:405-11.

71. Shanahan F. Crohn's diseasie. Lancet $2002 ; 359: 62-9$.

72. van Deventer SJ. Immunology in medical practice. IV. Inflammatory bowel diseases: pathogenic starting points for specific therapy. Ned Tijdschr Geneeskd 1997;141:1956-9.

73. Rath HC, Herfarth HH, Ikeda JS, et al. Normal luminal bacteria, especially Bacteroides species, mediate chronic colitis, gastritis, and arthritis in HLAB27/human beta2 microglobulin transgenic rats. J Clin Invest 1996;98:945-53.

74. Rath HC, Schultz M, Dieleman LA, et al. Selective vs broad spectrum antibiotics in the prevention and treatment of experimental colitis in two rodent models. Gastroenterology 1998;114:G4367.

75. Sellon RK, Tonkonogy S, Schultz M, et al. Resident enteric bacteria are necessary for development of spontaneous colitis and immune system activation in interleukin-10-deficient mice. Infect Immun 1998;66:5224-31.

76. Rutgeerts $P$, Goboes $K$, Peeters $M$, et al. Effect of faecal stream diversion on recurrence of Crohn's disease in the neoterminal ileum. Lancet 1991;338:771-4.

77. Wellmann W. Fink PC, Benner F, Schmidt FW. Endotoxaemia in active Crohn's disease. Treatment with whole gut irrigation and 5-aminosalicylic acid. Gut $1986 ; 27: 814-20$.

78. Janowitz HD, Croen EC, Sachar DB. The role of the fecal stream in Crohn's disease: an historical and analytic review. Inflamm Bowel Dis 1998;4:29-39. 
79. Gionchetti $P$, Rizello $F$, Venturi $A$, et al: Review-Antibiotic treatment in inflammatory bowel disease: rifaximin, a new possible approach. Eur Review for Medical and Pharmacol Sciences 1999;3:27-30.

80. Sutherland L., Singleton J, Sessions J, et al. Double blind, placebo controlled trial of metronidazole in Crohn's disease. Gut 1991;32:1071-5.

81. Danielsson D, Kjellander J, Jarnerot $G$. The effect of metronidazole and sulfasalazine on the fecal flora in patients with Crohn's disease. Scand J Gastroenterol 1981;16:183-92.

82. Favier $C$, Neut $C$, Mizon $C$, Cortot $A$, Colombel JF, Mizon J. Fecal beta-D. galactosidase production and Bifidobacteria are decreased in Crohn's disease. Dig Dis Sci 1997;42:817-22.

83. Swidsinski A, Ladhoff A, Pernthaler A, et al. Mucosal flora in inflammatory bowel disease. Gastroenterology 2002;122:44-54.

84. Ruseler-van Embden JG, Both-Patoir HC. Anaerabic gram-negative faecal flora in patients with Crohn's disease and healthy subjects. Antonie Van Leeuwenhoek 1983:49:125-32.

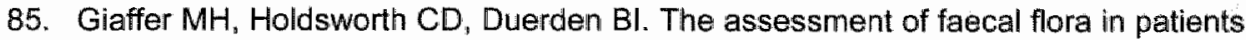
with inflammatory bowel disease by a simpified bacteriological technique. لI Med Microbiol 1991;35:238-43.

86. Fabia $R, A r^{\prime}$ Rajab $A$, Johansson $M L$, et al. Impairment of bacterial flora in human ulcerative colitis and experimental colitis in the rat. Digestion 1993;54:248-55.

87. Madsen KL, Doyle JS, Jewell LD, Tavernini MM, Fedorak RN. Lactobacillus species prevents colitis in interleukin 10 gene-deficient mice. Gastroenterology 1999;116:1107-14.

88. Mao $Y$, Nobaek $S$, Kasravi $B$, et al. The effects of Lactobacillus strains and oat fiber on methotrexate- induced enterocolitis in rats. Gastroenterology 1996;111:334-44.

89. Malin $M$, Suomalainen $H_{3}$ Saxelin $M$, Isolauri E. Promotion of IgA immune response in patients with Crohn's disease by oral bacteriotherapy with Lactobacillus GG. Ann Nutr Metab 1996;40:137-45.

90. Gupta P, Andrew H, Kirschner BS, Guandalini S. Is lactobacillus GG helpful in children with Crohn's disease? Results of a preliminary, open-liabel study. J Pediatr Gastroenterol Nutr 2000;31:453-7.

91. Guslandi $M$, Mezzi $G$, Sorghi $M$, Testoni PA. Saccharomyces boulardili in maintenance treatment of Crohn's disease. Dig Dis Sci 2000;45:1462-4.

92. Malchow HA. Crohn's disease and Escherichia coli. A new approach in theripy to maintain remission of colonic Crohn's disease? J Clin Gastroenterol 1997;25: 653-8.

93. Matilla-Sandholm T, Blum $S$, Collins $J K_{*}$ et all. Probiotics: towards demonstrating efficacy. Trends in Food Science \& Technology 1999;10:393-9.

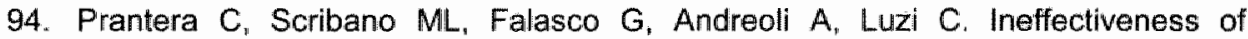
probiotics in preventing recurrence after curative resection for Crohn's disease: a randomised controlled triall with Lactobacillus GG. Gut 2002;51:405-9.

95. Bennet JD, Brinkman M. Treatment of ulcerative colitis by implantation of normal colonic flora. Lancet 1989;1:164.

96. Kruis $W$, Schutz $E$, Fric P, Fixa $B$, Judmaier $G$, Stolte M. Double-blind comparison of an oral Escherichia coli preparation and mesalazine in maintaining remission of ulcerative colitis. Aliment Pharmacol Ther 1997;11:853-8.

97. Kruis $W$, Fric $P$, Pokrotnieks $J$, et al. Maintaining remission of ulcerative colitis with the probiotic Escherichia coli Nissle 1917 is as effective as with standard mesalazine. Gut 2004;53:1617-23. 
98. Rembacken BJ, Sneling AM, Hawkey PM, Chalmers DM, Axon AT. Nonpathogenic Escherichia coli versus mesalazine for the treatment of ullcerative colitis: a randomised trial. Lancet 1999;354:635-9.

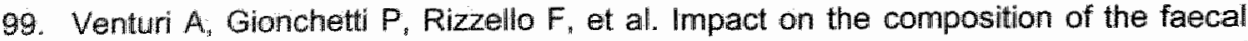
flora by a new probiotic preparation: preliminary data on maintenance treatment of patients with ulcerative colitis. Aliment Pharmacol Ther 1999;13:1103-8.

100. Gionchetti $P$, Morselli $C$, Rizzello $F$, et al. Management of pouch dysfunction or pouchitis with an illeoanal pouch. Best Pract Res Clin Gastroenterol 2004;18: 993-1006.

101. Ruseler-Van Embden JG, Schouten WR, van Lieshout LM. Pouchitis: result of microbial imbalance? Gut 1994;35:658-64.

102. Salemans $\mathbf{J M}$, Nagengast FM. Clinical and physiological aspects of ileal pouchanal anastomosis. Scand J Gastroenterol Suppl 1995;212:3-12.

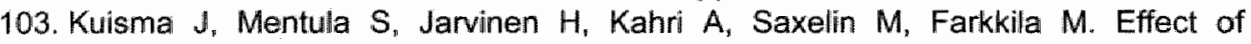
Lactobacillus thamnosus $G G$ on ileal pouch inflammation and microbial flora. Aliment Pharmacol Ther 2003;17:509-15.

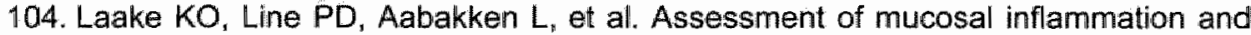
circulation in response to probiotics in patients operated with ileal pouch anal anastomosis for ulcerative colitis. Scand J Gastroenterol 2003;38:409-14.

105. Laake KO, Line PD, Grzyb K, et all. Assessment of mucosal inflammation and blood flow in response to four weeks" intervention with probiotics in patients operated with a J-configurated ileal-pouch-anal-anastomosis (IPAA). Scand $J$ Gastroenterol 2004;39:1228-35.

106. Gionchetti P, Rizzello F, Venturi $A$, et al. Oral bacteriotherapy as maintenance treatment in patients with chronic pouchitis: a double-blind, placebo-controlled trial. Gastroenterology 2000;119:305-9.

107. Mimura T, Rizzello F, Helwig U, et al. Once daily high dose probiotic therapy (VSL\#3) for maintaining remission in recurrent or refractory pouchitis. Gut 2004;53:108-14.

108. Gionchetti P. Rizzello F, Helwig U, et al. Prophylaxis of pouchitis onsel with probiotic therapy: a double-blind, placebo-controlled trial. Gastroenterology 2003; 124:1202-9.

109. Gosselink MP. Schouten WR, van Lieshout LM, Hop WC, Laman JD, Ruseler-van Embden JG. Delay of the first onset of pouchitis by oral intake of the probiotic strain Lactobacillus rhamnosus GG. Dis Colon Rectum 2004;47:876-84.

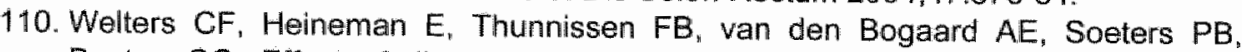
Baeten CG. Effect of dietary inulin supplementation on inflammation of pouch mucosa in patients with an lleal pouch-anal anastomosis. Dis Colon Rectum 2002:45:621-7.

111. Mckendrick MW. Read NW. Irritable bowel syndrome--post salmonella infection. J Infect 1994;29:1-3.

112. Drossman DA. Irritable bowel syndrome. Gastroenterologist 1994:2:315-26.

113. Balsari A, Ceccarelli A, Dubini F, Fesce $E$, Poli $G$. The fecal microbial population in the irritable bowel syndrome. Microbiologica 1982;5:185-94.

114. Wyatt GM, Bayliss CE, Lakey AF, Bradley HK, Hunter JO, Jones VA. The faecal flora of two patients with food-related irritable bowel syndrome during challenge with symptom-provoking foods. J Med Microbiol 1988;26:295-9.

115. Bradley HK, Wyatt GM, Bayliss CE. Hunter JO. Instability in the faecal flora of a patient suffering from food-related irritable bowel syndrome. J Med Microbiol 1987;23:29-32. 
116. Haderstorfer B, Psycholgin D, Whitehead WE, Schuster MM. Intestinal gas production from bacterial fermentation of undigested carbohydrate in irritable bowel syndrome. Am J Gastroenterol 1989;84:375-8.

117. King $\mathrm{TS}_{\mathrm{i}}$ Elia $\mathrm{M}$, Hunter JO. Abnormal colonic fermentation in irritable bowel syndrome. Lancet 1998;352:1187-9.

118. Halpern GM, Prindiville T, Blankenburg M. Hsia T, Gershwin ME. Treatment of irritable bowel syndrome with Lacteol Fort: a randomized, double-blind, cross-over trial. Am J Gastroenterol 1996;91:1579-85.

119. Hunter JO, Lee AJ, King TS, Barratt MEJ, Linggood MA, Blades JA. Enterococcus faecium strain PR88-an effective probiotic. Gut 1996;38:A62.

120. Niedzielin $K$, Kordecki $H$, Birkenfeld B. A controlled, double-blind, randomized study on the efficacy of Lactobacillus plantarum $299 \mathrm{~V}$ in patients with irritable bowel syndrome. Eur J Gastroenterol Hepatol 2001;13:1143-7.

121. Nobaek $S$, Johansson $M L$, Molin $G$, Ahrne $S$, Jeppsson $B$. Alteration of intestinal microflora is associated with reduction in abdominal bloating and pain in patients with irritable bowel syndrome. Am J Gastroenterol 2000;95:1231-8.

122. O'Mahony L, McCarthy J, Kelly $P$, et al. Lactobacillus and bifidobacterium in irritable bowel syndrome: symptom responses and relationship to cytokine profiles. Gastroenterology 2005;128:541-51.

123. O'Sullivan MA, O'Morain CA. Bacterial supplementation in the irritable bowel syndrome. A randiomised double-blind placebo-controlled crossover study. Dig Liver Dis 2000;32:294-301.

124. Sen S, Mullan MM, Parker T』, Woolner JT. Tarry SA, Hunter JO. Effect of Lactobacillus plantarum $299 \mathrm{v}$ on colonic fermentation and symptoms of irritable bowel syndrome. Dig Dis Sci 2002;47:2615-20.

125. Vesa $\mathrm{TH}$, Marteau P, Korpela R. Lactose intolerance. J Am Coll Nutr 2000;19:165S-75S.

126. Solomons NW. Fermentation, fermented foods and lactose intolerance. Eur $\mathrm{J}$ Clin Nutr 2002;56 Suppl 4:S50-5.

127. Matthews SB, Waud JP, Roberts AG, Campbell AK. Systemic lactose intolerance: a new perspective on an old problem. Postgrad Med J 2005;81:167-73.

128. Kim HJ, Camilleri M, McKinzie S, et al. A randomized controlled trial of a probiotic, VSL\#3, on gut transit and symptoms in diarrhoea-predominant irritable bowel syndrome. Aliment Pharmacol Ther 2003;17:895-904.

129. Alm L, Humble D, Ryd-Kejellan D, Setterberg G. "The effect of acidophilus millk in the treatment of constipation in hospitalised geriatric patients. Symp Swd Nutr Found 1983:15:131-8.

130. Saltzman JR, Russell, RM, Golner B, Barakat S, Dallall GE, Golldin BR. A randomized trial of Lactobacillus acidophillus BG2FO4 to treat lactose intolerance. Am J Clin Nutr 1999;69:140-6.

131. Vesa T, Pochart $P$, Marteau $P$. Pharmacokinetics of Lactobaclllus plantarum NCIMB 8826, Lactobacillus fermentum KLD, and Lactococcus lactis MG 1363 in the human gastrointestinal tract. Aliment Pharmacol Ther 2000;14:823-8.

132. Newcomer AD, Park HS, O'Brien PC, McGill DB. Response of patients with irritable bowel syndrome and lactase deficiency using unfermented acidophilus milk. Am J Clin Nutr $1983: 38: 257-63$.

133. de Vrese $M$, Stegelmann $A$, Richter $B$, Fenselau $S$, Laue $C$, Schrezenmeir J. Probiotics-compensation for lactase insufficiency. Am J Clin Nutr 2001;73: 421S-9S. 
134. Michetti $P$, Dorta $G$, Wiesel PH, al. Effect of whey-based culture supernatant of Lactobacillus acidophitus (johnsonii) La1 on Helicobacter pylori infection in humans. Digestion 1999;60:203-9.

135. Midolo $P D$, Lambert JR, Hull $R$, Luo $F$, Grayson ML. In vitro inhibition of Helicobacter pylori NCTC 11637 by organic acids and lactic acid bacteria. J Appl Bacteriol 1995;79:475\%9.

136. Kabir AM, Aiba $Y$. Takagi A, Kamiya $S$, Miwa $T$, Koga $Y$. Prevention of Helicobacter pylori infection by lactobacili in a gnotobiatic murine model. Gut 1997;41:49-55.

137. Aiba $Y$, Suzukik N, Kabir AM, Takagi A, Koga $Y$. Lactic acid-mediated suppression of Helicobacter pylori by the oral administration of Lactobacillus salivarius as a probiotic in a gnotobiotic murine model. Am J Gastroenterol 1998;93:2097-101.

138. Felley $\mathrm{C}$, Corthesy-Theulasz I, Blanco Rivero J. Favourable effect of an acidified millk (LC-1) on Helicobacter pylori gastritis in man. Eur J Gastroenterol 2001;13: 25-9.

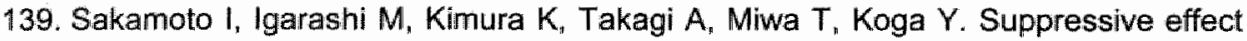
of Lactobacillus gasseri OLL 2716 (LG21) on Helicobacter pylori infection in humans. J Antimicrob Chemother 2001;47:709-10.

140. Bazzoli $F_{*}$ Zagari RM, Fossi $S$. In vivo Helicobacter pylori clearance failure with Lactobacillus acidophilus. Gastroenterology $2002 ; 192$.

141. Cremonini $F$, Di Caro $S$, Covino $M$, et al. Effect of different probiotic preparations on anti-Helicobacter pylori therapy-related side effects: a parallel group, triple blind, placebo-controlled study. Am J Gastroenterol 2002;97:2744-9.

142. Armuzzi $A$, Cremonini $F$, Bartolozzi $F$, et al. The effect of oral administration of Lactobacillus GG on antibiotic- associated gastrointestinal side-effects during Helicobacter pylori eradication therapy. Aliment Pharmacol Ther 2001;15:163-9.

143. Canducci $F$, Armuzzi $A$. Cremonini $F$, et al. A lyophilized and inactivated culture of Lactobacillus acidophilus increases Helicobacter pyloril eradication rates. Aliment Pharmacol Ther 2000;14:1625-9.

144. Gibson GR, Beatty ER, Wang $X$, Cummings JH. Selective stimulation of bifidobacteria in the human colon by oligofructose and inulin. Gastroenterology 1995; 108:975-82.

145. Kleessen $B$, Sykura $B$, Zunft HJ, Blaut M. Effects of inulin and lactose on fecal microflora, microbial activity, and bowel habit in elderly constipated persons. Am J Clin Nutr 1997;65:1397-402.

146. Nakamura $T$, Nishida $S$, Mizutani M, lino $H$. Effects of yogurt supplemented with brewer's yeast cell wall on constipation and intestinal microflora in rats. J Nutr Sci Vitaminol $2001 ; 47: 367-72$.

147. Sanders ME. Effect of consumption of lactic cultures on human health. Adv Food Nutr Res 1993;37:67-130.

148. Ouwehand AC, Lagstrom H, Suomalainen $T$, Salminen $S$. Effect of probiotics on constipation, fecal azoreductase activity and fecal mucin content in the elderly. Ann Nutr Metab 2002;46:159-62.

149. Salminen $S$, Salminen E. Lactulose, lactic acid bacteria, intestinal microecology and mucosal protection. Scand J Gastroenterol Suppl 1997;222:45-8.

150. Banaszkiewicz A, Szajewska $H$. Ineffectiveness of Lactobacillus $G G$ as an adjunct to lactulose for the treatment of constipation in children: a double-blind, placebocontrolled randomized trial. J Pediatr 2005;146:364-9.

151. Ling $W H$, Hanninen $O$, Mykkanen $H$, Heikura $M$, Sallminen $S$, Von Wright $A$. Colonization and fecal enzyme activities after oral Lactobacillus $G G$ administration in elderly nursing home residents. Ann Nutr Metab 1992;36:162-6. 
152. Parker SL, Tong $T$, Bolden $S$, Wingo PA. Cancer statistics. CA Cancer $\$ Clin $1997 ; 47: 5-27$.

153. Visser $O$, Coebergh JWW, Schouten LJ, Van Dijck JAAM. Incidence of cancer in The Netherlands 1994. Utrecht, 1997.

154. Malhotra SL. Dietary factors in a study of cancer colon from Cancer Registry, with special reference to the role of saliva, milk and fermented milk products and vegetable fibre. Med Hypotheses 1977;3:122-6.

155. Shahani KM, Ayebo AD. Role of dietary lactobacilli in gastrointestinal microecology. Am J Clin Nutr 1980;33:2448-57.

156. Peters RK, Pike MC, Garabrant D, Mack TM. Diet and colon cancer in Los Angeles County, California. Cancer Causes Control 1992;3:457-73.

157. Young TB, Wolf DA. Case-control study of proximal and distal colon cancer and diet in Wisconsin. Int $J$ Cancer 1988;42:167-75.

158. Pool-Zobel $B L$, Bertram $B$, Knoll M, et al. Antigenotoxic properties of lactic acid bacteria in vivo in the gastrointestinal tract of rats. Nutr Cancer 1993;20:271-81.

159. Zhang $X B$, Ohta $Y$. Binding of mutagens by fractions of the cell wall skeletion of lactic acid bacteria. J Dairy Sci 1991;74:1477-81.

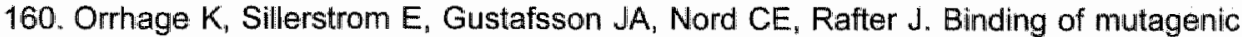
heterocyclic amines by intestinal and lactic acid bacteria. Mutat Res 1994;311: 239-48.

161. Pool-Zobel BL, Neudecker C, Domizlaff I, et al. Lactobacillus- and Bifidobacteriummediated antigenotoxicity in the colon of rats. Nutr Cancer 1996;26:365-80.

162. Redidy BS, Rivenson A. Inhibitory effect of Bifidobacterium longum on colon, mammary, and liver carcinogenesis induced by 2-amino-3-methylimidazo[4,5f]quinoline, a food mutagen. Cancer Res. 1993;53:3914-8.

163. Sekine K, Toida $T$, Saito M, Kuboyama M, Kawashima T, Hashimoto Y. A new morphologically characterized cell wall preparation (whole peptidoglycan) from Bifidobacterium infantis with a higher efficacy on the regression of an established tumor in mice. Cancer Res 1985;45:1300-7.

164. Reddy BS. Prevention of colon cancer by pre- and probiotics: evidence from laboratory studies. Br J Nutr 1998;80:S219-23.

165. Arimochi $H$, Kinouchi $T$, Kataoka K, Kuwahara T, Ohnishi Y. Effect of intestinal bacteria on formation of azoxymethane-induced aberrant crypt foci in the rat colon. Biochem Biophys Res Commun 1997;238:753-7.

166. Bolognani F. Rumney CJ, Pool-Zobel BL, Rowland IR. Effect of lactobacilli, bifidobacteria and inulin on the formation of aberrant crypt foci in rats. Eur al Nutr 2001;:40:293-300.

167. Ayebo AD, Angelo IA, Shahani KM. Effects of ingesting Lactobacillus acidophilus milk upon fecal flora and enzyme activity in humans. Milk Wissenschaft $1980 ; 35: 730-3$.

168. Ling WH, Korpela R, Mykkanen $H$, Salminen $\mathrm{S}$, Hanninen $\mathrm{O}$. Lactobacillus strain GG supplementation decreases colonic hydrolytic and reductive enzyme activities in healthy female adults. J Nutr 1994;124:18-23.

169. Bartram HP, Scheppach W, Gerlach S, Ruckdeschel G, Kelber E, Kasper H. Does yogurt enriched with Bifidobacterium longum affect colonic microbiology and fecal metabolites in health subjects? Am J Clin Nutr 1994;59:428-32.

170. Nielsen $\mathrm{OH}$, Jorgensen $\mathrm{S}$, Pedersen $\mathrm{K}$, Justesen T. Microbiological evaluation of jejunal aspirates and faecal samples after oral administration of bifidobacteria and lactic acid bacteria. J Appl Bacteriol 1994;76:469-74. 


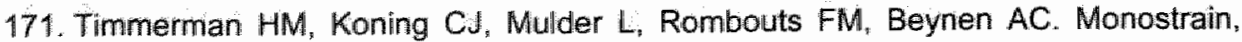
multistrain and multispecies probiatics-A comparison of functionality and efficacy. Int J Food Miorobiol 2004;96:219-33.

172. Johansson $M$, Molin $G$, Jeppsson $B$, Nobaek $S$, Ahrne $S$, Bengmark $S$. Administration of different Lactobacillus strains in fermented oatmeal soup: in vivo colonization of human intestinal mucosa and effect on the indigenous flora. Appl Environ Microbiol 1993;59:15-20.

173. Tannock $G$, Munro $K$, Harmsen $H$, Welling $G$, Smart J, Gopal P. Analysis of the fecal microflora of thuman subjects consuming a probiotic product containing Lactobacillus thamnosus DR20. Appl Environ Microbiol 2000;66:2578-88.

174. Link-Amster $H_{1}$ Rochat $F$, Saudlan KY, Mignot O, Aeschlimann JM. Modulation of a specific humoral immune response and changes in intestinal flora mediated through fermented milk intake. FEMS Immunol Med Microbiol 1994;10:55-63.

175. Marteau P. Pochart $P$. Flourie $B$, et al. Effect of chronic ingestion of a fermented dairy product containing Lactobacillus acidophilus and Bifidobacterium bifidum on metabolic activities of the colonic flora in humans. Am J Clin Nutr 1990;52:685-8.

176. Molin G, Jeppsson B, Johansson ML, at al. Numerical taxonomy of Lactobacillus spp. associated with healthy and diseased mucosa of the human intestines. J Appl Bacteriol 1993;74:314-23.

177. Adlerberth I. Ahrne $S$, Johansson M, Molin G, Hanson L. Wold A. A mannosespecific adherence mechanism in Lactobacillus plantarum conferring binding to the human colonic cell line HT-29. Appl Environ Microbiol 1996;62:2244-51.

178. Wullt M. Hagslatt ML, Odenholt L. Lactobacillus plantarum $299 \mathrm{v}$ for the treatment of recurrent Clostridium difficile-associated diarrhoea: a double-blind, placebocontrolled trial. Scand J Infect Dis 2003;35:365-7.

179. McNaught CE, Woodcock NP, MacFie J, Mitchell CJ. A prospective randomised study of the probiotic Lactobacillus plantarum $299 \mathrm{~V}$ on indices of gut barrier function in elective surgical patients. Gut 2002;51:827-31.

180. Naruszewicz $M$, Johansson ML, Zapolska-Downar D, Bukowska $H$. Effect of Lactobacillus plantarum $299 \mathrm{v}$ on cardiovascular disease risk factors in smokers. Am J Clin Nutr 2002;76:1249-55.

181. Schultz M, Veltkamp $C$, Dielemans LA, Wyrick PB, Tonkonogy SL, Sartor RB. Continuous feeding of Lactobacillus plantarum attenuates established colitis in interleukin-10 deficient mices. Gastroenterology 1998;114:A1081.

182. Schultz M, Veltkamp $C$, Dieleman LA, et al. Lactobacillus plantarum $299 \mathrm{~V}$ in the treatment and prevention of spontaneous colitis in interleukin-10-deficient mice. Inflamm Bowel Dis 2002;8:71-80.

183. Herias MV, Hessle $C_{*}$ Telemo $E_{*}$ Midtvedt $T$, Hanson LA, Wold AE. Immunomodulatory effects of Lactobacillus plantarum colonizing the intestine of gnotobiotic rats. Clin Exp Immunol 1999;116:283-90.

184. Mangell $P$, Nejdfors $P$, Wang $M_{n}$ et al. Lactobacillus plantarum $299 \mathrm{~V}$ inhibits Escherichia coli-induced intestinal permeability. Dig Dis Sci 2002;47:511-6.

185. Pathmakanthan S, Li CK, Cowie J, Hawkey CJ. Lactobacillus plantarum 299: beneficial in vitro immunomodulation in cells extracted from inflamed human colon. J Gastroenterol Hepatol 2004;19:166-73. 


\section{Chapter 2}

The effect of $L$. plantarum $299 \mathrm{v}$ on the bacterial composition and metabolic activity in faeces of healthy volunteers: a placebo-controlled study on the onset and duration of effects

D. Goossens, D. Jonkers, M. Russel, E. Stobberingh, A. van den Bogaard, R. Stockbrügger 


\title{
Abstract
}

\begin{abstract}
Aim
To study the onset and duration of a possible effect of a fermented oatmeal drink containing $L$. plantarum $299 \mathrm{v}$ on the composition of the faecal flora of healthy voluniteers in a placebo-controblled double-blind study.

\section{Methods}

Twenty two participants consumed a fermented oatmeal drirk with or without $L$. plantarum $299 \mathrm{v}$ for four weeks. Faecal samples were collected weekly: two samples before four during, and four aufter consumption of the drinks. Several bacterial species were counted and enzyme activities, stinort chain fatty acid (SCFA) concentrations, endotoxin concentration and $\mathrm{pH}$ were determined. $L$. plantarum 299w was identified with RAPD.
\end{abstract}

\section{Results}

in contrast to the placebo group, median lactobacilli counts increased significantly from 4.2 (33.46.3) to $8.2(7.3-8.5) \log$ cfu/gram faeces $(p=0.005)$ after 1 week consumption of $L$. plantarum $29 \$ 9 \mathrm{v}$, thereafter remaining stable during the treatment period. One week after cessation, a significsant decrease of lactobacilli (towards $4.4(2.2-6.5) \mathrm{lag}$ CFU/gram faeces) was observed ( $p=0.0033$ ). These lactobacili were identified as L. plantarum 299v. All other bacterial counts, enzyrme activities; SCFA concentrations, endotoxin concentration and $\mathrm{pH}$ remained unchanged.

\section{Conclusions}

L. plantarum $299 \mathrm{v}$ intake significantly increased the number of lactobacilli in the faecal flora within one week and this effect disappeared within one week after cessation of intake. No other changges in bacterial counts and metabolic products were observed. 


\section{Introduction}

In the colon $10^{11}-10^{12}$ micro-organisms per gram faeces are found. It is estimated that at least 400-500 different species are present, but only about 100 species have been identified in faecal specimens from healthy individuals ${ }^{1}$. The intestinal bacterial flora is involved in a wide variety of metabolic and immunologic processes, which can play a role in health and disease of the host $^{2}$. Nowadays, there is growing interest in probiotics which are defined as "mono- or mixed cultures of live micro-organisms that, when applied to animal or man, beneficially affect the host by improving the properties of the indigenous microflora" ${ }^{3}$. Monocultures of lactobacilli, bifidobacteria or Saccharomyces spp. are frequently used as probiotics but the use of multispecies products is also growing. Clinical studies have suggested that probiotics may be useful in the prevention and treatment of diarrhoea (antibiotic-associated, rotavirus, Clostridium difficile associated or traveller's diarrhoea), lactose-intolerance, reduction of food allergy symptoms, reduction of serum cholesterol levels and the protection against colon and bladder cancer $^{4-8}$. Furthermore, some studies have shown that probiotics might be efficient in the treatment of inflammatory bowel disease, irritable bowel syndrome and pouchitis ${ }^{9-13}$.

To be effective, probiotics have to be able to survive passage through the gastrointestinal tract and to colonise the intestinal mucosa ${ }^{4,14-17}$. However, there are several unresolved issues concerning the use of probiotic bacteria and their effect on the intestinal bacterial flora; the number of bacteria to be given, the use of a mono-, or multispecies probiotic preparation, the frequency and duration of administration and the duration of an effect after cessation of the consumption of a probiotic.

Some of these questions were investigated in a limited number of studies. Tannock et al. performed an uncontrolled study with ten healthy volunteers who consumed milk containing Lactobacillus rhamnosus DR20 for six months and found a change in the number of colony forming units (CFU) of lactobacilli and enterococci in the faecal samples during the consumption period ${ }^{18}$. In this study samples were collected only once per month. An increase in the number of lactobacilli was also found by Spanhaak et al and Johansson et al., who studied the effect of Lactobacillus casei shirota and Lactobacillus plantarum $299 \mathrm{v}$, respectively, on the bacterial composition in the faeces of healthy volunteers in placebo-controlled studies. However, in these studies only one faecal sample was collected after either one and two weeks consumption of probiotic drinks ${ }^{19,20}$.

Besides studying the composition of the intestinal bacterial flora, the flora can also be considered as a metabolic entity with a variety of metabolites. Short chain fatty acids are formed by fermentation of non-starch polysaccharides by colonic bacteria ${ }^{21}$. Endotoxins, or lipopolysaccharides, are major components of the cell wall of Gram-negative bacteria and changes in the composition of 
the bacterial flora can result in a change of endotoxin concentrations. Finally, bacterial enzymes like $\beta$-glucosidase and $\beta$-glucuronidase can play a role in the conversion of pre-carcinogens into carcinogens ${ }^{22}$. Lactobacilli might provide some protection against ingested pre-carcinogens by decreasing the enzyme activity of the colonic flora ${ }^{23}$. Furthermore, probiotics may also affect other microflora-associated characteristics like cholesterol metabolism, transformation of bilirubin, trypsin activity, degradation of B-aspartylglycine and degradation of mucin ${ }^{24}$. These bacterial metabolites can be of importance for the host in both health and disease. Measurement of these metabolites can be used as indicators for changes in the composition of the intestinal bacterial flora $^{23,24}$.

In this placebo-controlled double-blind study, the effects of a fermented oatmeal drink with L. plantarum $299 \mathrm{v}$ on both the bacterial flora and metabolites is studied in faecal samples of healthy volunteers. Special attention is paid to the onset and duration of the effects.

\section{Methods}

\section{Subjects}

Twenty-two healthy volunteers were enrolled in this study using the following exclusion criteria: pre-existing bowel-pathology including irritable bowel syndrome, inflammatory bowel disease, diverticulitis, diarrhoea and cancer. volunteers were not allowed to use gastric acid inhibitors, laxantia, antidiarrhoea medication or antibiotics for at least one month before as well as during the study. Furthermore, the consumption of other probiotics or prebiotics for at least two weeks before the start of the study as well as during the study was not allowed. Participants were asked to continue their normall diet.

\section{Study design}

The study was double-blind and placebo-controlled. Total duration of the study was ten weeks: a pre-treatment period (week 1-2), a treatment period (week 3-6), and a post-treatment period (week 7-10). During the four week treatment period, participants consumed daily $200 \mathrm{ml}(100 \mathrm{ml}$ in the morning and $100 \mathrm{ml}$ in the evening) of a fermented oatmeal drink with $10^{9} \mathrm{CFU} / \mathrm{ml} L$. plantarum $299 \mathrm{v}$ (probiotic group, $\mathrm{n}=11$ ) or without $L$. plantarum $299 \mathrm{v}$ (placebo group, $n=11$ ). The two drinks were indistinguishable in colour, smell and taste. Ten faecal samples were collected: two just before the start of the study, four during consumption and four after consumption of the drinks. Samples were collected every Thursday ( \pm one day) to avoid major influences of changed dietary habits during the weekend. At the time of each faeces collection, a short questionnaire had to be completed on bowel habits (stool frequency and consistency according to the Bristol scale ${ }^{25}$ ), side effects and compliance with 
regard to the consumption of the drinks. Participants were excluded from analyses if less than $80 \%$ of the faecal samples were collected or the drinks were consumed less than six days a week based on the questionnaires.

\section{Microbiological analyses}

Faecal samples were collected in sterile containers of $20 \mathrm{ml}$, brought to the laboratory within twelve hours after defaecation and were divided into three parts. Five grams were diluted (1:4) in pepton water with cysteine $(2.1 \mathrm{mM})$ and glycerol $(37 \%)$ and homogenised with the ultraturax for two minutes. Cultures were performed directly and the remaining part of the material was frozen $\left(-18^{\circ} \mathrm{C}\right)$ for analysis of enzyme activities and short chain fatty acids. Ten grams were centrifuged at $4^{\circ} \mathrm{C}$ for 2 hours at $25.000 \mathrm{~g}$ to obtain faecal water that was frozen at $-80^{\circ} \mathrm{C}$ for analysis of endotoxins and determination of the $\mathrm{pH}$. The remaining material was frozen immediately for future additional analyses.

\section{Culture}

Ten-fold serial dilutions of the faecal samples $\left(10^{-1}-10^{-6}\right)$ were made in physiological saline $(0.9 \%)$ and $40 \mu l$ were inoculated, using a spiral plater, (Eddy Jet $v 1.2$, IUL-instruments, Barcelona, Spain) on the following agar plates: Blood agar plates (Oxoid $\mathrm{CM}$ 271, Basingstoke, UK) for total (facultative) aerobic bacteria, Eosin-methylene blue agar plates (Oxoid CM69, Basingstoke, UK) for enterobacteriaceae, KF-streptococcus agar plates (Oxoid Cm701, Basingstoke, UK) for enterococci, Fastidious anaerobic agar plates (Lab M LabGo, Lancashire BI9, 6AJ, UK) for total (facultative) anaerobic bacteria, Bile-esculine agar plates (Becton Dickinson 287920, La Pont de Claix, France) for Bacteroides spp., Egg yolk agar plates for spore-forming clostridia, Rogosa agar plates (Oxoid CM627, Basingstoke, UK) for lactic acid bacteria and LAMVAB (lactobacillus anaerobic MRS with vancomycin and bromocresol green) for lactobacillit ${ }^{26}$.

Egg yolk agar plates were prepared with proteose peptone (46 g/l) (Oxoid L85), sodium phosphate dibasic-2-hydrate $(7.2 \mathrm{~g} / \mathrm{l})$, magnesium sulphate-7-hydrate (23 $\mathrm{mg} / \mathrm{l})$, potassium phosphate $(1.15 \mathrm{~g} / \mathrm{l})$, sodium chloride $(2.3 \mathrm{~g} / \mathrm{l})$, glucose $(2.3 \mathrm{~g} / \mathrm{l})$ and agar $(23 \mathrm{~g} / \mathrm{l})(\mathrm{BBL} 11849$, Cockeysville, USA). Finally, hemin $(5 \mathrm{mg} / \mathrm{ml})$, vitamin $\mathbb{K}(1 \mathrm{mg} / 1)$, egg yolk (sterile egg yolk diluted with physiological saline $1: 1)$ and neomycin (10 $\mathrm{mg} / \mathrm{ml})$ were added. Before inoculation, the faecal suspensions were heated at $80^{\circ} \mathrm{C}$ for ten min.

LAMVAB ( $\mathrm{pH} 5)$ was prepared with MRS-broth $(104.4 \mathrm{~g} / \mathrm{l})$, cysteine-HCl $(0.5 \mathrm{~g} / \mathrm{l})$, bromocresol green $(0.05 \mathrm{~g} / \mathrm{l})$, agar $(40 \mathrm{~g} / \mathrm{l})$ and vancomycin hydrochloride ( $>95 \%$ purity, $2 \mathrm{mg} / \mathrm{ml}$ ) according to the method described by Hartemink et al. ${ }^{26}$.

Blood agar and Eosin-methylene blue agar plates were incubated aerobically at $37^{\circ} \mathrm{C}$ for 24 hours. KF- streptococcus agar was incubated aerobically at $42^{\circ} \mathrm{C}$ for 48 hours. Fastidious anaerobic, Bile-esculine, Egg yolk, Rogosa and LAMVAB agar plates were pre-reduced in the anaerobic cabinet for 24 hours 
before inoculation and were incubated in the anaerobic cabinet at $37^{\circ} \mathrm{C}$ for 48 hours after inoculation.

\section{Identification of lactobacilli}

From each $\angle A M V A B$ agar plate four colonies with the appearance of lactobacilli were isolated and purified on blood agar plates. Isolates were frozen at $-80^{\circ} \mathrm{C}$ for molecular identification of L. plantarum $299 \mathrm{v}$ using randomly amplified polymorphic DNA (RAPD), eventually confirmed by restriction enzyme analyses (REA) according to the method described by Johansson et al. ${ }^{27,28}$.

\section{Bacterial enzyme activities}

The $\beta$-glucosidase and $B$-glucuronidase activities were analysed aerobically. Faecal samples were diluted (1:1) in $0.1 \mathrm{M}$ PBS $\left(\mathrm{pH} 6.8,5-7^{\circ} \mathrm{C}\right)$, sonicated for one $\mathrm{min}$. at $D^{\circ} \mathrm{C}$ and subsequently centrifuged at $3000 \mathrm{rpm}$ during $15 \mathrm{~min}$. at $4^{\circ} \mathrm{C}$. The supernatant was used for the assessment of B-glucosidase and $\mathrm{B}$ glucuronidase activities.

B-Glucosidase: $0.2 \mathrm{ml}$ faecal supernatant was added to $0.8 \mathrm{ml}$ reaction mixture (0.1 M PBS, $1 \mathrm{mM}$ p-nitrophenyl $B$-glucopyronoside). The reaction ran for one hour at $37^{\circ} \mathrm{C}$ and was stopped by adding $5 \mathrm{ml} 0.1 \mathrm{M} \mathrm{NaOH}$ per ml reaction mixture. For every sample, a control was also determined (faecal sample with reaction mixture without incubating). Readings were taken at $405 \mathrm{~nm}$. Concentrations were calculated, after correction for controls, from a standard curve for $\mathrm{p}$-nitrophenol and were expressed as $\mathrm{mg}$ p-nitrophenol released per 60 min per gram faeces ${ }^{29}$.

B-Glucuronidase: $0.1 \mathrm{ml}$ faecal supernatant was added to $0.9 \mathrm{ml}$ reaction mixture (0.02 M PBS, $0.1 \mathrm{mM}$ EDTA, $1 \mathrm{mM}$ phenylphatalein BD glucuronide). The reaction ran for $30 \mathrm{~min}$. at $37^{\circ} \mathrm{C}$ and was stopped by adding $5 \mathrm{ml}$ of $0.2 \mathrm{M}$ glycine buffer $(\mathrm{pH} 10.4)$ containing $0.2 \mathrm{M} \mathrm{NaCl}$ per ml reaction mixture. For every sample, also a control was determined (faecal sample with reaction mixture without incubating). Readings were taken at $520 \mathrm{~nm}$. Concentrations were calculated, after correction for controls, from a standard curve for phenylphatalein and were expressed as $\mathrm{mg}$ phenolphthalein per gram faeces per $30 \mathrm{~min}^{29}$.

Azoreductase: The azoreductase was analysed anaerobically. Faecal samples were diluted (1:1) in pre-reduced Tris buffer $(0.2 \mathrm{M}, \mathrm{pH} 7.8)$ and were vortexed and centrifuged at $7000 \mathrm{rpm}$ during five min. in the anaerobic cabinet. One $\mathrm{ml}$ pre-reduced Tris-buffer $(\mathrm{pH} \mathrm{7.8,0.2} \mathrm{M)} \mathrm{was} \mathrm{added} \mathrm{to} \mathrm{one} \mathrm{ml} \mathrm{supernatant.}$ Direct blue 15 solution (Sigma D2535, Steinham, Germany, final concentration $24 \mu \mathrm{g} / \mathrm{ml}$ ) was added. For every sample, a control without direct blue solution was determined. The samples were incubated anaerobically at $37^{\circ} \mathrm{C}$ for 16 hours until the dye had been decolourised. After incubation, direct blue was added to the control samples and the absorbance was read at $615 \mathrm{~nm}$. The amount of dye reduced per gram faeces per 16 hours was calculated from a 
standard curve generated for direct blue, after correction for controls and was expressed as $\mu \mathrm{g}$ direct blue converted per gram faeces per 16 hours $^{30}$.

\section{Endotoxin assay}

The endotoxin concentration was determined in faecal water using the microtechnique of the Limu/us amoebocyte lysate test (Endosafe, end point chromogenic analysis endochrome test kit, Charles River, Kent). Pyrogen-free water was used to dilute the faecal samples, to dissolve the solutions and as negative control. The analysis was performed according to the manufacturer's instructions under pyrogen-free conditions. The range of the detectable concentration of the assay was between 0.015 and $1.2 \mathrm{EU} / \mathrm{ml}$. The mean value of faecal endotoxin was expressed as log $\mathrm{ng}$ endotoxin per $\mathrm{ml}$ faecal water.

\section{Short chain fatty acid assay}

Short chain fatty acids (SCFA) were measured in the faeces using gas-liquid chromatography (GLC). The GLC system consisted of a DANI 8521-a gas chromatograph equipped with flame ionisation detector in conjunction with Maestro software (Chrompack, Middelburg, Holland) for calculations. The chromatographic column used, was WCOT fused silica $25 \mathrm{~m} \times 0.32 \mathrm{~mm}$ id, coated with FFAP-CB df 0.3 . This column was used in an isotherm mode at $140^{\circ} \mathrm{C}$ and the injector and detector temperature were $270^{\circ} \mathrm{C}$. The injection type was split with a ratio of 1:50. Helium was used as carrier gas, with a head pressure of 0.8 bar.

One $\mathrm{ml} \mathrm{HCl}$ with heptanoic acid (internal standard, $10 \mathrm{mmol} / \mathrm{l}$ ) was added to one $\mathrm{ml}$ of the diluted faecal samples to form free fatty acids. SCFA were extracted with two $\mathrm{ml}$ of diethyl ether. One $\mu \mathrm{l}$ of the diethyl ether extract was injected for measurement. Concentrations of SCFA were determined in mmol/g faeces after correction for dilution ${ }^{31}$.

$\mathrm{pH}$

The $\mathrm{pH}$ was measured in faecal water using a $\mathrm{PHM} 201$ portable $\mathrm{pH}$ meter (Radiometer, Nederland BV).

\section{Statistical analyses}

Statistical evaluation of changes within groups was carried out using the nonparametric Friedman test and the Wilcoxon signed-rank test. The MannWhitney U-test was used for comparisons between groups. P-values were adjusted with the Bonferroni-Holm correction because of multiple comparisons. A p-value below 0.05 was considered to be statistically significant. 


\section{Results}

Twenty participants completed the study ( 9 males, mean age $34.1 \pm 12.9 / 11$ females, mean age $31.9 \pm 7.2$ ). Two participants from the placebo group were excluded: one person was not able to collect $80 \%$ of the faecal samples and one person did not tolerate the fermented oatmeal drink and suffered from more than five liquid stools per day. No further side effects were reported. One probiotic and one placebo consumer mentioned a change of defaecation frequency during the consumption period, from one to two defaecations per day. However, comparing the probiotic and the placebo group no significant differences were observed in defaecation frequency and consistency (table 2.1). The compliance to the drinks was approximately $100 \%$ in both groups.

Table 2.1 Faeces frequency, consistency (mean \pm SEM) before (week 1-2), during (week 3-6) and after (week $7-10$ ) the consumption of the probiotic drink or placebo drink.

\begin{tabular}{lccccccc}
\hline & \multicolumn{3}{c}{ Probiotic group } & \multicolumn{3}{c}{ Placebo group } \\
& before & during & after & before & during & after \\
\hline Faeces frequency & $1.4 \pm 0.1$ & $1.2 \pm 0.1$ & $1.2 \pm 0.1$ & $0.9 \pm 0.2$ & $0.9 \pm 0.1$ & $0.9 \pm 0.1$ \\
Faeces consistency & $3.4 \pm 0.3$ & $3.5 \pm 0.2$ & $3.6 \pm 0.2$ & $4.1 \pm 0.3$ & $3.7 \pm 0.2$ & $3.9 \pm 0.2$ \\
\hline
\end{tabular}

\section{Culture}

During the consumption of the probiotic drink, a significant increase in the number of lactobacilli in the probiotic group was observed $(p=0.005)$ (figure 2.1). The number of lactobacilli reached levels of eight log CFU per gram faeces after one week consumption of the probiotic drink and did not increase further after two, three or four weeks treatment. The number of lactobacilli decreased significantly one week after ending the consumption of the probiotic drink ( $p=0.003$ ) (figure 2.1). During the consumption of the drinks, a significant difference could be observed between the probiotic and placebo group $(p=0.006)$. Lactic acid bacteria (lactobacilli and bifidobacteria) counted on Rogosa agar plates changed in a similar way as the lactobacilli counted on LAMVAB agar plates.

L. plantarum $299 \mathrm{v}$ was identified during the consumption periad in all participants of the probiotic group in all faecal samples during the probiotic treatment. No $L$. plantarum $299 \mathrm{v}$ could be recovered one week after ending the consumption of the probiotic drinks except for one person.

The number of aerobic bacteria, enterocacci, enterobacteriaceae, anaerobic bacteria Bacteroides spp., and spore-forming clostridia did not change in both groups (table 2.2). 


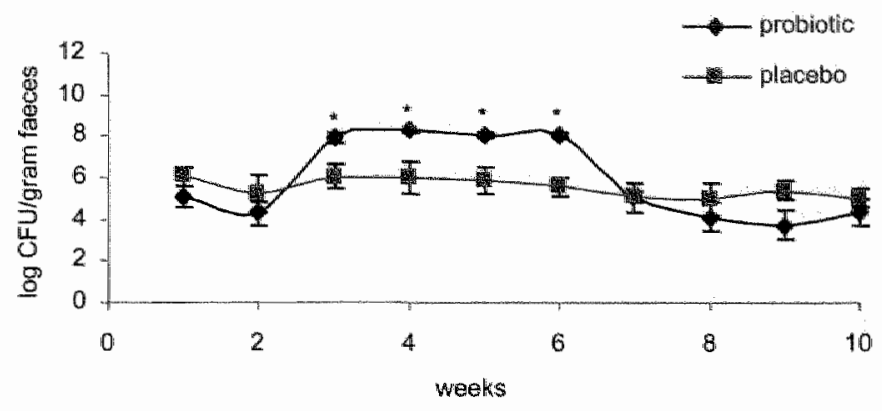

Figure 2.1 Concentration of lactobacilli (log CFU/gram faeces) before (week 1-2), during (week 36) and after (week $7-10$ ) the consumption of the probiotic or placebo drinks (mean \pm SEM).

${ }^{*} p<0.05$ between probiotic and placebo group during the consumption of the drinks.

Table 2.2 Concentrations of bacterial strains (log CFU/gram faeces), median and ranges before (week 1-2), during (week 3-6) and after (week 7-10) the consumption of the probiotic or placebo drink.

\begin{tabular}{|c|c|c|c|c|c|c|}
\hline & \multicolumn{3}{|c|}{ Probiotic group } & \multicolumn{3}{|c|}{ Placebo group } \\
\hline & before & during & after & before & during & after \\
\hline Aerobic bacteria & $6.8(5.7-8.7)$ & $7.1(5.5-8.2)$ & $7.1(6.0-7.3)$ & $6.9(6.4-7.9)$ & $6.9(5.5 \cdots 8.1)$ & $7.4(6.0-8.3)$ \\
\hline Enterobacteriaceae & $6.2(0-7.2)$ & $6.2(2.6-7.0)$ & $6.1(3.5-7.2)$ & $6.7(4.6-8.0)$ & $6.5(5.1-8.1)$ & $6.9(3.6-8.0)$ \\
\hline Enterococci & $4.5(0-6.1)$ & $4.6(2.7-3.3)$ & $3.7(0-6.9)$ & $4.4(3.0-6.4)$ & $4.2(3,3-5,6)$ & $4.7(2.6-6.5)$ \\
\hline Anaerobic bacteria & $9.8(8.4-10.4)$ & $9.9(9.4-10.1)$ & $9.9(9.6-10.2)$ & $9.9(9.6-10.4)$ & $9.8(9.5-10.3)$ & $9.8(8.1-10.1)$ \\
\hline Bacteroides spp. & $8.0(7.0-9.7)$ & $8.5(7.8-8.6)$ & $8.3(7.8-8.6)$ & $8.1(7.3-9.0)$ & $8.4(8.0-8.9)$ & $8.4(8.0-8.7)$ \\
\hline Clostridia & $4.1(0-5.4)$ & $4.3(2.8-6.0)$ & $4.6(3.5-5.6)$ & $4.8(1.9-6.3)$ & $5.0(2.9-5.6)$ & $4.7(2.3-5.3)$ \\
\hline Bifidobacteria & $7.7(2.0-9.1)$ & $8.2(6.4-9.0)^{\mathrm{a}}$ & $4.9(3.2-7.3)$ & $7.4(6.8-9.3)$ & $7.6(4.5-8.9)$ & $5.8(2.8-7.7)$ \\
\hline Lactobacilli & $4.2(3.4-6.3)$ & $8.2(7.3-8.5)^{a}$ & $4.4(2.2-6.5 i)$ & 5. $1(3.4-7.9)$ & $5.4(4.2-8.4)$ & $5.2(1.9 .7 .6)$ \\
\hline
\end{tabular}

a $p<0.05$ between concentrations of bacteria before, during and after the consumption of the probiotic drink

\section{Metabolic activity}

B-Glucosidase and B-glucuronidase activity did not change significantly neither in the probiotic nor in the placebo group during the ten weeks study period (table 2.3).

Table 2.3 Enzyme activities (mean \pm SEM) measured before (week 1-2), during (week 3-6) and after (week 7-10) the consumption of the drinks, expressed in $\mathrm{mg} / 60 \mathrm{~min} / \mathrm{g}$ faeces (Bglucosidase) and in $\mathrm{mg} / 30 \mathrm{~min} / \mathrm{g}$ faeces (B-glucuronidase).

\begin{tabular}{lcccccc}
\hline & \multicolumn{3}{c}{ Probiotic group } & \multicolumn{3}{c}{ Placebo group } \\
& before & during & after & before & during & after \\
\hline B-glucosidase & $1.71 \pm 0.41$ & $2.64 \pm 0.45$ & $2.32 \pm 0.37$ & $2.32 \pm 0.51$ & $3.19 \pm 0.82$ & $2.71 \pm 0.60$ \\
B-glucuronidlase & $0.51 \pm 0.23$ & $0.56 \pm 0.20$ & $0.72 \pm 0.21$ & $0.69 \pm 0.32$ & $0.99 \pm 0.34$ & $0.75 \pm 0.26$ \\
\hline
\end{tabular}

No significant changes could be seen in endotoxin concentration between groups and within the probiotic and placebo group (figure 2.2). 


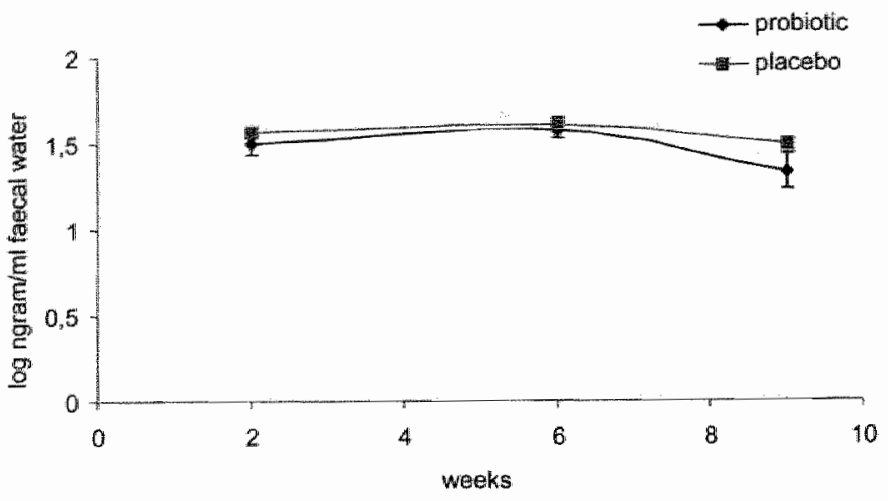

Figure 2.2 Endotoxin concentration (mean \pm SEM) measured before (week 2), during (week 6) and after (week 9 ) the consumption of the drinks, expressed in log $\mathrm{ng} / \mathrm{ml}$ faecal water.

Short chain fatty acids were analysed in all samples. Mean values of SCFA before (week 1-2), during (week 3-6) and after (weeks 7-10) treatment are given in table 2.4. Acetic, propionic, isobutyric, butyric, isovaleric, valeric and caproic acid concentration did not change significantly as a consequence of the probiotic or placebo drink. Moreover, no differences were observed between week 1 and 2, between week 3-6 and between week 7-10 (data not shown). Before consumption of the drinks, there was a significant difference between probiotic and placebo group in the isocaproic acid concentration. After ending the administration of the placebo drinks the isocaproic acid concentration decreased significantly in comparison to the concentration measured before and during consumption of the placebo drinks.

Table 2.4 Short chain fatty acids concentrations (mean \pm SEMI measured before, during and after the consumption of the drinks.

\begin{tabular}{|c|c|c|c|c|c|c|}
\hline & \multicolumn{3}{|c|}{ Probiotic group } & \multicolumn{3}{|c|}{ Placebo group } \\
\hline & before & during & after & before & during & after \\
\hline Acetic acid & $80.0 \pm 6.3$ & $75.0 \pm 7.9$ & $82.7 \pm 10.6$ & $87.5 \pm 12.7$ & $80.5 \pm 13.4$ & $92.6 \pm 12.3$ \\
\hline Propionic acid & $21.0 \pm 1.5$ & $18.8 \pm 2.2$ & $22.1 \pm 3.6$ & $24.6 \pm 4.3$ & $22.1 \pm 4.2$ & $22.4 \pm 3.9$ \\
\hline Isobutyric acid & $2.9 \pm 0.3$ & $2.5 \pm 0.4$ & $2.9 \pm 0.5$ & $2.6 \pm 0.4$ & $2.6 \pm 0.5$ & $2.4 \pm 0.6$ \\
\hline Butyric caid & $20.7 \pm 2.9$ & $17.0 \pm 2.2$ & $21.1 \pm 3.9$ & $24.6 \pm 4.6$ & $22.2 \pm 4.9$ & $27.6 \pm 4.3$ \\
\hline Isovaleric acid & $4.0 \pm 0.4$ & $3.4 \pm 0.4$ & $4.1 \pm 0.7$ & $3.9 \pm 0.7$ & $3.2 \pm 0.6$ & $4.0 \pm 1.2$ \\
\hline Valeric acid & $3.4 \pm 0.3$ & $2.9 \pm 0.3$ & $2.9 \pm 0.6$ & $3.6 \pm 0.5$ & $2.8 \pm 0.4$ & $2.7 \pm 0.4$ \\
\hline Isocaproic acid & $0.8 \pm 0.1^{a}$ & $0.4 \pm 0.06$ & $0.3 \pm 0.04$ & $0.5 \pm 0.1$ & $0.4 \pm 0.1$ & $0.2 \pm 0.04^{b}$ \\
\hline Caproic acid & $3.3 \pm 0.5$ & $2.2 \pm 0.4$ & $2.2 \pm 0.6$ & $2.7 \pm 0.3$ & $2.1 \pm 0.4$ & $2.6 \pm 0.5$ \\
\hline
\end{tabular}

${ }^{a}$ p $<0.05$ significant difference in isocaproic acid concentration in the probiotic group compared to the placebo group before the consumption of the drinks; $p<0.05$ significant difference in isocaproic acid concentration in the placebo group after consumption of the drink in comparison to concentrations before and during the consumption of the drinks. 
No significant differences in $\mathrm{pH}$ between probiatic and placebo group and within both groups were observed (figure 2.3).

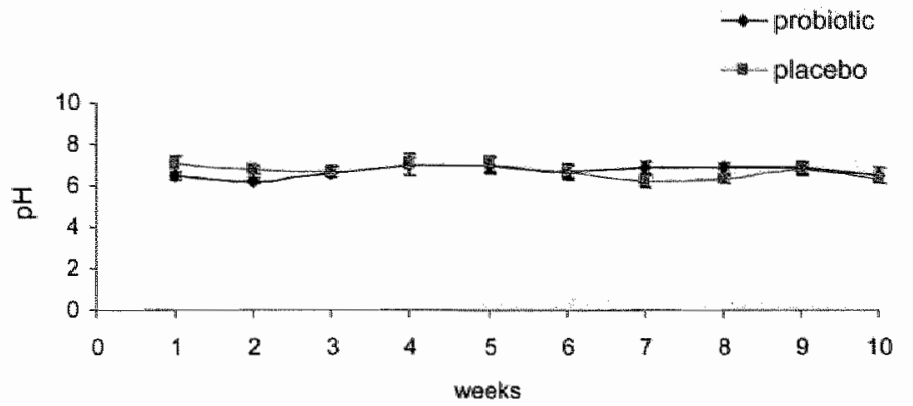

Figure 2.3 $\mathrm{pH}$ (mean \pm SEM) measured in faecal water before (week 1-2), during (week 3-6) and after (week 7-10) the consumption of probiotic and placebo drinks.

\section{Discussion}

Probiotics are advertised as treatment modality for various gastrointestinal diseases and for improving general health. However, there are still many unresolved issues concerning probiotic bacteria and their effects on the human body and intestinal flora. intervention studies are often performed without basic biological data being obtained. The aim of this study was to investigate the onset and duration of a possible effect of L. plantarum $299 \mathrm{v}$ on both the bacterial composition and metabolic activity in healthy volunteers before starting clinical studies.

In the present study, twice daily intake of $L$. plantarum $299 \mathrm{v}$ (total daily dosis $\left.10^{11} \mathrm{CFU}\right)$ significantly increased the number of lactobacilli in the faecal flora after one week consumption, indicating that $L$. plantarum $299 \mathrm{v}$ is able to survive passage through the gastrointestinal tract. This increase disappeared within one week after ending the consumption of the fermented oatmeal drink with $L$. plantarum $299 \mathrm{v}$, showing that $L$. plantarum $299 \mathrm{v}$ did not colonise the colon permanently. L. plantarum $299 \mathrm{v}$ could be recovered in the probiotic group with RAPD and REA during the consumption period, but not after ending the consumption of the probiotic drink except for one person. In a study of Johansson et al., L. plantarum $299 \mathrm{v}$ was found in faecal samples of five of 24 persons eight days after ending the administration of the probiotic drink ${ }^{19}$. In addition, $L$. plantarum $299 \mathrm{v}$ could also be recovered from the mucosa in eight of the 13 patients, 11 days after the consumption of $L$. plantarum $299 \mathrm{v}^{32}$. Unfortunately, in these two studies samples were not collected for a longer period of time after ending the administration of $L$. plantarum $299 \mathrm{v}$.

An increase in the faecal number of lactobacilli was also observed after the consumption of $L$. plantarum $299 \mathrm{v}, L$. rhamnosus or Lactobacillus acidophilus for three weeks, six months and three weeks, respectively ${ }^{18,32,33}$. In these 
studies, with healthy volunteers, no attention was paid to the onset and duration of lactobacilli increase. However, in some patient groups several faecal samples were collected during long-term treatment and one faecal sample thereafter, demonstrating a significant increase in the number of lactobacilli 20 and 30 days after starting treatment and a significant decrease 15 and 30 days after cessation ${ }^{12,13}$. The number of lactobacilli in the pretreatment and post-treatment period in our study is relatively low in comparison with the studies performed by Johansson et al. and Spanhaak et al. but comparable with the patient studies performed by Venturi et al. and Gionchetti et at. ${ }^{12,13,19,20}$. Differences in lactobacilli counts can possibly be explained by the use of a recently developed more selective agar for the culture of lactobacilli in our study: LAMVAB (lactobacillus anaerobic MRS with vancomycin and bromocresol green) ${ }^{26}$. The studies mentioned above ${ }^{18-20}$, used Rogosa agar for culture of lactobacilli. This medium is not selective for lactobacilli as growth of other acid-resistent bacteria such as bifidobacteria, corynebacteria and enterococci is not completely suppressed ${ }^{34}$. Differences in basal numbers of lactobacilli might also be caused by differences in the consumption of fermented dairy products. In the present study, healthy volunteers did not consume standardised diets but were asked to continue the consumption of their normal dietary habits.

One of the possible therapeutic mechanisms of probiotics is the partial replacement of other bacteria in the intestinal lumen. The consumption of the fermented oatmeal drink with or without $L$. plantarum $299 \mathrm{v}$ had no influence on the numbers of other faecal aerobic and anaerobic bacteria investigated. However, in the study of Johansson et al. a significant decrease in the number of sulphite-reducing clostridia was found, but this decrease was present in both the probiotic and placebo group ${ }^{19}$. The number of bacteria counted in the present study, were investigated by culture techniques. As many intestinal bacteria cannot be cultured or are not yet identified, molecular methods will be of additional value in studying the effects of probiotics on the intestinal flora ${ }^{35}$.

A change in the composition of the intestinal flora can be accompanied by a change in enzyme activities like B-glucosidase, B-glucuronidase and azoreductase. A decrease of these enzymes is expected to be beneficial because $B$-glucosidase and B-glucuronidase could produce carcinogenic endproducts $^{22}$. In this study with healthy volunteers, the fermented oatmeal drink with $L$. plantarum $299 \mathrm{v}$ had no influence on the B-glucosidase and Bglucuronidase activities. These results are in accordance with results of previous studies in which $L$. rhamnosus DR20 and L. acidophilus A1 had no influence on the B-glucuronidase activities ${ }^{18,36}$. However, B-glucuronidase activities have been decreased as consequence of lactobacilli consumption in some other studies including healthy volunteers using $L$. casei Shirota and $L$. acidophilus ${ }^{20,22}$. Furthermore, an increase in B-glucosidase activity during $L$. acidophilus A1 consumption and a decrease after $L$. caseiShirota consumption were observed ${ }^{20,36}$. These differences could be explained by the use of different lactobacilli strains as probiotic. Different lactobacilli subspecies could 
replace the intestinal fiora, change the intestinal conditions like the $\mathrm{pH}$ and stimulate reactions leading to the production of potentially beneficial or damaging products in different ways ${ }^{37}$. These aspects as well as the hetero versus homofermentative capacities of lactobacilli may thereby affect the SCFA concentration or enzyme activities differently.

In the study of Spanhaak et al. the bacterial enzyme activities were expressed in units per $10^{10} \mathrm{CFU}^{20}$. In our study the bacterial enzyme activities are expressed in $\mathrm{mg}$ per gram faeces per hour, which makes comparisons between the studies difficult. Calculations of the enzyme activity per $\mathrm{mg}$ protein to correct for metabolic changes did not result in significant differences in $\beta$ glucosidase and $\beta$-glucuronidase activities during the consumption of the fermented oatmeal drink (data not shown).

No azoreductase activity could be measured as values were often below the detection limit.

The consumption of the probiotic drink did not change the endotoxin concentrations. This result is in accordance with the finding that no changes were seen in the total counts of enterobacteriaceae because the intestinal endotoxin is mainly released by aerobic Gram-negative bacteria such as enterobacteriaceae $e^{38,39}$.

No influence of the probiotic drinks was seen on the concentration of short chain fatty acids in faecal samples. Butyric acid is an important energy source for colonocytes and one of the effects of probiotics could be an increase in butyric acid concentration ${ }^{40}$. However, no increase in the butyric acid concentration was found in the probiotic or placebo group. This result is in accordance with a previous animal study where no changes in SCFA concentration were seen after inoculation of $L$. plantarum $299 \mathrm{v}$ to germ-free mice ${ }^{41}$. A human study, in which healthy volunteers consumed $L$. plantarum $299 \mathrm{v}$ in a rose-hip drink with fermented oats, also showed no change in butyric acid concentration but a significant increase in the total SCFA, acetic and propionic acids concentration was found ${ }^{19}$. The concentrations described in that study were low compared to the concentrations in the present study, which might be due to different methods. A significant decrease of acetic acid and propionic acid was noticed after consumption of a fermented drink with $L$. casei Shirota ${ }^{20}$. Results can be different due to the consumption of different bacterial strains. Furthermore, in that study the concentration of SCFA was determined in faecal water using a high-performance liquid chromatography, which makes a comparison between the results of the studies difficult.

We cannot explain the difference in isocaproic acid concentration before the start of the consumption of the drinks and the significant decrease of isocaproic acid concentration in the placebo group after ending the administration of the drinks.

Two patients from the placebo-group were excluded from analyses of faecal bacterial counts, SCFA, enzyme activities and endotoxin concentration 
because of non-compliance. However, statistical evaluation with an intentionto-treat analysis did not change the results. In this placebo-controlled study, healthy volunteers consumed a fermented oatmeal drink with $L$. plantarum $299 \mathrm{v}$ resulting in increased lactobacilli counts but no effects on other bacteriall counts, SCFA and metabolic activities were observed. Major changes in metabolic activities or faecal bacterial counts other than the lactobacilli increase in the probiotic group could not be observed in individuals.

These participants were assumed to have 'normal' values for enzyme activities, endotoxins, SCFA concentration and the numbers of faecal bacteria. However, in persons with intestinal inflammatory conditions like Crohn's disease (CD), ulcerative colitis (UC), pouchitis and irritable bowel syndrome (IBS), the composition of the faecal bacterial composition might be disturbed. In pouchitis and UC patients, also a deficient metabolism of butyrate has been found ${ }^{42,43}$. For these reasons, it would be interesting to investigate the effect of $L$. plantarum 299v on the intestinal bacterial flora and metabolic activities in these conditions. Furthermore, some studies indicate that also clinical benefits can be expected from $L$. plantarum $299 \mathrm{v}$. In UC patients and CD patients systemically circulating levels of endotoxins have found to be increased and to be correlated positively with the anatomic region and disease activity ${ }^{44}$. L. plantarum $299 \mathrm{v}$ has a strong adhesiveness to the mucosa by mannose-containing glycoproteins, which could result in preventing $E$. coli from adhering to the mucosa and from delivering endotoxins into the body $y^{4,45}$. In animal studies, $L$. plantarum $299 \mathrm{v}$ was found to reduce colitis in methotrexate-induced inflarnmation in rats and interleukin-10-deficient mice also suggesting a potential therapeutic role in $1 B D^{46,47}$. Moreover, in human studies $L$. plantarum $299 \mathrm{~V}$ was proven to decrease symptoms like pain and flatulence in IBS patients ${ }^{48,49}$. However, in general the number of studies including patients is still limited and the studies often suffer from some methodological problems. Studies are needed to explore whether the effects of probiotic treatment in inflammatory disorders of the bowell, causes changes of the intestinal environment that are more evident than those seen in healthy volunteers, before studies on the clinical efficacy of probiotics are performed.

In conclusion, this study shows that the fermented oatmeal drink with $L$. plantarum $299 \mathrm{v}$ increases the number of lactobacilli in the faeces of healthy volunteers but has no influence on other bacterial counts or on metabolic activities. Nevertheless, studies to evaluate the effect of this probiotic drink on the faecal flora of patients, such as those with inflammatory bowel disease, are warranted. The observed effect of $L$. plantarum $299 \mathrm{v}$ on the intestinal flora appears already within 1 week after the start of the consumption of the probiotic drink and disappears completely 1 week after cessation of consumption of the drink. 


\section{References}

1. Gorbach $S L$, Nahas $L$, Lerner PI, Weinstein L. Studies of intestinal microflora. Effects of diet, age, and periodic sampling on numbers of fecal microorganisms in man. Gastroenterology $1967 ; 53: 845-55$.

2. Rafil F, Ruseler-Van Embden JG, Asad YF. Azoreductase and nitroreductase activity of bacteria in feces from patients with an ileal reservoir. Dig Dis Sci 1997; 42:133-6.

3. Havenaar R, Ten Brink B, Huis in 't Veld J. Selection of strains for probiotic use. In: Chapmann and Hall, editor. Probiotics, The scientific basis. London. 1992:209-24.

4. Bengmark $S$. Ecological control of the gastrointestinal tract. The role of probiotic flora. Gut 1998;42:2-7.

5. Mombelli B, Gismondo MR. The use of probiotics in medical practice. Int J Antimicrob Agents 2000;16:531-6.

6. Schrezenmeir $J_{\text {" de }}$ Vrese MM. Probiotics, prebiotics, and symbiotics-approaching a definition. Am J Clin Nutr 2001;73(2 Part 2):361S-4S.

7. Rolfe RD. The role of probiotic cultures in the control of gastrointestinal helalth. J Nutr 2000;130:396S-402S.

8. Ohashi $Y$, Nakai S, Tsukamoto $T$, Masumori $N$, Akaza $H$, Miyanaga $N$ et al. Habitual intake of lactic acid bacteria and risk reduction of bladder cancer. Urol int $2002 ; 68: 273-80$.

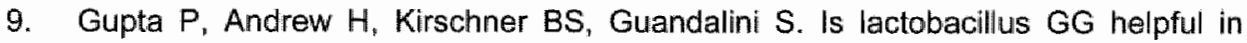
children with Crohn's disease? Results of a preliminary, open-label study. J Pediatr Gastroenterol Nutr 2000;31:453-7.

10. Guslandi M, Mezzi G, Sarghi M, Testoni PA. Saccharamyces boulardil in maintenance treatment of Crohn's disease. Dig Dis Sci 2000;45:1462-4.

11. Rembacken BJ, Snelling AM, Hawkey PM, Chalmers DM, Axon AT. Nonpathogenic Escherichia coli versus mesalazine for the treatment of ulcerative colitis: a randomised trial. Lancet 1999;354:635-9.

12. Venturi $A$, Gionchetti $P$, Rizzello $F$, Johansson $R$, Zucconi $E$, Brigidi $P$ et al. Impact on the composition of the faecal flora by a new probiotic preparation: preliminary data on maintenance treatment of patients with ulcerative colitis. Aliment Pharmacol Ther 1999;13:1103-8.

13. Gionchetti $P$, Rizzello F, Venturi A, Brigidi $P$, Matteuzzi $D$, Bazzocchi $G$ et al. Oral bacteriotherapy as maintenance treatment in patients with chronic pouchitis: a double-blind, placebo-controlled trial. Gastroenterology 2000; 119:305-9.

14. Holzapfel $W H$, Haberer $P$, Snel J, Schillinger $U$, Huis in 't Veld J. Overview of gut flora and probiotics. Int J Food Microbiology $2001 ; 41: 85-101$.

15. Gionchetti $P$, Rizella F, Venturi A, Helwig $U$, Amandini $C$, Romboli $E$ et al. Remission maintenance in ulcerative colitis and Crohn's disease: unpublished data. In: Rogler G, Kullmann F, Rutgeerts P, Sartor RB, Sicholmerich J, editors. IBD at the end of the first century. 2000:265-70.

16. Vanderhoof JA, Young RJ. The role of probiotics in the treatment of intestinal infections and inflammation. Curr Opin Gastroenterol 2001;17:58-62.

17. Shanahan F. Probiotics in inflammatory bowel disease. Gut 2001;48:609. 
18. Tannock GW, Munro K, Harmsen Hd, Welling GW, Smart J, Gopal PK. Analysis of the fecal microflora of human subjects consuming a probiotic product containing Lactobacillus thamnosus DR20. Appl Environ Microbiol 2000;66:2578-88.

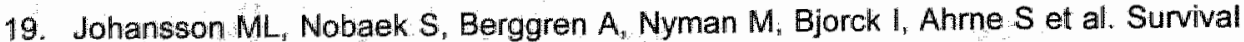
of Lactobacillus plantarum DSM 9843 (299v), and effect on the short-chain fatty acid content of faeces after ingestion of a rose-hip drink with fermented oats. Int $s$ Food Microbiol 1998; $42: 29-38$.

20. Spanhaak $S$, Havenaar $R$, Schaafsma $G$. The effect of consumption of milk fermented by Lactobacillus casei strain Shirota on the intestinal microflora and immune parameters in humans. Eur $\mathrm{J}$ Clin Nutr 1998;52:899-907.

21. Cummings $\mathrm{JH}$. Short chain fatty acids in the human colon. Gut 1981,22:763-79.

22. Goldin BR, Swenson L, Dwyer J, Sexton M, Gorbach SL. Effect of diet and Lactobacillus acidophilus supplements on human fecal bacterial enzymes. J Natl Cancer Inst 1980;64:255-61.

23. Simon GL, Gorbach SL. The human intestinal mïcroflora. Dig Dis Sci 1986:31: $147-62$.

24. Gustafsson A, Berstad A, Lund-Tonnesen $S$, Midtvedt T, Norin E. The effect of faecal enema on five microflora-associated characteristics in patients with antibiotic-associated diarrhoea. Scand J Gastroenteroll 1999;34:580-6.

25. O'Donnell LJ, Virjee J, Heaton KW. Detection of pseudodiarrhoea by simple clinical assessment of intestinal transit rate. BMJ 1990;300:439-40.

26. Hartemink $R$, Domenech VR, Rombouts FM. LAMVAB-a new selective medium for the isolation of lactobacilli from faeces. J Microbiol Methods 1997;29:77-84.

27. Johansson ML, Quednau M, Molin G, Ahrne S. Randomly amplified polymorphic DNA (RAPD) for rapid typing of Lactobacillus plantarum strains. Lett Appl Microbiol 1995;21:155-9.

28. Johansson ML, Quednau M, Ahrne $S$, Molin $G$. Classification of Lactobacillus plantarum by restriction endonuclease analysis of total chromosomal DNA Using conventional agarose gel electrophoresis. Int J Syst Bacteriol 1995;45:670-5.

29. Goldin BR, Gorbach SL. The relationship between diet and rat fecal bacterial

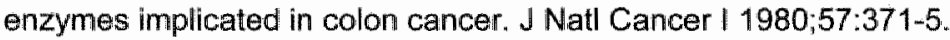

30. Rafii $F$, Ruseler-Van Embden JG, van Lieshout LM. Changes in bacterial enzymes and PCR profiles of fecal bacteria from a patient with ulcerative colitis before and after antimicrobial treatments. Dig Dis Sci 1999;44:637-42.

31. vam den Bogaard $\mathrm{AE}$, Hazen $\mathrm{MJ}$, van Boven $\mathrm{CP}$. Quantitative gas chromatographic analysis of volatile fatty acids in spent culture media and body fluids. J Clin Microbiol 1986;23:523-30.

32. Johansson ML, Molin G, Jeppsson B, Nobaek $S$, Ahrne $S_{n}$ Bengmark $S$. Administration of different Lactobacillus strains in fermented oatmeal soup: in vivo collonization of human intestinal mucosa and effect on the indigenous flora. Appl Environ Microbiol 1993;59:15-20.

33. Link-Amster $H$, Rochat $F$, Saudan $K Y$, Mignot $O$. Aeschlimann JM. Modulation of a specific humoral immune response and changes in intestinal flora mediated through fermented milk intake. FEMS Immunol Med Microbiol 1994;10:55-63. 
34. Hartemink R, Rombouts FM. Comparison of media for the detection of bifidobacteria, lactobacilli and total anaerobes from faecal samples. I Microbiol Methods 1999;36:181-92.

35. Tannock GW. Molecular methods for exploring the intestinal ecosystem. Br $\downarrow$ Nutr 2002;87(S2):S199-S201.

36. Marteau P, Pochart P. Flourie B, Pellier P, Santos L, Desjeux JF el al. Effect of chronic ingestion of a fermented dairy product containing Laclobacillus acidophilus and Bifidobacterium bifidum on metabolic activities of the colonic flora in humans. Am: J Clin Nutr 1990;52:685-8.

37. Rowland 1. Modification of gut flora metabolism by probiotics and oligosaccharides. In: Fuller R, Heidt P, Rusch V, Waaij D, editors. Old Herbom University Seminar: Probiotics: prospects of use in opportunistic infections. 1995:35-46.

38. Leenstra TS, van Saene JJ, van Saene HK, Martin MV. Oral endotoxin in healthy adults. Oral Surg Oral Med Oral Pathol Oral Radiol Endod 1996:82:637-43.

39. Goris $H$, de Boer $F$, van der WD. Oral administration of antibiotics and intestinal flora associated endotoxin in mice. Scand J infect Dis 1986;18:55-63.

40. Roediger WE. Oxidative and synthetic functions of n-Butyrate in colonocytes. Dis Colon Rectum 1992;35:511-2.

41. Cardona ME, Midtvedt T, Norin E. Probiotics in gnotobiatic mice: Short-chaim fatty acids production in vitro and in wivo. Scand J Lab Anim Sci 2002;28:75-84.

42. Ruseler-Van Embden $J_{G}$, Schouten WR, van Lieshout LM. Pouchitis: result of microbilal imbalance? Gut 1994;35:658-64.

43. Roediger WE, Duncan A, Kapaniris O, Millard S. Reducing sulfur compounds of the colon impair colonocyte nutrition: implications for ulcerative colitis. Gastroenterology 1993;104:802-9.

44. Gardiner KR, Halliday MI, Barclay GR, Milne L, Brown D, Stephens $S$ et al. Significance of systemic endotoxaemia in inflammatory bowel disease. Gut 1995; 36:897-901.

45. Adlerberth $I_{\text {, Ahrne }}$, Jahansson ML, Molin G, Hanson LA, Wold AE. A mannosespecific adherence mechanism in Lactobacillus plantarum conferring binding to the human colonic cell line HT-29. Appl Environ Microbiol 1996;62:2244-51.

46. Mao $Y$, Nobaek $S$, Kasravi B, Adawi D, Stenram U, Molin G et al. The effects of Lactobacillus strains and oat fiber on methotrexate- induced enterocolitis in rats. Gastroenterology 1996:111:334-44.

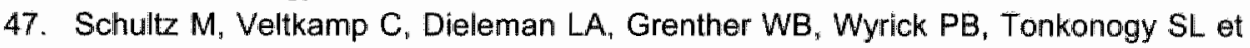
al. Lactobacillus plantarum $299 \mathrm{~V}$ in the treatment and prevention of spontaneous colitis in interleukin-10-deficient mice. Inflamm Bowel Dis 2002;8:71-80.

48. Nobaek S, Johansson ML, Molin G, Ahrne S, Jeppsson B. Alteration of intestinal microflora is associated with reduction in abdominal bloating and pain in patients with irritable bowel syndrome. Am J Gastroenterol 2000;95:1231-8.

49. Niedzielin $K$, Kordecki $H$, Birkenfeld $B$. A controlled, double-blind, randomized study on the efficacy of Lactobacillus plantarum $299 \mathrm{~V}$ in patients with irritable bowel syndrome. Eur J Gastroenterol Hepatol 2001;13:1143-7. 


\section{Chapter 3}

Survival of the probiotic,

L. plantarum 299v and its effects on the faecal bacterial flora, with and without gastric acid inhibition

D. Goossens, D. Jonkers, M. Russel, A. Thijs, A. van den Bogaard,

E. Stobberingh, R. Stockbrügger

Digestive and Liver Disease 2005;37:44-50 


\section{Abstract}

Introduction

Problotic bacteria have to survive passage through the gastrointestinal tract. In this placebom controlled double-blind study, the effect of Lactobacillus plantarum $299 \mathrm{v}$ on the faecal flora wass studied with and without gastric acid inhibition.

\section{Methods}

Thirty two healthy volunteers were given pantoprazole (40 mg/day) or placebo during three weeks from week 2 until week 4 . In addition, from week 3 until week $4, L$ plantarum $299 \mathrm{v}$ in an oatmeall fermented drink (109 CFU/mi) was given twice daily to both groups. From each healthy wolunteer faecal samples were collected at the end of week 1,2, 4 and 8 (4 weeks after cessation off L-plantarum $299 \mathrm{~V}$ and pantoprazole/placebo). Several aerobically and anaerobically growing bacteria were counted and short chain fatty acid concentrations were determined.

\section{Results}

In both the pantoprazole and the placebo group, median lactobacilli counts increased significantly' in week 4 compared to week 1 (from log 4.5 to 8.0 CFU/g faeces in pantoprazole and from log 4.2 to $7.7 \mathrm{CFU} / \mathrm{g}$ faeces in placebo group) and decreased significantly in week B (to $\log 4.5 \mathrm{CFU} / \mathrm{g}$ faeces in pantoprazole and log $4.3 \mathrm{CFU} / \mathrm{g}$ faeces in placebo group). These lactobacilli were identified as $L$ plantarum $299 \mathrm{~V}$. No significant differences were observed in all other bacterial counts and short chain falty acid concentrations.

\section{Conclusions}

The comparable increases of faecal lactabacilli counts in both the pantoprazole and the placebo treated group demonstrate that $L$. plantarum $299 \mathrm{v}$ survives passage through the gastrointestinal tract irrespective of gastric acidity. The increment of the intragastric $\mathrm{pH}$ in combination with L. plantarum $299 \mathrm{v}$ did not modulate bacterial composition and/or the production of short chain fatty acids. 


\section{Introduction}

Probiotics as defined by Havenaar et al. are "mono- or mixed cultures of live micro-organisms which, when applied to animal or man, beneficially affect the host by improving the properties of the indigenous microflora"1. Probiotics such as lactobacilli have been reported to effect positively gastrointestinal disorders such as diarrhoea (rotavirus-associated and antibiotic-associated), inflammatory bowel disease, pouchitis, irritable bowel syndrome, colorectal cancer, lactose absorption, Helicobacter pylori infection, and constipation and are increasingly used as a treatment modality ${ }^{2-9}$.

For therapeutic purposes, probiotics are restricted by certain selection criteria: probiotics have to be of human origin, have to be safe for the host, and genetically stable $e^{8}$. Above all, it is important that probiotics are able to survive passage through the gastrointestinal tract irrespective of gastric acidity, pancreatic enzymes and bile acids so that they may reach the ileum and colon and can colonise the intestinal mucosa ${ }^{10}$. Furthermore, as high as possible numbers of probiotic bacteria reaching the large intestine seem to be warranted, because of the complexity of the intestinal flora and the high bacterial load.

The healthy stomach contains relatively small numbers of bacteria $\left(0-10^{3}\right.$ colony forming units per $\mathrm{ml}$ gastric content) due to the intragastric acidity ${ }^{10.11}$. In healthy volunteers, the median 24-hours intragastric $\mathrm{pH}$ is below 3 in about $80 \%$ of time ${ }^{12}$. Most of the ingested bacteria cannot be metabolically active at $\mathrm{pH}$ values below 4 and $99.9 \%$ of the bacteria are killed at $\mathrm{pH}$ less than 4.0 within 30 minutes ${ }^{13,14}$. The survival of lactobacilli in acid environments has been tested by in vitro studies: after four hours, Lactobacillus GG showed no loss of viability in gastric juice within a $\mathrm{pH}$ range $3.0-7.0$, but there was a rapid loss in viability at $\mathrm{pH} 1.0^{15}$. Lactobacil/us plantarum $299 \mathrm{v}$ was able to survive at least four hours incubation at $\mathrm{pH} 2.5$ in vitro, but no growth or replication could occur $^{14}$.

In healthy volunteers, the median 24-hours intragastric $\mathrm{pH}$ has been found to be $1.7^{12}$. This may affect survival and/or metabolic activity of probiotic bacteria. An increase in the intragastric $\mathrm{pH}_{\text {, for instance by use of gastric acid inhibitors }}$ may theoretically improve the survival of lactobacilli and may increase the metabolic activities of probiotics such as the production of short chain fatty acids.

In this double-blind placebo-controlled study, the effect of $L$. plantarum $299 \mathrm{v}$ on the faecal flora was studied with and without gastric acid inhibition. Special attention was paid to the recovery of $L$. plantarum $299 \mathrm{v}$ in the faeces. 


\section{Methods}

\section{Subjects}

Thity-two healthy volunteers were enrolled in this study. Exclusion criteria were pre-existing bowel-pathology including irritable bowel syndrome, inflammatory bowel disease, diverticulitis, diarrhoea and cancer. Volunteers were not allowed to have used gastric acid inhibitors, laxantia, anti-diarrhoea medication or antibiotics for at least one month before as well as during the study. Furthermore, the consumption of other probiotics or prebiotics for at least two weeks before the start of the study as well as during the study was not allowed. Participants were asked to continue their 'normal' diet. Participants were recruited by local advertisement. The study was approved by the Medical Ethical Committee of the University Hospital Maastricht and was performed in accordance with good clinical practice and the declaration of Helsinki. All participants have given written informed consent.

\section{Study design}

The study was double-blind and placebo-controlled. Total duration of the study was eight weeks: a pre-treatment period (week 1), one week treatment with pantoprazole or placebo (week 2), two weeks treatment with pantoprazole or placebo in combination with the fermented oatmeal drink with $L$. plantarum $299 \mathrm{v}$ (week 3 and 4) and a four weeks post-treatment period (week 5 until 8) (figure 3.1). Volunteers were first treated with pantoprazole $(40 \mathrm{mg} /$ day) $(\mathrm{n}=16)$ or placebo $(n=16)$ to stabilise the intragastric $\mathrm{pH}$ profile. Pantoprazole or placebo (indistinguishable in colour, smell and taste) were taken half an hour before breakfast.

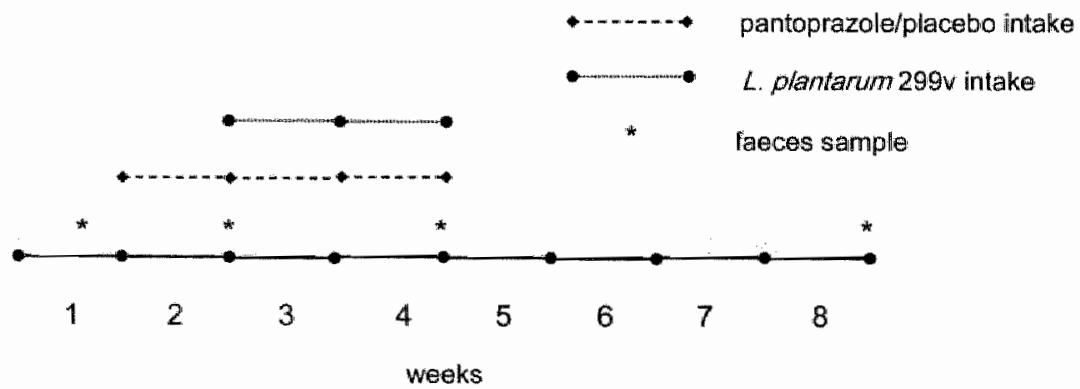

Figure 3.1 Time schedule of the study.

During weeks 3 and 4 , participants daily consumed $200 \mathrm{ml}(100 \mathrm{ml}$ in the morning and $100 \mathrm{ml}$ in the evening) of a fermented oatmeal drink with L. plantarum $299 \mathrm{v}\left(10^{9} \mathrm{CFU} / \mathrm{ml}\right)$. In the morning, the probiotic drink was consumed two hours after pantoprazole or placebo intake to minimize direct antibacterial effect of pantoprazole on the probiotic strain. Four faecal samples 
were collected: at the end of week 1 (before administration), at the end of week 2 (after one week pantoprazole/placebo administration), at the end of week 4 (after three weeks pantoprazole/placebo administration and probiotic consumption) and after week 8 (four weeks after cessation pantoprazole/ placebo administration and probiotic consumption) (figure 3.1). Faecal samples were collected every Thursday ( \pm one day) to avoid major influences of possible changed dietary habits during the weekend. At each faeces collection, a short questionnaire had to be completed on bowel habits (stool frequency and consistency according to the Bristol scale ${ }^{16}$ ), side effects and compliance with regard to the consumption of pantoprazole/placebo and the probiotic drinks. Participants were asked to return their study medication at the end of the study period. Participants were excluded from analyses if less than $80 \%$ of the faecal samples were collected and/or the pantoprazole/ placebo and/or probiotic drinks were consumed less than six days per week based on questionnaires and counting of the study medication.

\section{Microbiological analyses}

Faecal samples ( \pm 20 gram) were collected in sterile containers, kept at room temperature and brought to the laboratory within twelve hours after defaecation and were divided into three parts. Five grams were diluted (1:4) in pepton water with cysteine $(2.1 \mathrm{mM})$ and glycerol $(37 \%)$ and homogenised with an ultraturrax (IKA ${ }^{\circledR}$, Sigma-Aldrich Chemie B.V., Zwijndrecht, The Netherlands) during two minutes. Cultures were performed directly and the remaining part of the material was frozen $\left(-18^{\circ} \mathrm{C}\right)$ for further analyses. Ten grams were centrifuged at $4^{\circ} \mathrm{C}$ for two hours at $25.000 \mathrm{~g}$ to obtain faecal water that was frozen at $-80^{\circ} \mathrm{C}$ for determination of the $\mathrm{pH}$. The remaining material was immediately frozen for additional analyses.

\section{Culture}

Ten-fold serial dilutions of the faecal samples were inoculated with a spiral plater (Eddy Jet v1.2, IUL-instruments, Barcelona, Spain) on selective agar plates for total aerobic bacteria, enterobacteriaceae, enterococci, total (facultative) anaerobic bacteria, Bacteroides spp. Clostridia spp., lactic acid bacteria and lactobacilli according to the method previously described ${ }^{17}$.

$\mathrm{pH}$

The $\mathrm{pH}$ was measured in faecal water using a PHM201 portable $\mathrm{pH}$ meter (Radiometer Nederland BV).

\section{Short chain fatty acids}

Short chain fatty acid concentrations (acetic, propionic, isobutyric, butyric, isovaleric, valeric, isocaproic, caproic acid) were measured in the faeces with gas-liquid chromatography (GLC) as described elsewhere ${ }^{17,18}$. SCFA were analysed in the faecal samples collected in week 1 and week 4 (before and 
after probiotic consumption). Concentrations were expressed in $\mathrm{mmol} / \mathrm{g}$ faeces after correction for dilution.

\section{Statistical analyses}

Statistical evaluation of changes within groups during the study period and between groups was carried out using the linear mixed model analysis with SPSS version 11.0. A p-value below 0.05 was considered to be statistically significant.

\section{Results}

Twenty-nine participants completed the study ( 9 males, mean age 34 years \pm 13 and 20 females, mean age 26 years \pm 9 ). Three participants were excluded: one person did not start to take the pantoprazole/ placebo for personal reasons, another person used antibiotics (flucloxacillin) during the second week of the study and the third person used antibiotics (metronidazole) in week five of the study. No side effects were reported after the treatment with pantoprazole and $L$. plantarum $299 \mathrm{v}$ and no significant differences in defaecation frequency and consistency of faeces were seen between or within the groups (table 3.1 ).

The compliance to pantoprazole was $99.0 \%$, to the placebo $100 \%$ and to the probiotics drinks $100 \%$ and $99.5 \%$ in the pantoprazole and placebo group, respectively.

Table 3.1 Defaecation frequency (per day), consistency of faeces (median \pm SEM) according to the Bristol scale in week 1 (before administration), week 2 (after one week pantoprazole/placebo administration), week 4 (after three weeks pantoprazole/placebo administration and two weeks probiotic consumption) and in the end of week 8 (four weeks after cessation pantoprazoie/placebo administration and probiotic consumption) in the pantoprazole and placebo group.

\begin{tabular}{lcccc}
\hline & Week 1 & Week 2 & Week 4 & Week 8 \\
\hline $\begin{array}{l}\text { Consistency" } \\
\text { Pantoprazole }\end{array}$ & $4.0 \pm 0.3$ & $4.0 \pm 0.3$ & $3.5 \pm 0.3$ & $3.0 \pm 0.3$ \\
Placebo & $3.0 \pm 0.3$ & $3.0 \pm 0.2$ & $4.0 \pm 0.3$ & $3.0 \pm 0.2$ \\
& & & & \\
Frequency & & & & \\
$\quad$ Pantopiazole & $1.0 \pm 0.2$ & $1.0 \pm 0.3$ & $1.0 \pm 0.2$ & $1.0 \pm 0.2$ \\
Placebo & $1.0 \pm 0.3$ & $1.0 \pm 0.2$ & $1.0 \pm 0.2$ & $1.0 \pm 0.2$ \\
\hline "Consistency scale from 1 (hard lumps) until 7 (watery). & &
\end{tabular}




\section{Culture}

The intake of pantoprazole did not influence the number of total aerobic bacteria, Enterococcus spp., enterobacteriaceae, total anaerobic bacteria, Bacteroides spp., Clostridia spp. and lactic acid bacteria or lactobacilli compared to the placebo group (table 3.2).

Table 3.2 Numbers of bacterial strains (log CFU/g faeces), median \pm SEM in week 1 (before administration), week 2 (after one week pantoprazole/placebo administration), week 4 (after three weeks pantoprazollelplacebo administration and two weeks probiotic consumption) and in the end of week $B$ (four weeks after cressation pantoprazole/placebo administration and probiotic consumption) in the pantoprazole and placebo group.

\begin{tabular}{|c|c|c|c|c|}
\hline & Week 1 & Week 2 & Woek 4 & Week 8 \\
\hline \multicolumn{5}{|c|}{ Total aerobic flora } \\
\hline Pantoprazole & $7.13 \pm 0.27$ & $7.75 \pm 0.20$ & $7.95 \pm 0.19^{\mathrm{a}}$ & $7.34 \pm 0.23$ \\
\hline Placebo & $7.36 \pm 0.20$ & $7.26 \pm 0.15$ & $7.82 \pm 0.13^{\mathrm{a}}$ & $7.49 \pm 0.20$ \\
\hline \multicolumn{5}{|l|}{ E.coll } \\
\hline Pantoprazole & $6.60 \pm 0.28$ & $6.94 \pm 0.32$ & $6.49 \pm 0.49$ & $5.94 \pm 0.76$ \\
\hline Placebo & $7.05 \pm 0.27$ & $6.78 \pm 0.23$ & $6.59 \pm 0.20$ & $6.68 \pm 0.33$ \\
\hline \multicolumn{5}{|l|}{ Enterococci } \\
\hline Pantoprazale & $4.91 \pm 0.43$ & $4.66 \pm 0.43$ & $4.89 \pm 0.49$ & $5.01 \pm 0.48$ \\
\hline Placebo & $4.12 \pm 0.55$ & $4.59 \pm 0.31$ & $3.45 \pm 0.54$ & $3.67 \pm 0.61$ \\
\hline \multicolumn{5}{|c|}{ Total anaerobic flora } \\
\hline Pantoprazole & $9.63 \pm 0.14$ & $10.02 \pm 0.08$ & $9.90 \pm 0.08$ & $9.92 \pm 0.12$ \\
\hline Placebo & $9.63 \pm 0.18$ & $9.85 \pm 0.11$ & $9.93 \pm 0.09$ & $9.99 \pm 0.07$ \\
\hline \multicolumn{5}{|l|}{ Bacteroides spp. } \\
\hline Pantoprazale & $7.59 \pm 0.55$ & $8.15 \pm 0.18$ & $8.00 \pm 0.17$ & $8.35 \pm 0.11$ \\
\hline Placebo & $7.57 \pm 0.28$ & $7.21 \pm 0.57$ & $8.11 \pm 0.12$ & $8.16 \pm 0.14$ \\
\hline \multicolumn{5}{|l|}{ Clostridia spp. } \\
\hline Pantoprazole & $5.04 \pm 0.18$ & $4.83 \pm 0.47$ & $4.85 \pm 0.28$ & $4.67 \pm 0.23$ \\
\hline Placebo & $4.96 \pm 0.25$ & $4.41 \pm 0.19$ & $3.54 \pm 0.58$ & $4.45 \pm 0.20$ \\
\hline \multicolumn{5}{|c|}{ Lactic acid bacteria } \\
\hline Pantoprazale & $6.46 \pm 0.49$ & $5.58 \pm 0.26^{18}$ & $8.02 \pm 0.16^{6}$ & $4.57 \pm 0.25^{\mathrm{b}}$ \\
\hline Placebo & $6.30 \pm 0.53$ & $4.34 \pm 0.52^{13}$ & $7.63 \pm 0.19^{18}$ & $4.03 \pm 0.52^{b}$ \\
\hline \multicolumn{5}{|l|}{ Lactobacilli } \\
\hline Pantoprazole & $4.50 \pm 0.21$ & $5.50 \pm 0.36$ & $8.02 \pm 0.17^{\oplus}$ & $4.50 \pm 0.28^{\circ}$ \\
\hline Placebo & $4.23 \pm 0.48$ & $4.17 \pm 0.53$ & $7.74 \pm 0.18^{m}$ & $4.30 \pm 0.53^{\circ}$ \\
\hline
\end{tabular}

\footnotetext{
a statistically significant difference $(p<0.05)$ compared to before L. plantarum $299 \mathrm{w}$ intake (week 1 , $2) ;$ " statistically significant difference $(p<0.05$ ) comprared to before treatment (week 1); statistically significant difference $(p<0.05$ ) compared to during $L$. plantarum $299 \mathrm{v}$ intake (weok 4)
} 
In week 4 (after two weeks consumption of the probiotic drink in addition to the pantoprazole/placebo intake) the number of lactic acid bacteria and lactobacilli increased significantly compared to the figures before probiotic intake (week 1) in both the pantoprazole and placebo group. No significant difference could be seen between the pantoprazole and placebo group in week 4 . In week 8 , the number of lactic acid bacteria and lactobacilli decreased significantly and the number of lactobacill reached pre-treatment levels (figure 3.2). A significant decrease in the number of lactic acid bacteria was observed in week 2 and 8 compared to week 1 in both the pantoprazole and placebo group. In week 4 a significant increase in the number of total aerobic bacteria was found (table 3.2).

圈 pantoprazole

圈 placebo

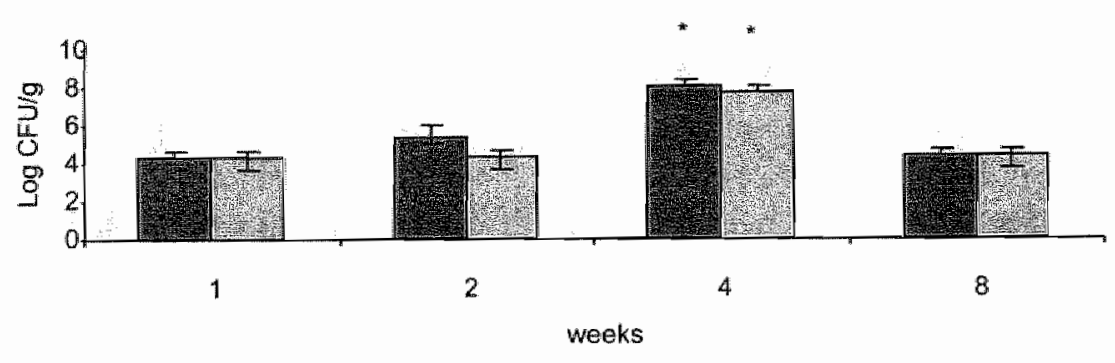

Figure 3.2 Numbers of lactobacilli (log CFU/g faeces) (median \pm SEM) at week 1 (before administration), 2 (after one week pantoprazole/placebo administration), 4 (after three weeks pantoprazole/placebo administration and probiotic consumption), and 8 (four weaks after cessation pantoprazole/placebo administration and probiatic consumption) * $p<0.05$ in the pantoprazole and placebo group during probiotic consumption compared to before and after the consumption.

\section{Recovery of L. plantarum 299v}

Before probiotic intake, L. plantarum $299 \mathrm{v}$ was identified in one faecal sample in week 1 and in two faecal samples in week 2 of three different individuals. In contrast, $L$. plantarum $299 \mathrm{v}$ was identified in all faecal samples during probiotic consumption (week 4). Four weeks after ending probiotic consumption (week 8), no $L$. plantarum $299 \mathrm{v}$ could be recovered except for one person in whom of the three isolated lactobacilli, one was identified as L. plantarum $299 \mathrm{v}$.

\section{$\mathrm{pH}$ of faecal water}

The $\mathrm{pH}$ of faecal water did not change significantly between the pantoprazole and placebo group in week 1 (6.3 and 6.7), in week 2 (6.4 and 6.7), in week 4 (6.3 and 6.5) and in week 8 (6.5 and 6.6) or within both groups. 


\section{Short chain fatty acids}

No significant differences in acetic, propionic, isobutyric, butyric, isovaleric, valeric, isocaproic and caproic acids could be demonstrated in the faecal samples collected in week 1 and week 4 between and within pantoprazole and placebo group (table 3.3).

Table 3.3 Short chain fatty acids concentration (mean \pm SEM), expressed in $\mathrm{mmol} / \mathrm{g}$ faeces, measured in week 1 (before administration) and week 4 (after three weeks pantoprazole/placebo administration and probiotic consumption).

\begin{tabular}{|c|c|c|}
\hline & Week 1 & Week 4 \\
\hline \multicolumn{3}{|l|}{ Acetic acid } \\
\hline Pantoprazole & $67.2 \pm 11.5$ & $74.5 \pm 10.0$ \\
\hline Placebo & $90.4 \pm 19.0$ & $101.7 \pm 22.1$ \\
\hline \multicolumn{3}{|l|}{ Propionic acid } \\
\hline Pantoprazole & $19.5 \pm 3.7$ & $19.8 \pm 4.1$ \\
\hline Placebo & $23.2 \pm 3.0$ & $24.2 \pm 4.8$ \\
\hline \multicolumn{3}{|l|}{ Isobutyric acid } \\
\hline Pantoprazole & $2.5 \pm 0.2$ & $3.0 \pm 0.8$ \\
\hline Placebo & $3.4 \pm 0.7$ & $3.0 \pm 1.3$ \\
\hline \multicolumn{3}{|l|}{ Butyric acid } \\
\hline Pantoprazole & $18.6 \pm 5.1$ & $18.4 \pm 3.3$ \\
\hline Placebo & $21.0 \pm 3.8$ & $23.1 \pm 7.1$ \\
\hline \multicolumn{3}{|l|}{ Isovaleric acid } \\
\hline Pantoprazolie & $3.2 \pm 0.4$ & $3.0 \pm 0.9$ \\
\hline Placebo & $3.7 \pm 0.6$ & $3.4 \pm 1.7$ \\
\hline \multicolumn{3}{|l|}{ Valeric acid } \\
\hline Pantoprazole & $3.8 \pm 0.9$ & $3.6 \pm 0.8$ \\
\hline Placebo & $4.0 \pm 0.7$ & $3.4 \pm 1.0$ \\
\hline \multicolumn{3}{|l|}{ Isocaproic acid } \\
\hline Pantoprazole & $1.3 \pm 0.9$ & $0.7 \pm 0.6$ \\
\hline Placebo & $0.8 \pm 0.3$ & $0.6 \pm 0.4$ \\
\hline \multicolumn{3}{|l|}{ Caproic acid } \\
\hline Pantoprazole & $3.7 \pm 1.5$ & $2.3 \pm 0.9$ \\
\hline Placebo & $2.9 \pm 0.7$ & $2.0 \pm 0.9$ \\
\hline
\end{tabular}

\section{Discussion}

Probiotics may be of interest as adjuvant therapy in diseases like irritable bowel syndrome, diarrhoea, inflammatory bowel diseases and lactose intolerance. The aim of the present study was to investigate the effect of gastric acid inhibition on the survival of $L$. plantarum $299 \mathrm{v}$ in faecal samples. Moreover, the influence of gastric acid inhibition in combination with the consumption of 
L. plantarum $299 \mathrm{v}$ on the composition of the faecal flora and metabolic activity (i.e. SCFA) was studied.

Twice daily intake of the probiotic L. plantarum $299 \mathrm{v}$ for two weeks significantly increased the number of faecal lactobacilli from $\log 4.4$ to $\log 7.9 \mathrm{CFU} / \mathrm{g}$ faeces. The comparable increase of lactobacilli in the pantoprazole and placebo treated group indicates that $L$. plantarum $299 \mathrm{v}$ survives passage through the gastrointestinal tract very well, irrespective of gastric acidity. The increment of lactobacilli and lactic acid bacteria disappeared within four weeks after cessation of the consumption of $L$. plantarum $299 \mathrm{v}$ demonstrating that prolonged colonisation does not occur. The recovery of log 8 lactobacilli per gram faeces after probiotic consumption is, considering a consumption of $10^{11}$ lactobacilli per day and a faecal volume of $100 \mathrm{~g}$ per day, relatively high. Other studies with healthy volunteers also found high concentrations of lactobacilli after $L$, plantarum $299 \mathrm{v}$ consumption: $\log 8.2 \mathrm{CFU} / \mathrm{g}$ faeces and $\log 9.0 \mathrm{CFU} / \mathrm{g}$ faeces, respectively ${ }^{17.19}$. The recovery data found in this study were similar to the results found in a placebo-controlled study performed with 21 healthy volunteers consuming $L$. plantarum $299 \mathrm{v}$ for four weeks ${ }^{17}$. L. plantarum $299 \mathrm{v}$ could be isolated using molecular techniques in the faecal samples collected during consumption of the probiotic drinks but could not be identified in most persons after cessation of the probiotic drinks. The high recovery of $L$. plantarum $299 \mathrm{v}$ during probiotic consumption in both the pantoprazole and placebo group indicates that $L$. plantarum 299v survives passage through the gastrointestinal tract.

The aerobic and anaerobic bacterial counts before probiotic intake were comparable to former studies performed with healthy volunteers ${ }^{17,19}$. The significant decrease in number of lactic acid bacteria in week 2 and 8 compared to the numbers before treatment could not be explained.

The consumption of the fermented oatmeal drink with $L$. plantarum $299 \mathrm{v}$ had no influence on the other aerobic and anaerobic bacteria measured, with the exception of the total aerobic bacteria which numbers increased in both pantoprazole and placebo group during probiotic consumption. Such an increase after probiotic consumption was not demonstrated in the former study with healthy volunteers ${ }^{17}$ nor in a study performed by Johansson et al., where 26 healthy volunteers consumed L. plantarum $299 \mathrm{v}\left(5 \times 10^{7} \mathrm{CFU} / \mathrm{ml}\right)$ during 21 days ${ }^{19}$. Previous observations from our group found an increase of aerobic Gram-positive cocci after long-term (at least 12 months) treatment with proton pump inhibitors. In line with these findings, pantoprazole treatment may result in a significant increase found in the pantoprazole group but the increase in the placebo group cannot be explained ${ }^{20}$. In addition, during this short-term treatment, pantoprazole did not change the composition of the faecal flora.

The consumption of $L$. plantarum could increase the concentration of short chain fatty acids like acetic and propionic acid ${ }^{19}$. However, during passage through the gastrointestinal tract the gastric acidity may lower the metabolic activity (i.e. production of SCFA) of L. plantarum 299v. SCFA concentrations 
were measured in faecal samples but no increase in SCFA production could be demonstrated in the group with gastric acid inhibition compared to the placebo group during probiotic consumption. An increase in SCFA concentrations could probably not be seen because SCFA are excreted in the faeces for only $5 \%$, suggesting that an increase in the SCFA production may result in an increase in SCFA absorbed in the colon without an increase in faecal concentrations of $\mathrm{SCFA}^{21}$. Moreover, SCFA production could lower the colonic $\mathrm{pH}$. However, no decrease of $\mathrm{pH}$ in faecal water was demonstrated in this study. SCFA concentrations were comparable to concentrations found in a previous study ${ }^{17}$. Measuring bacterial enzyme activities or for instance the production of bacteriocins could give further insight in the influence of gastric acidity on the metabolic activity of L. plantarum $299 \mathrm{v}$.

Although the short-term use of pantoprazole did not seem to improve the survival or to increase the metabolic activity (i.e. production of SCFA) of L. plantarum $299 \mathrm{v}$, gastric acid inhibition may be of benefit in influencing survival and metabolic activities of other bacteria used as probiotic. In a study performed by Jacobsen et al. 15 of the 44 lactobacilli strains tested did not survive a $\mathrm{pH}$ of 2.5 during four hours in vitro, whereas L. plantarum $299 \mathrm{v}$ showed a good survival under these circumstances ${ }^{22}$. These lactobacilli, that cannot survive a $\mathrm{pH}$ below 2.5, may benefit from adding gastric acid inhibitors to the probiotics to increase survival through the gastrointestinal tract. Moreover, secretions of mucus, lysozyme, bile salts and pancreatic juice in the duodenum can also influence the viability of lactobacilli ${ }^{23,24}$. L. plantarum $299 \mathrm{v}$ has a relatively high resistance to bile salts ${ }^{14}$. However, Drouault et al. have shown that testing duodenal survival is important for selection of (future) probiotic strains ${ }^{25}$.

In this study, the intragastric $\mathrm{pH}$ has not been measured. However, it has been demonstrated in several studies with healthy volunteers that an once-daily dose of $40 \mathrm{mg}$ pantoprazole increased the intragastric $\mathrm{pH}$ to a median 24-hours $\mathrm{pH}$ above $3.0^{26-28}$. Pantoprazole was taken half an hour before breakfast because this dosing regimen results in high steady state gastric acid inhibition over the total 24 -hours period ${ }^{29}$. The probiotic drinks were consumed at least two hours after pantoprazole or placebo administration to avoid a direct contact between L. plantarum $299 \mathrm{v}$ and pantoprazole/placebo as proton pump inhibitors could have an antibacterial effect. Omeprazole showed a decrease in the number of active growing Gram-positive bacteria in vitro ${ }^{30}$, pantoprazole also has an antibacteriall effect in vitro ${ }^{31}$. Recently, probiotics are sometimes added to Helicobacter pylori eradication therapy (i.e. proton pump inhibitors) to decrease side effects. The direct effect of proton pump inhibitors on lactobacilli is not known. As faecal lactobacilli were not significantly decreased after pantoprazole compared to placebo intake, intake of pantoprazole did not seem to have an antibacterial effect on lactobacilli in the fermented oatmeal drink if an interval of at least two hours was taken into account. This lack of interaction 
is important in an era where both proton pump inhibitors and probiotics are frequently used.

In conclusion, this double-blind placebo-controlled study supports the capacity of $L$. plantarum $299 \mathrm{v}$ to survive passage through the gastrointestinal tract in healthy volunteers irrespective of gastric acidity. Because of the documented survival of $L$ plantarum $299 \mathrm{v}$ in vivo, $L$. plantarum $299 \mathrm{v}$ is a good candidate to study the effect on the faecal flora and metabolic activities in clinical trials. 


\section{References}

1. Havenaar R, Ten Brink B. Huis in "t Veld J. Selection of strains for probiotic use. lin: Chapmann and Hall, ed. Probiotics, The scientific basis. London, 1992:209-4.

2. Cremonini $F$, Di Caro $S$, Nista $E C$, et al. Meta-analysis: the effect of probiotic administration on antibiotic-associated diarrhoea. Aliment Pharmacol Ther 2002; 16:1461-7

3. Kruis W, Schutz E, Fric P. Fixa B, Judmaier G, Stolte M. Double-blind comparison of an oral Escherichia coli preparation and mesalazine in maintaining remission of ulcerative colitis. Aliment Pharmacol Ther 1997;11:853-8.

4. Gionchetti $P$, Rizzello $F$, Venturi $A$, et al. Oral bacteriotherapy as maintenance treatment in patients with chronic pouchitis: a double-blind, placebo-controlled trial. Gastroenterology 2000;119:305-9.

5. Nobaek S, Johansson ML, Molin G, Ahrme S, Jeppsson B. Alteration of intestinal microflora is associated with reduction in abdominal bloating and pain in patients with irritable bowel syndrome. Am J Gastroenteroll 2000;95:1231-8.

6. Saltzman $U R$, Russell $R M$, Golner $B$, Barakat $S$, Dallal $G E$, Goldin BR. A randomized trial of Lactobacillus acidophilus $\mathrm{BG} 2 \mathrm{FO} 4$ to treat lactose intolerance. Am J Clin Nutr 1999;69:140-6.

7. Felley C, Corthesy-Theulasz, I, Blanco Rivero, J. Favourable effect of an acidified milk (LC-1) on Helicobacter pylori gastritis in man. Eur J Gastroenterol Hepatol 2001;13:25-9.

8. Ouwehand $\mathrm{AC}$, Salminen $\mathrm{S}$, Isolauri $\mathrm{E}$. Probiotics: an overview of beneficial effects. Antonie van Leeuwenhoek 2002;82:279-89.

9. Goldin BR, Swenson L, Dwyer J, Sexton M, Gorbach SL. Effect of diet and Lactobacillus acidophilus supplements on human fecal bacterial enzymes. J Natl Cancer Inst 1980;64:255-61.

10. Holzapfel $W H_{*}$, Haberer $P$, Snel $J$, Schillinger $U$, Huis in 't Veld $J$. Overview of gut flora and probiotics. Int J Food Microbiology 2001;41:85-101.

11. Simon GL, Gorbach SL. Intestinal flora in health and disease. Gastroenterology $1984 ; 86: 174-93$.

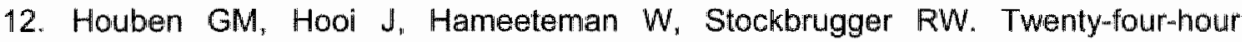
intragastric acidity: $300 \mathrm{mg}$ ranitidine b.d., $20 \mathrm{mg}$ omeprazole $0 . \mathrm{m}$., $40 \mathrm{mg}$ ameprazole o.m. vs. placebo. Aliment Pharmacol Ther 1995;9:649-54.

13. Giannella RA, Broitman $S A$, Zamcheck $N$. Gastric acid barrier to ingested microorganisms in man: studies in vivo and in vitro. Gut 1972;13:251-6.

14. Jacobsen $C N$, Rosenfeldt-Nielsen $V$, Hayford $A E$, et al. Screening of probiotic activities of forty-seven strains of Lactobacillus spp. by in vitro techniques and evaluation of the colonization ability of five selected strains in humans. Appl Environ Microbiol 1999:65:4949-56.

15. Goldin BR, Gorbach $S L$, Saxellin M, Barakat S, Gualtieri L, Salminen S. Survival of Lactobacillus species (strain GG) in human gastrointestinal tract. Dig Dis Sci $1992 ; 37: 121-8$

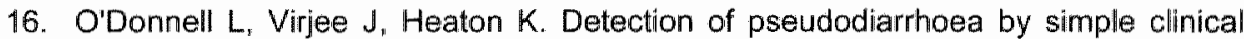
assessment of intestimal transit rate. British Medical Journal 1990;300:439-40.

17. Goossens $D$, Jonkers $D$, Russel $M_{*}$ Stobberingh $E_{\text {, Van }}$ Den Bogaard $A_{\text {, }}$ Stockbrugger R. The effect of Lactobacillus plantarum $299 \mathrm{~V}$ on the bacterial composition and metabolic activity in faeces of healthy volunteers: a placebocontrolled study on the onset and duration of effects. Alliment Pharmacol Ther 2003;18:495-505. 
18. van den Bogaard $A E$, Hazen MJ, van Boven CP. Quantitative gas chromatographic analysis of volatile fatty acids in spent culture media and body fluids. I Clin Microbiol 1986;23:523-30.

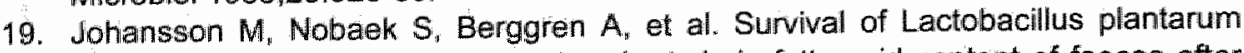
DSM 9843 (299v), and effect on the short-chain fatty acid content of faeces after ingestion of a rose-hip drink with fermented oats. Int J Food Microbiol 1998;42: $29-38$.

20. Jonkers DM, Stobberingh EE, Houben GMP, Stockbrugger RW. The influence of long-term treatment with omeprazole on changes in faecal aerobic flora. Gastroenterology 1994:106:A101.

21. Berggren AM, Bjork IME, Nyman EMGL. Short-chain fatty acids content and $\mathrm{pH}$ in caecum of rats given various sources of carbohydrates. J Sci Food Agric $1993 ; 63: 397-406$.

22. Tutuian $R$, Katz $P O$, Bochenek $W$, Castell $D O$. Dose-dependent control of intragastric $\mathrm{pH}$ by pantoprazole, 10,20 or $40 \mathrm{mg}$, in healthy volunteers. Aliment Phamacol Ther 2002;16:829-36.

23. Harwig SS, Tan $L$, Qu $X D$, Cho $Y$, Eisenhauer $P B$, Lehrer RI. Bactericidal properties of murine intestinal phospholipase A2. J Clin Invest 1995;95:603-10.

24. Peeters $T$, Vantrappen $G$. The Paneth cell: a source of intestinal lysozyme. Gut $1975 ; 16: 553-8$

25. Drouault $S$, Corthier $G$, Ehrlich SD, Renault $P$. Survival, physiology, and lysis of Lactococcus lactis in the digestive tract. Appl Environ Microbiol 1999;65:4881-6.

26. Koop $H$, Kuly $S$, Flug $M$, et al. Intragastric $p H$ and serum gastrin during administration of different doses of pantoprazole in healthy subjects. Eur $\mathrm{J}$ Gastroenterol Hepatol 1996;8:915-8.

27. Hannan A, Weil $J$, Broom $C$, Walt RP. Effects of oral pantoprazole on 24-hour intragastric acidity and plasma gastrin profiles. Aliment Pharmacol Ther 1992;6:373-80.

28. Hartmann $M$, Theiss $U$, Huber $R$, et al. Twenty-four-hour intragastric pH profiles and pharmacokinetics following single and repeated oral administration of the proton pump inhibitor pantoprazole in comparison to omeprazole. Aliment Pharmacol Ther 1996;10:359-66.

29. Mussig S, Witzel L, Luhmann R, Schneider A. Morning and evening administration of pantoprazole: a study to compare the effect on 24-hour intragastric $\mathrm{pH}$. Eur $\mathrm{J}$ Gastroenterol Hepatol 1997;9:599-602.

30. Jonkers D, Stobberingh E, Stcckbrugger R. Omeprazole inhibits growth of grampositive and gram-negative bacteria including Helicobacter pylori in vitro. J Aritimicrob Chemother 1996;37:145-50.

31. Cheer SM, Prakash A, Faulds D, Lamb HM. Pantoprazole: an updatte of its pharmacological properties and therapeutic use in the management of acid-related disorders. Drugs 2003;63:101-33. 


\section{Chapter 4}

Can L. plantarum 299v change the faecal flora after bowel cleansing for colonoscopy?

D. Goossens, D. Jonkers, M. Russel, E. Vaughan, E. Stobberingh, R. Stockbrügger 


\section{Abstract}

Introduction

The intestinal fora may be washed out after bowel cleansing and may be beneficially influenced by probiotics during recolonisation, In this ranidomised placebo-controlled double-blind study, the effect of bowel cleansing with or without subsequent inoculation by $L$. plantarum $299 \mathrm{v}$ was assessed:

\section{Methods}

Patlents, who underwert bowel cleansing, were included. After colonoscopy, patients consumed a drink with or without L plantarum $299 \mathrm{v}$ ( $10^{111}$ CFU/day). Faecal samples were collected: before bowel cleansing (woek 0 ), the first sample after colonoscopy (week 1), after two and faur weeks $6 f$ consumption (week 2 and week 4), and four weeks after cessation of the drinks (week 8). Total colony forming units (CFU) per gram faeces of bacteria were counted. Denaturating gradient 96 electrophoresis (DGGE) was used to analyse the dominant flora, expressed as 'similarity values'.

Results

Twenty-two patients completed the study (12 probiotic, 10 placebo). The mean concentration of lactobacilli increased $(p<0.05)$ from $4.7 \pm 1.9$ at week 0 to $6.5 \pm 0.8$ at week 2 in the probiotic groulp and returned back to 4.641 .4 at week $8(p<0.05)$. DGGE profiles demonstrated high similarify values within subjects over time: mean value $86.5 \% \pm 2.6$. No significant differences in similarity values were seen after bowel cleansing (week 2) or between probiotic and placebo group.

\section{Conclusions}

Although faecal lactobacilli counts increased during probiotic consumption, no further changes in culture and DGGE results were observed. Therefore, the faecal flora can be considered as relatively stable over time: bowel cleansing or probiotic consumption had no major influence on the composition of the faecal flora. 


\section{Introduction}

The human gastrointestinal tract comprises a complex ecosystem with a myriad of bacteria that probably have substantial impact on the physiology and health of the host. The highest numbers of bacteria are found in the colon containing about $10^{11}$, mainly anaerobic $(99.9 \%)$, bacteria per gram intestinal content. The predominant isolates found in the colon are Bacteroides spp., bifidobacteria, Clostridium spp. and eubacteria ${ }^{1-4}$. The intestinal flora contains enzymes, and produces vitamins and short chain fatty acids from nonabsorbed carbohydrates and plays a role in the defence against pathogens by influencing the barrier function of the gut, the immune system and the colonisation resistance of the intestinal tract ${ }^{2,5-7}$. The intestinal flora is suspected to play a role in the pathogenesis of gastrointestinal diseases such as ulcerative colitis, Crohn's disease and irritable bowel syndrome $e^{8-10}$.

Each individual is thought to develop an unique, stable and complex intestinal flora (i.e. 'bacterial fingerprint') ${ }^{11}$ after birth by ingestion of environmental microbes colonising the previously sterile colon ${ }^{12}$. After two years of age, the intestinal flora has stabilised and adapted to an 'adult-like' composition influenced by genotype and environmental factors ${ }^{12}$. High similarity values between the bacterial fingerprints of monozygotic twins have been found compared to the similarity values found in marital partners or genetically unrelated individuals. This demonstrates the important role of genetic factors influencing the composition of the intestinal flora ${ }^{13}$. Furthermore, environmental factors like diet and antibiotic use have been shown to influence the intestinal flor ${ }^{13-16}$. Adequate knowledge of factors influencing the composition of the intestinal flora may give further insight into the development and pathogenesis of gastrointestinal diseases and may provide opportunities to modulate the flora with the aim of therapeutic intervention.

Bowel cleansing, required as preparation for colonoscopic examinations, could be a factor influencing the future composition of the intestinal flora by elimination of the mass of luminal bacteria from the gastrointestinal tract. Bowel cleansing has been found to decrease disease activity and to induce clinical improvement in patients with Crohn's disease ${ }^{17-19}$. Van den Bogaard et al. demonstrated a reduction in aerobic as well as in anaerobic faecal bacteria after bowel cleansing and found an overgrowth of an Escheria coli strain after contamination of this bacterial strain indicating that the intestinal flora has a decreased resistance against the colonisation of bacteria and has to recolonise after bowel cleansing ${ }^{20}$.

Probiotics, defined as "mono- or mixed cultures of live micro-organisms which, when applied to animal or man, beneficially affect the host by improving the properties of the indigenous flora" may have a beneficial effect in this recolonisation phase ${ }^{21}$. Nowadays, Lactobacillus spp. and Bifidobacterium spp. are frequently used as probiotics ${ }^{3}$. One of the selection criteria for probiotics is the ability to colonise and adhere to the mucosa ${ }^{3}$. As Lactobacillus plantarum 
$299 \mathrm{v}$ can adhere to human mucosa cells in vitro, competing with the colonisation of $E$. coli, and is able to survive passage through the gastrointestinal tract, this bacterium may be a suitable candidate to influence the recolonisation of the intestinal flora after bowel cleansing ${ }^{22-24}$.

Changes in the composition of the intestinal flora can be studied by culture techniques. Due to insufficiently selective media, it is estimated that over $50 \%$ of the bacteria in the gastrointestinal tract have not yet been cultured and/or are not yet identified ${ }^{11,25,26}$. For these reasons the intestinal flora should preferably be studied with molecular techniques ${ }^{27}$. Polymerase chain reaction (PCR) in combination with denaturating gradient gel electrophoresis (DGGE) is a useful technique to study changes in the dominant individual faecal flora over time by producing bacterial fingerprints ${ }^{28,29}$.

In this study the effect of bowel cleansing on the intestinal bacterial composition with and without subsequent treatment by the probiotic L. plantarum $299 \mathrm{v}$ was investigated using both culture techniques and PCR/DGGE analyses.

\section{Materials and methods}

\section{Subjects}

Twenty-three consecutive patients undergoing a bowel cleansing procedure prior to colonoscopy were enrolled in the study. Patients were not allowed to consume probiotics, prebiotics or antibiotics during the two weeks before as well as during the study. The use of medication was registered and, if clinically possible, dose and type of the medication were kept stable during the study period. Participants were asked to continue their normal dietary habits. The study was approved by the Medical Ethical Committee of the University Hospital Maastricht and was performed in accordance with the declaration of Helsinki. All participants have given written informed consent.

\section{Study design}

The study was double-blind and placebo-controlled. The patients were randomised to consume probiotic or placebo drinks. Total duration of the study was nine weeks: one week before bowel cleansing and colonoscopy (week 0 ), four weeks probiotic or placebo consumption after colonoscopy (week 1 until 4) and four weeks after cessation of the probiotic or placebo consumption (week 5 untill 8).

Patients started with the consumption of the probiotic and placebo drinks in the evening after the colonoscopy. During week 1 until 4 , patients consumed daily $200 \mathrm{ml}(100 \mathrm{ml}$ in the morning and $100 \mathrm{ml}$ in the evening) of a fermented oatmeal drink with L. plantarum $299 \mathrm{v}\left(10^{9} \mathrm{CFU} / \mathrm{ml}\right)$ (probiotic) or without 
L. plantarum 299v (placebo). Probiotic and placebo drinks were indistinguishable in smell, taste and colour.

Twenty-four hours prior to the colonoscopy, the patients took the macrogol/electrolytes laxative Kleanprep ${ }^{10}$ to clean the gastrointestinal lumen. After colonoscopy, the endoscopist completed a questionnaire about the effectiveness of the bowel cleansing in colon ascendens, transversum, descendens and rectum ('very good': no faeces visible, not even in the diverticula; 'good': some faeces visible without hampering the colonoscopy; 'poor': faeces visible, hampering the colonoscopy).

Five faecal samples were collected: one before bowel cleansing (week 0 ), the first faecal sample which could be produced after the colonoscopy (week 1), after two and four weeks of probiotic or placebo consumption (week 2 and 4) and four weeks after cessation of the drinks (week 8). Together with the faecal sampling, the patients completed a questionnaire on medication, bowel habits (defaecation frequency and faeces consistency scores from hard lumps (1) until watery diarrhoea (7) according to the Bristol scale ${ }^{30}$ ), compliance, sideeffects and changes in dietary habits. Participants were excluded from analyses if less than $85 \%$ of the faecal samples were collected and/or less than $85 \%$ of the probiotic/placebo drinks were consumed.

\section{Microbiological analyses}

Faecall samples were collected and processed as described previously ${ }^{31}$. Tenfold serial dilutions of the faecal samples were made in physiological saline and $40 \mu \mathrm{l}$ were inoculated on agar plates to culture and count total (facultative) aerobic bacteria, enterobacteriaceae, enterococci, total (facultative) anaerobic bacteria, Bacteroides spp., clostridia, lactic acid bacteria and lactobacilli ${ }^{31}$.

\section{DNA extraction}

DNA from faecal samples was isolated with the fast DNA SPIN ${ }^{(10}$ Kit for soil (Qbiogene, Heidelberg, Germany) with disruption of bacterial cells by highly energetic mechanical means using the FastPrep ${ }^{\circledast}$ Instrument (Q-biogene, Heidelberg, Germany). Genomic DNA was purified with a proprietary silica matrix, eliminating contaminants that inhibit reactions.

\section{PCR}

PCR was performed with a Taq polymerase kit. The primers, F-0968-GC and R-1401, used in this study amplify the V6 to V8 region of $16 S$ rRNA. The PCR mixture contained $5 \mu \mathrm{l}$ of $10 \times \mathrm{PCR}$ buffer containing $15 \mathrm{mM} \mathrm{MgCl}, 3 \mu \mathrm{l}$ of $50 \mathrm{mM} \mathrm{MgCl} 2,1 \mu \mathrm{l}$ of deoxynucleoside triphosphate preparation $(10 \mathrm{mM}), 1 \mu \mathrm{l}$ of each primer $(10 \mu \mathrm{M}), 0.25 \mu \mathrm{l}$ of Taq DNA polymerase $(5 \mathrm{U} / \mu \mathrm{l}), 37.75 \mu \mathrm{l}$ sterile Milli-Q water and $1 \mu$ lof a ten-fold diluted DNA-solution.

The following PCR program was used: pre-denaturation for 5 minutes at $94^{\circ} \mathrm{C}$, 35 cycles of denaturation at $94^{\circ} \mathrm{C}$ for 30 seconds, annealing at $56^{\circ} \mathrm{C}$ for 20 seconds and elongation at $68^{\circ} \mathrm{C}$ for 45 seconds. The program ended with a 
post-elongation step at $68^{\circ} \mathrm{C}$ for 7 minutes followed by cooling down to $4^{\circ} \mathrm{C}$. The amplification of the amplicons was confirmed on ethidium-stained $1 \%$ agarose gels for 20 minutes at $100 \mathrm{~V}$.

\section{DGGE analysis}

PCR products were analysed on DGGE gels according to the method described by Zoetendal et al. ${ }^{11}$ with the following modifications. The $8 \%$ polyacrylamide gels contained a urea / formamide gradient from $30 \%$ to $60 \%$. Electrophoresis was performed in $0.5 x$ Tris acetic acid EDTA (TAE) buffer ( $2.42 \mathrm{~g}$ tris, $570 \mu \mathrm{l}$ acetic acid, $0.37 \mathrm{~g}$ EDTA) at $85 \mathrm{~V}$ during 16 hours using the DCode System apparatus (Bio-rad, Hercules, California). Amplicons of isolates of $L$. plantarum 299v were electrophoresed next to the PCR products of the faecal samples as well as a marker. After electrophoresis, the gels were stained as described by Sanguinetti et al. using the rapid silver staining procedure $^{32}$ and scanned at $400 \mathrm{DPI}$. DGGE profiles were compared using the Bionumerics software version 3.0 (Applied-Maths, Sint-Martens-Latem, Belgium). The similarity between the five faecal samples of each individual was determined by calculating the similarity value using the Pearson's productmoment correlation coefficient ${ }^{33}$.

Similarity values were called 'deviant' when the value was below the mean similarity value of the group minus one standard deviation. Similarity values at different time points were correlated with changes in type or dose of medication.

\section{Statistical analyses}

Statistical evaluation of changes in culture results between groups and within groups during the study period was carried out using the linear mixed model analysis with SPSS version 11.0. Non-parametric Wilcoxon signed-rank test and Mann-Whitney U-test with a Bonferroni-Holm correction were used for comparison of DGGE results within and between groups, respectively. A pvalue below 0.05 was considered to be statistically significant.

\section{Results}

Twenty-two patients completed the study: twelve in the probiotic group ( 4 male, 8 female, mean age $46.5 \pm 8.7$ years) and ten in the placebo group ( 3 malle, 7 female, mean age $55.0 \pm 16.1$ years). No significant differences in gender and age were seen between probiotic and placebo group. One patient (probiotic group) was excluded because he collected only three out of five faecal samples. Clinical diagnoses of patients at colonoscopy included: inflammatory bowel diseases (IBD) $(n=5)$, irritable bowel syndrome $(n=4)$, colorectal adenomas $(n=5)$, diverticular disease $(n=2)$, rectal ulcer $(n=1)$ and ileocaecal resection $(n=1)$. Four patients had normal findings at colonoscopy and had no 
diagnoses of gastrointestinal diseases. Patients used different types of medication such as corticosteroids $(n=3), 5$-ASA medication $(n=4)$, proton pump inhibitors $(n=3)$, laxatives or anti-diarrhoea medication $(n=7)$, and other non-gastrointestinal medication such as antihistamines, analgesis and cholesterol-lowering medication $(n=17)$. Ten patients changed the type and two patients the dose of their gastrointestinal medication during the study period.

No significant differences were observed in defaecation frequency and faeces consistency scores between probiotic and placebo group or within both groups over time (table 4.1). Mean period of time between colonoscopy and collection of the first faecal sample produced after colonoscopy (i.e. sample of week 1) was 82 hours (range 20-146) in the probiotic group and 60 hours (range 23$120)$ in the placebo group and did not differ significantly $(p=0.46)$.

In thirteen patients the effectiveness of the bowel cleansing was scored: two patients had a 'poor' bowel cleansing in the whole colon and rectum and five patients in some parts of the colon and rectum. The other six patients had a 'very good' or 'good' bowel cleansing procedure. Furthermore, no side effects were reported after the treatment with $L$. plantarum $299 \mathrm{v}$ or the placebo drink. The compliance was $96 \%$ for the probiotic drinks and $90 \%$ for the placebo drinks.

Table 4.1 Defaecation frequency (per day) and faeces consistency scores according to the Bristol scale (1:hard lumps-7:watery diarrhoea) in week 0 (before bowel cleansing). week 1 (first faecal sample after colonoscopy), week 2 (after two weeks probiotic/placebo consumption), week 4 (after four weeks probiotic/placebo consumption) and week 8 (four weeks after cessation of the probiotic/placebo consumption) in 22 patients (mean $\pm \mathrm{sd}$ ).

\begin{tabular}{lccccc}
\hline & Week 0 & Week 1 & Week 2 & Week 4 & Week 8 \\
\hline Consistency & & & & & \\
$\quad$ Probiotic & $4.4 \pm 1.4$ & $4.8 \pm 1.6$ & $4.2 \pm 1.3$ & $4.2 \pm 1.5$ & $3.7 \pm 1.6$ \\
Placebo & $4.2 \pm 1.8$ & $4.1 \pm 1.6$ & $3.9 \pm 1.3$ & $4.1 \pm 1.3$ & $4.3 \pm 1.1$ \\
Frequency & & & & & \\
Probiotic & $1.9 \pm 1.6$ & $1.2 \pm 1.6$ & $1.7 \pm 1.5$ & $1.5 \pm 0.8$ & $1.4 \pm 0.8$ \\
Placebo & $0.9 \pm 0.9$ & $0.9 \pm 1.1$ & $1.3 \pm 0.9$ & $1.6 \pm 0.7$ & $1.6 \pm 0.7$ \\
\hline
\end{tabular}

\section{Culture}

During the consumption of the drinks (weeks 2 and 4), a significant increase in the number of lactic acid bacteria $(p=0.008)$ and lactobacilli $(p<0.005)$ was observed in the probiotic group but not in the placebo group (table 4.2). The number of lactic acid bacteria $(p=0.006)$ and lactobacilli $(p<0.005)$ decreased significantly after cessation of the drinks (week 8 ) compared to the number during the consumption of the probiotic drinks (week 2 and 4). No significant differences could be observed in other aerobic and anaerobic bacterial counts before (week 0 ) and after bowel cleansing (week 1) and during probiotic intake (week 2 and 4 ) with the exception of the total number of aerobic bacteria, which 
increased significantly $(p=0.001)$ in the probiotic group in week 1 compared to week 0 .

Table 4.2 Concentrations of bacterial strains (log CFU/g faeces) in week 0 (before bowel cleansing), week 1 (first faecal sample after colonoscopy), week 2 (after two weeks probiotic/placebo consumption), week 4 (after four weeks probiotic/placebo consumption) and week 8 (four weeks after cessation of the probiotic/placebo consumption) in 22 patients (mean $\pm \mathrm{sd}$ ).

\begin{tabular}{|c|c|c|c|c|c|}
\hline & Week 0 & Week 1 & Week 2 & Week 4 & Week 8 \\
\hline \multicolumn{6}{|c|}{ Total aerobic flora } \\
\hline Probiatic & $6.2 \pm 0.8$ & $7.4 \pm 0.7^{a 1}$ & $6.4 \pm 0.5$ & $6.2 \pm 1.2$ & $6.1 \pm 1.0$ \\
\hline Placebo & $7.3 \pm 1.1$ & $7.3 \pm 0.9$ & $7.1+1.3$ & $7.5 \pm 1.0$ & $6.7 \pm 1.3$ \\
\hline \multicolumn{6}{|l|}{ E.coli } \\
\hline Probiotic & $57 \pm 1.2$ & $6.7 \pm 2.1$ & $5.6 \pm 1.7$ & $6.0 \pm 2.1$ & $4.6 \pm 2.4$ \\
\hline Placebo & $6.9 \pm 1.2$ & $6.7 \pm 1.0$ & $6.4 \pm 2.3$ & $6.6 \pm 2.5$ & $6.1 \pm 2.4$ \\
\hline \multicolumn{6}{|l|}{ Enterococci } \\
\hline Probiotic & $2.6 \pm 1.6$ & $3.2 \pm 2.2$ & $3.3 \pm 1.6$ & $2.7 \pm 1.6$ & $2.5 \pm 1.6$ \\
\hline Placebo & $4.5 \pm 1.7$ & $4.8 \pm 2.2$ & $3.9 \pm 1.9$ & $4.1 \pm 2.0$ & $3.5 \pm 1.7$ \\
\hline \multicolumn{6}{|c|}{ Total anaerobic flora } \\
\hline Probiotic & $8.2 \pm 1.6$ & $8.3 \pm 1.3$ & $8.2 \pm 1.0$ & $8.5 \pm 1.1$ & $7.9 \pm 1.1$ \\
\hline Placebo & $8.5 \pm 1.2$ & $8.1 \pm 1.6$ & $8.5 \pm 1.3$ & $8.8 \pm 1.4$ & $8.4 \pm 1.1$ \\
\hline \multicolumn{6}{|c|}{ Bacteroides spp. } \\
\hline Probiatic & $5.5 \pm 2.2$ & $6.4 \pm 1.2$ & $5.5 \pm 1.6$ & $4.9 \pm 2.5$ & $5.3 \pm 1.8$ \\
\hline Placebo & $6.3 \pm 1.4$ & $6.7 \pm 1.0$ & $6.4 \pm 2.1$ & $6.3 \pm 2.3$ & $6.9 \pm 0.8$ \\
\hline \multicolumn{6}{|l|}{ Clostridia } \\
\hline Probiotic & $4.1 \pm 1.4$ & $3.7 \pm 1.3$ & $4.2 \pm 0.9$ & $4.1 \pm 0.8$ & $3.5 \pm 1.3$ \\
\hline Placebo & $4.7 \pm 0.4$ & $3.9 \pm 1.3$ & $5.0 \pm 0.6$ & $4.3 \pm 1.0$ & $4.5 \pm 0.8$ \\
\hline \multicolumn{6}{|c|}{ Lactic acid bacteria } \\
\hline Probiatic & $5.2 \pm 1.3$ & $6.4 \pm 0.9^{a}$ & $6.4 \pm 0.9^{8}$ & $6.6 \pm 0.9^{a}$ & $5.0 \pm 1.4$ \\
\hline Placebo & $4.9 \pm 2.2$ & $5.4 \pm 1.3$ & $5.7 \pm 1.5$ & $4.9 \pm 2.3$ & $4.2 \pm 2.1$ \\
\hline \multicolumn{6}{|l|}{ Lactobacilli } \\
\hline Prabiotic & $4.7 \pm 1.9$ & $6.6 \pm 1.3^{a}$ & $6.5 \pm 0.8^{a}$ & $6.8 \pm 1.0^{ \pm}$ & $4.6 \pm 1.4$ \\
\hline Placebo & $5.0 \pm 2.2$ & $5.2 \pm 1.5$ & $4.9 \pm 2.0$ & $47 \pm 20$ & $4.4 \pm 1.7$ \\
\hline
\end{tabular}

statistically significant difference $(\mathrm{p}<0.05)$ compared to week 0 .

\section{DGGE analyses}

Faecal samples for DGGE analyses and calculations of similarity values were available for 20 patients (11 probiotic and 9 placebo group). Mean similarity values over-time were relatively high (probiotic group: $86.8 \pm 3.1$ and placebo group: $86.3 \pm 2.2$ ) (figure 4.1). No major differences could be observed between probiotic and placebo group or within the groups. 


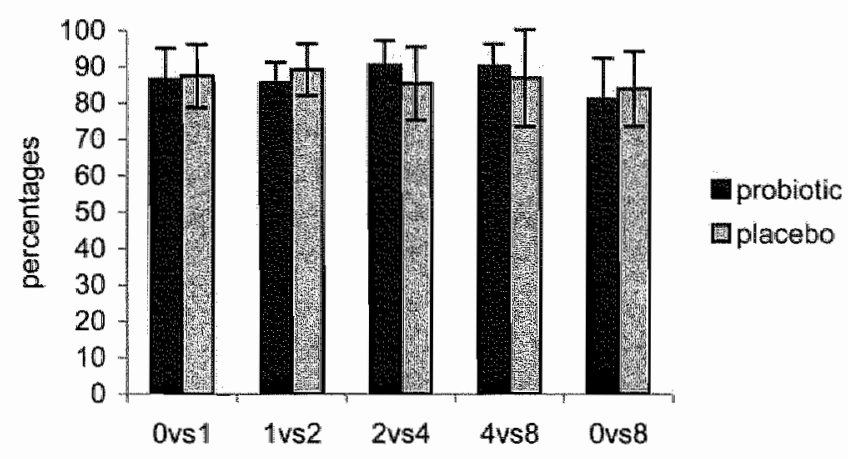

Figure 4.1 Mean DGGE similarity values (in percentages) in the probiotic $(n=\| 1)$ and placebo group $(n=9)$. Comparisons were made between week 0 and $1(0$ vs. 1$)$, week 1 and 2 ( 1 vs. 2 ), week 2 and 4 ( 2 vs. 4 ), week 4 and 8 ( 4 vs. 8 ) and week 0 and 8 ( 0 vs. 8 ).

Eighteen individual similarity values were lower than the mean of the total group minus the standard deviation and therefore defined as 'deviant'. These time points were checked for possible changes in type or dose of medication. No correlation could be seen between these time points and changes in medication except for one patient who stopped the use of loperamide in week 4 resulting in a 'deviant' similarity value comparing week 2 to week 4 .

Figure 4.2 shows the DGGE pattern of two individual patients during the study period: one from the probiotic and one from the placebo group. Changes in individual banding patterns could be observed in both probiotic and placebo patients mainly after bowel cleansing $(n=11)$, and returned within two weeks. For example, in the probiotic patient (figure $4.2 \mathrm{~b}$ ), some bands disappeared after bowel cleansing procedure (week 1 compared to week 0). However, in week 8 these bands were again present.

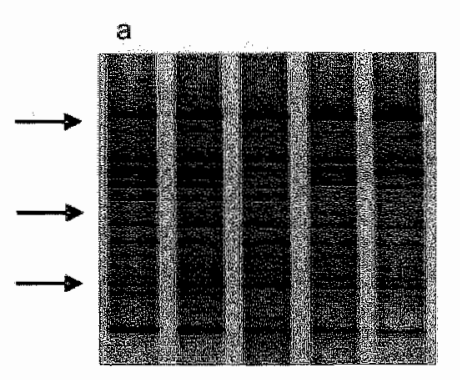

$\begin{array}{lllll}0 & 1 & 2 & 4 & 8\end{array}$

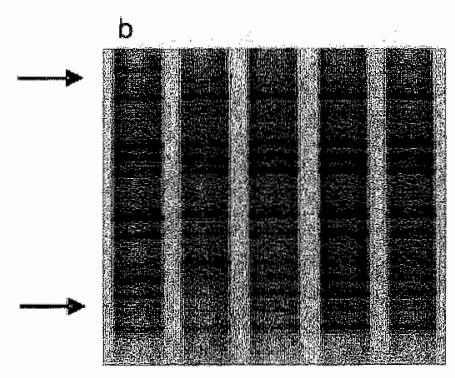

$\begin{array}{lllll}0 & 1 & 2 & 4 & 8\end{array}$

Figure 4.2 DGGE banding patterns of one patient of the placebo group (a) and one patient of the probiotic group (b). Lane $0=$ week 0 , lane 1=week 1, lane 2=week 2, lane 4=week 4, lane $8=$ week 8 . Arrows indicate changes in indiwidual bands. 


\section{Discussion}

In this study, pre-colonoscopic bowel cleansing procedure and subsequent consumption of L. plantarum $299 \mathrm{v}$ had no significant influence on the composition of the colonic flora based on both culture results and bacterial fingerprints of the dominant faecal flora, indicating that the composition of the faecal flora remains relatively stable over time despite these major interventions.

No changes in the faecal bacterial numbers due to bowel cleansing could be demanstrated by culture with the exception of the number of total aerobic bacteria. The effectiveness of the bowel cleansing (very good, good and poor) did not influence the culture results significantly (data not shown) and was successful in the majority of patients. The number of total aerobic bacteria increased significantly after bowel cleansing in all patients in the probiotic group. In contrast, van den Bogaard et al. demonstrated a reduction of $\log 2$ to 3 in the faecal number of total aerobic bacteria and of log 4 to 5 in the number of total anaerobic bacteria after bowel cleansing ${ }^{20}$. These inconsistent results might be explained by the use of different bowel cleansing procedures (saline versus Kleanprep). Moreover, van den Bogaard et al. collected clear rectal effluent immediately after bowel cleansing, while in the present study the first faecal sample after colonoscopy was collected with a mean period of time of 82 hours in the probiotic and 60 hours in the placebo group. This difference in faeces collection time comparing the probiotic to the placebo group could not be explained by differences in defaecation frequency or faeces consistency.

The increase in the number of total aerobic bacteria might also be caused by the consumption of the probiotic drinks. However, the increase in aerobic bacteria did not persist during the probiotic consumption and has been disappeared in week 4. In addition, previous studies performed with healthy volunteers consuming $L$. plantarum $299 \mathrm{v}$ for 4 and 2 weeks respectively, could not observe an increase in the number of total aerobic bacteria ${ }^{24,31}$.

Furthermore, the consumption of the probiotic, L. plantarum $299 \mathrm{~V}$ increased the amount of lactic acid bacteria and lactobacilli significantly with $\log 1.5 \mathrm{CFU} / \mathrm{g}$ faeces. These results were in accordance with the results of a previous study in which twenty healthy volunteers consumed L. plantarum $299 \mathrm{v}$ during four weeks ${ }^{31}$. However, the number of lactobacilli recovered in faeces during probiatic consumption was lower in this study (log $6.8 \mathrm{CFU} / \mathrm{g}$ faeces) compared to the previous one (log $8.2 \mathrm{CFU} / \mathrm{g}$ faeces) while the daily dose of $L$. plantarum $299 \mathrm{v}$ was the same $\left(10^{11} \mathrm{CFU} / \mathrm{day}\right)$. Comparison of the pre-treatment faecal bacterial concentrations to the results found in a previous study with the healthy volunteers ${ }^{31}$, demonstrated lower bacterial concentrations for total aerobic bacteria, enterococci, total anaerobic bacteria, Bacteroides spp. and lactic acid bacteria in the present study, although similar culture methods were used in both studies. These differences could be explained by higher 
defaecation frequency and faeces consistency scores found in the present study, which can result in dilution of the faecal samples and lower numbers of bacteria counted per gram faeces. These looser stool samples could be due to the inclusion of various types of patients such as IBD patients. For example, decreased numbers of lactobacilli and aerobic bacteria have been reported in IBD patients in literature ${ }^{3,34-37}$. However, exclusion of the bacterial concentrations of the IBD patients did not result in an increase of bacterial concentrations.

In this study, PCR combined with DGGE analyses was found to be an useful additive tool to study the effects of bowel cleansing and probiotic consumption on the dominant faecal flora over time. The intra-individual similarity values calculated between the faecal samples obtained before and after bowel cleansing were relatively high: mean $86.5 \%$. Zoetendal et al. calculated similarity values ranging from 66 to $88 \%$ comparing two faecal samples of four individuals over time in a four month period ${ }^{13}$. In this study, bowel cleansing did not significantly influence the overall banding patterns of the dominant flora. Although bowel cleansing was successful, it cannot be ruled out that even very small amounts of remaining bacteria can result in a recolonisation of the original flora.

The increase in the number of lactobacilli during probiotic consumption was not reflected in one single band of the molecular fingerprint as the dominant flora consists for less than $1 \%$ of lactobacilli and universal primers used for the analyses of the dominant faecal flora detect the most prevalent species, representing $90-99 \%$ of the total faecal flora ${ }^{38}$.

Factors affecting the intestinal flora, except for bowel cleansing and L. plantarum $299 \mathrm{v}$ intake, were kept as stable as possible during the study period. However, medication taken in this study such as sulfasalazine and proton pump inhibitors has been demonstrated to influence the faecal bacterial composition ${ }^{16,35,39,40}$. Changes in dose and type of these compounds could not be correlated to the 'deviant' similarity values found in this study except in one patient. This patient stopped the use of loperamide in week 4 , resulting in changes in the banding patterns of the dominant flora and in a similarity value of $76 \%$. Loperamide has been found to change the number of streptococci, but did not cause bacterial overgrowth in 14 children receiving the drug because of severe diarrhoea $a^{41,42}$.

Similarity values did not change due to bowel cleansing but some changes in individual bands occurred, mainly in the first week after bowel cleansing, suggesting that bowel cleansing could have an influence on specific bacterial species. Moreover, repeated bowel cleansing procedures might result in a more prominent elimination of the bacterial mass. To get further insight into bowel cleansing as therapeutic modality in gastrointestinal diseases like IBD, influences of bowel cleansing on specific bacterial subspecies have to be studied in defined patient groups using PCR/DGGE with specific primers instead of universal primers. 
This study was performed with consecutive patients undergoing a bowel cleansing procedure instead of healthy volunteers, which could have influenced culture results and DGGE banding patterns of the dominant faecal flora. However, even in this heterogeneous population, the intestinal flora remained stable over time. Unfortunately, numbers of patients with specific clinical diagnoses were too small to compare these groups statistically and in a future study more patients should be included.

Seven patients in this study were older than 60 years. As the faecal flora might change by the physiological conditions of the elderly, their flora might be different compared to the younger participants ${ }^{43}$. However, no significant differences were found in the faecal samples collected before bowel cleansing of the younger ( $<60$ years) compared to the older patients ( $>60$ years) (data not shown).

In conclusion, drastic environmental intervention and changes in dietary factors such as bowel cleansing and probiotic consumption did not result in major changes in the dominant faecal flora. Neither did changes in type or dose of medication significantly alter the bacterial fingerprint of the flora supporting the results of previous studies, indicating that the individual faecal flora is relatively stable over time. However, some changes in single species of the dominant flora of individuals could be noticed, particularly in the early phase of bowel recolonisation. 


\section{References}

1. Savage DC. Microbial ecology of the gastrointestinal tract. Annu Rev Microbiol 1977;31:107-33.

2. Simon $\mathrm{GL}$, Gorbach SL. The human intestinal microflora. Dig Dis Sci $1986 ; 31: 147$ S-162S.

3. Holzapfel $W H$, Haberer $P$, Snel $J_{\text {s }}$ Schillinger $U$, Huis in 't Veld J. Overview of gut flora and probiotics. Int J Food Microbiology 2001;41:85-101.

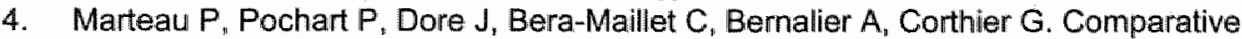
study of bacterial groups within the human cecal and fecal microbiota. Appl Environ Microbiol 2001;67:4939-42.

5. Vollaard EJ, Clasener HA. Colonization resistance. Antimicrob Agents Chemother 1994;38:409-14.

6. Lennard-Jones JE. Inflammatory bowel disease: medical therapy revisited. Scand J Gastroenterol Suppli 1992;192:110-6.

7. Rakoff-Nahoum $S$, Paglino J, Eslami-Varzaneh F, Edberg $S$, Medzhitov R. Recognition of commensal microflora by toll-like receptors is required for intestinal homeostasis. Cell 2004;118:229-41.

8. Swidsinski A, Ladhoff A, Pernthaler A, et al. Mucosal flora in inflammatory bowel disease. Gastroenterology 2002;122:44-54.

9. Fabia $R$, Ar'Rajab $A$, Johansson $M L$, et al. Impairment of bacterial flora in human ulcerative colitis and experimental colitis in the rat. Digestion 1993;54:248-55.

10. Bradley HK, Wyatt GM, Bayliss CE, Hunter JO. Instability in the faecal flora of a patient suffering from food-related irritable bowel syndrome. I Med Microbiol $1987 ; 23: 29-32$.

11. Zoetendal $E G$, Akkermans $A D$, de Vos WM. Temperature gradient gel electrophoresis analysis of $16 \mathrm{~S}$ rRNA from human fecal samples reveals stable and host-specific communities of active bacteria. Appl Environ Microbiol 1998;64:3854-9.

12. Hopkins MJ, Sharp R, Macfarlane GT. Variation in human intestinal microbiota with agle. Dig Liver Dis 2002;34 Suppl 2:12-8.

13. Zoetendal EG, Akkermans ADL, Akkermans-van Vliet WM, Visser de AGM, Vos de WM. The host genotype affects the bacterial community in the human gastrointestinal tract. Microb Ecol in Health and Dis 2001:13:129-34.

14. Finegold SM, Sutter VL, Sugihara PT, Elder HA, Lehmann SM, Phillips RL. Fecal imicrobial flora in Seventh Day Adventist populations and control subjects. Am I Clin Nutr 1977;30:1781-92.

15. Finegold SM, Sutter VL. Fecal flora in different populations, with speciall reference to diet. Am J Clin Nutr 1978;31:S116-22.

16. Danielsson $D$, Kjellander $J$, Jarnerot $G$. The effect of metronidazole and sulfasalazine on the fecal flora in patients with Crohn's disease. Scand J Gastroenterol 1981; $16: 183-92$.

17. Wellmann W. Fink PC, Schmidt FW. Whole-gut irrigation as antiendotoxinaemic therapy in inflammatory bowel disease. Hepatogastroenterology 1984;31:91 3 .

18. Wellmann W, Schmidt FW. Intestinal lavage in the treatment of Crohn's disease: a pilot study. Klin Wochenschr 1982;60:371-3.

19. Wellmann W, Fink PC, Benner $F$, Schmidt FW. Endotoxaemia in active Crohn's disease. Treatment with whole gut irrigation and 5-aminosalicylic acid. Gut $1986 ; 27: 814-20$. 
20. van den Bogaard AE, Weidema WF, van Boven $C P$, van der Waay $D$. Recolonization and colonization resistance of the large bowel after three methods of preoperative preparation of the gastrointestinal tract for elective colorectal surgery. J Hyg 1986;97:49-59.

21. Havenaar $R$. Ten Brink $B$, Huis in 4 Veld J. Selection of strains for probiotic use. In: Chapmann and Hall, ed. Probiotics, The scientific basis. London, 1992:209-24.

22. Adlerberth 1 , Ahrne $S$, Johansson M, Molin $G$, Hanson L. Wold A. A mannosespecific adherence mechanism in Lactobacillus plantarum conferring binding to the human colonic cell line HT-29. Appl Environ Microbiol 1996;62:2244-51.

23. Herias MV. Hessle C, Telemo $E$, Midtwedt $T$, Hanson LA, Wold AE. Immunomodulatory effects of Lactobacillus plantarum colonizing the intestine of gnotobiotic rats. Clin Exp Immunol 1999;116:283-90.

24. Goossens D, Jonkers D, Russel M, et al. Survival of the probiotic $L$. plantarum $299 \mathrm{v}$ and its effects on the faecal bacterial flora, with and without gastric acid inhibition. Dig Liver Dis 2005;37:44-50.

25. Suau $A$, Bonnet $R$, Sutren $M_{*}$ et al. Direct analysis of genes encoding $16 S$ rRNA from complex communities reveals many novel molecular species within the human gut. Appl Environ Microbiol 1999;65:4799-807.

26. Tannock $G$, Munro $K$, Harmsen $H$, Welling $G$, Smart J, Gopal P. Analysis of the fecal microflora of human subjects consuming a probiotic product containing Lactobacillus rhamnosus DR20. Appl Environ Microbiol 2000;66:2578-88.

27. Vaughan EE, Heilig HGHJ, Zoetendal EG, et al. Molecular approaches to study probiotic bacteria. Trends in Food Science \& Technology 2002;10:400-4.

28. Muyzer $G$, de Waal EC, Uitterlinden $A G$. Profiling of complex microbial populations by denaturing gradient gel electrophoresis analysis of polymerase chain reactionamplified genes coding for 16S rRNA. Appl Environ Microbiol 1993;59:695-700.

29. Muyzer $G$, Smalla $K$. Application of denaturing gradient gel electrophoresis (DGGE) and temperature gradient gel electrophoresis (TGGE) in microbial ecology. Antonie Van Leeuwenhoek 1998;73:127-41.

30. O'Donnell $L$, Virjee $J$, Heaton $K$. Detection of pseudodiarrhoea by simple clinical assessment of intestinal transit rate. British Medical Journal 1990;300:439-40.

31. Goossens $D$, Jonkers $D$, Russel $M$, Stobberingh $E$, Van Den Bogaard $A$, Stockbrugger R. The effect of Lactobacillus plantarum $299 \mathrm{v}$ on the bacterial composition and metabolic activity in faeces of healthy volunteers: a placebocontrolled study on the onset and duration of effects. Aliment Pharmacol Ther 2003:18:495-505.

32. Sanguinetti $C J$, Dias Neto $E_{1}$ Simpson AJ. Rapid silver staining and recovery of PCR products separated on polyacrylamide gels. Biotechniques 1994;17:914-21.

33. Hane BG, Jager $K$. Drexler HG. The Pearson product-moment correlation coefficient is better suited for identification of DNA fingerprint profiles than band matching algorithms. Electrophoresis 1993;14:967-72.

34. Ruseler-van Embden JG, Both-Patoir HC. Anaerobic gram-negative faecal flora in patients with Crohn's disease and healthy subjects. Antonie Van Leeuwenhoek 1983;49:125-32.

35. Hartley MG, Hudson MJ, Swarbrick ET, et al. The rectal mucosa-associated microflora in patients with ulcerative colitis. J Med Microbiol 1992;36:96-103.

36. Fabia $R$, Ar'Rajab $A$, Johansson $M L$, et al. The effect of exogenous administration of Lactobacillus reuteri R2LC and oat fiber on acetic acid-induced colitis in the rat. Scand J Gastroenterol 1993;28:155-62. 
37. Ott $S$, Musfeldt $M$, Wenderoth $D$, et al Reduction in diversity of the colonic mucosa associated bacterial microflora in patients with active inflammatory bowel disease. Gut 2004:53:685-93.

38. Walter $J$ Hertel $C_{\text {, }}$ Tannock GW, Lis CM, Munro K Hammes WP Detection of Lactobacillus, Pediococcus, Leuconostoc, and Weissella species in human feces by using group-specific PCR primers and denaturing gradient gel electrophoresis. Appl Environ Microbiol 2001;67:2578-85.

39. Krook $A$, Jarnerot $G$, Danielsson $D$. Clinical effect of metronidazole and sulfasallazine on Crohn's disease in relation to changes in the fecal flora. Scand $J$ Gastroenterol 1981;16:569-75.

40. Jonkers DM, Stobberingh EE, Houben GMP, Stockbrugger RW The influence of long-term treatment with omeprazole on changes in faecal aerobic flora. Gastroenterology 1994;106:A101.

41. Lambert-Zechovsky N, Bingen E, Cezard JP, Mashako L, Marinier E Navarto J. Effects of loperamide on the fecal flora in children in severe diarneas. Pathol Biol 1987;35:656-60.

42. Cezard JP, Bingen $E_{x}$ Lambert-Zechowsky $N$, Marchand $M$, Marinier E Nawarro J. Effect of loperamide on fecal flora of children with severe prolanged diarrhea. Arch Fr Pediatr 1987;44:109-14.

43. Mitsuoka T. Intestinal flora and aging. Nutr Rev 1992;50:438-46. 


\section{Chapter 5}

The effect of a probiotic drink with L. plantarum $299 \mathrm{v}$ on the bacterial composition in faeces and mucosal biopsies of rectum and ascending colon

D. Goossens, D. Jonkers, M. Russel, E. Stobberingh, R. Stockbrügger 


\section{Abstract}

\section{Background}

Studies on probiotics mainly based their results on faecal samples, which may not represent the situation in the mucosa of distal and proximal colon.

Aim

In this placetio-controlled study. the effect of L. plantarum $299 \mathrm{v}$ was assessed on the bacterial composition of faecal versus mucosal samples.

\section{Methods}

Twenty-mine patients undergoing colonoscopic contral for polyps consumed a drink with or without $L$ plantarum $299 \mathrm{v}$ ( $10^{11} \mathrm{CFU} / \mathrm{day}$ ) for two weeks. Faecal samples were collected before and after consumption. During colonoscopy, biopsles were collected from the ascending colon and rectum. The faecal and mucosal bacterial concentrations and prevalence were determined.

\section{Results}

2. plantarum $299 \mathrm{v}$ significantly increased the concentration of faecal lactic acid bacteria, lactobacilli and clostridia and was identified in 2 rectal biopsies but not in the ascending colon biopsies of probiotic-treated persons. Concentrations and prevalence in ascending colon and rectum biopsies were comparable but were significantly lower compared to faecal samples.

\section{Conclusions}

After probiotic consumption, a significant increase in the faecal concentration of lactobacilli was found but concentrations were low in biopsies. The bacterial composition in biopsies of ascending coton and rectum did not differ based on culture techniques. To further elucidate the modes of action of probiotics, it might be necessary to study differences in colonisation with molecular techniques. 


\section{Introduction}

Probiotics defined as "mono- or mixed cultures of live micro-organisms which, when applied to animal or man, beneficially affect the host by improving the properties of the indigenous microflora" could have therapeutic effects in gastrointestinal diseases such as Crohn's disease, ulcerative colitis and irritable bowel syndrome ${ }^{1,2}$. However, clinical studies have often been performed without measuring (micro)biological parameters while the possible modes of action of probiotics are still unresolved. One of the potential modes of action of probiotics could be changing the intestinal bacterial composition. Probiotics were demonstrated to increase the numbers of faecal lactobacilli during consumption ${ }^{3-6}$, while a decrease in the number of enterococci and sulphate-reducing clostridia was found after Lactobacillus rhamnosus DR20 and Lactobacillus plantarum $299 \mathrm{v}$ intake, respectively ${ }^{3,5}$. L. plantarum $299 \mathrm{v}$ has been shown to strongly adhere to the mucosa by mannose-specific binding sites in vitro and in gnotobiotic rats, in this last model, preventing $E$. coli from adhering $^{7,8}$. This lactobacillus strain has been used in the present study.

Studies investigating the effects of probiotics on the intestinal flora mainly based their results on faecal samples. However, faecal samples may not represent the composition of the intestinal flora in the mucosa of the proximal and distal colon, while investigating the effects on the mucosal flora is important as the mucosal flora has a direct interaction with the host cells. A study including only ten persons, demonstrated that the bacterial composition in faecal samples was significantly different from that of biopsy samples ${ }^{9}$. However, this study investigated the composition of the dominant mucosaassociated flora and the lactobacilli qualitatively by denaturating gradient gel electrophoresis (DGGE) and not quantitatively by determining bacterial concentrations. Other studies only focused on the recovery of the probiotic strain in biopsy samples and did not compare mucosal to faecal bacterial composition $^{3,10,11}$. To our knowledge only one study showed an alteration in the mucosal concentrations after dietary modulation: a significant increase in the mucosal concentration of lactobacilli and bifidobacteria after treatment of prebiotic carbohydrates has been found ${ }^{12}$. However, in this study only biopsy samples were collected and comparisons between faecal and mucosal samples were not made ${ }^{12}$. Comparisons between the mucosal and faecal flora are needed to determine if analysis of faecal samples is representative in studying effects of dietary modulations on the intestinal mucosal flora.

In this context, it is important to pay attention to the differential distribution of probiotics over the length of the large bowel. It is plausible that the composition of the mucosal bacteria in the proximal colon differs from that in the distal colon as the availability of nutrients and of bacterial fermentation products differs between these locations: short chain fatty acid concentrations are highest in ascending colon while praducts of protein fermentation such as ammonia as well as the $\mathrm{pH}$ are highest in colon descendens ${ }^{13}$. Limited number of studies compared the bacterial composition in the proximal colon to that of the distal 
colon and concluded that there was no variation in the mucosal bacteria along the colon ${ }^{9,14,15}$. However, these studies included small numbers of participants (4, 10 and 12 individuals, respectively) of whom sorne persons have been diagnosed with ulcerative colitis ( 3 of 10 and 6 of 12) which may influence the bacterial composition ${ }^{16-18}$. More insight in the composition of the mucosal flora in the proximal colon versus that of the rectum is important to determine if analysis of rectal biopsy samples oniy is representative to study the effects of probiotics on the intestinal mucosal flora.

In this placebo-controlled double-blind study, the effect of the probiotic L. plantarum $299 \mathrm{v}$ was assessed on the bacterial composition of faecal versus mucosal samples and of rectal versus ascending colon biopsy samples.

\section{Methods}

\section{Subjects}

Thirty consecutive patients were enrolled in the study undergoing a colonoscopic control because of a previous history of polyps or a positive family history of colorectal cancer. Exclusion criteria were pre-existing bowel pathology including irritable bowel syndrome, inflammatory bowel disease, cancer and bowel resection. Participants were neither allowed to use antibiotics, laxatives, probiotics and/or prebiotics during two weeks before nor during the study. Participants were asked to continue their 'normal' dietary habits. All participants have given written informed consent. The study was approved by the Medical Ethical Committee of the University Hospital Maastricht and was performed in accordance with the declaration of Helsinki.

\section{Study design}

The study was randomised, placebo-controlled and double-blind. The total duration of the study period was two weeks. During the two weeks treatment period, patients consumed $100 \mathrm{ml}$ in the morning and $100 \mathrm{ml}$ in the evening of an oatmeal fermented drink without (placebo) or with (probiotic) L. plantarum $299 \mathrm{v}\left(10^{9} \mathrm{CFU} / \mathrm{ml}\right)$. Both probiotic and placebo drinks were provided by Probi $A B$, Lund, Sweden, who also performed the randomisation using a computer program and kept the codes until all samples were analysed. Probiotic and placebo drinks were indistinguishable in colour, smell and taste. Two faecal samples were collected: one before and one after the probiotic or placebo treatment. At the time of the collection of faecal samples, questionnaires had to be completed with questions about bowel habits (defaecation frequency and faeces consistency scores according to the Bristol scale ${ }^{19}$ ), compliance with regard to the consumption of the drinks and possible side effects. Patients were excluded from analyses if the drinks were consumed for less than 6 days per week based on the questionnaires. 
After coilection of the second faecal samples, patients started with the bowel cleansing procedure as preparation for the colonoscopy. All participants have taken a laxative containing macrogol and electrolytes (Kleanprep ${ }^{8}$ ) during 4.5 hours to clean the gastrointestinal lumen, 24 hours prior to colonoscopy. During the colonoscopy one biopsy sample from each rectum and ascending colon was collected with a sterile biopsy forceps.

\section{Collection of samples}

Faecal samples ( \pm 20 gram) were collected in a sterile container and brought to the laboratory within 12 hours after defaecation. Five grams were diluted (1:4) in peptone water with cysteine $(2.1 \mathrm{mM})$ and glycerol $(37 \%)$ and homogenised with an ultra-turrax (IKA $\left.{ }^{(}\right)$Sigma-Aldrich Chemie B.V., Zwijndrecht, The Netherlands) for one minute. The remaining undiluted part was frozen for additional analyses $\left(-20^{\circ} \mathrm{C}\right)$.

Biopsies from ascending colon and rectum were collected in sterile $0.8 \%$ sodium chloride with cysteine- $\mathrm{HCl}(0.1 \%)$ to limit exposure to oxygen and were processed immediately after collection.

\section{Bacteriological culture}

Within 12 hours after defaecation, ten-fold serial dilutions of the faecal samples $\left(10^{-1}-10^{-6}\right)$ were made in sodium chloride $(0.9 \%)$ and $40 \mu \mathrm{l}$ were inoculated using a spiral plater (Eddy Jet v1.2, IUL-instruments, Barcelona, Spain) on the following agar plates: Blood agar plates (Oxoid CM 271, Basingstoke, UK) for total (facultative) aerobic bacteria, Eosin-methylene blue agar plates (Oxoid CM69, Basingstoke, UK) for enterobacteriaceae, KF-streptococcus agar plates (Oxoid $\mathrm{Cm} 701$, Basingstoke, UK) for enterococci, Fastidious anaerobic agar plates (Lab M LabGo, Lancashire BI9, 6AU, UK) for total (facultative) anaerobic bacteria, Bile-esculine agar plates (Becton Dickinson 287920, La Pont de Claix, France) for Bacteroides spp., Egg Yolk agar plates for clostridia "Rogosa agar plates (Oxoid CM627, Basingstoke, UK) for lactic acid bacteria and LAMVAB (lactobacillus anaerobic MRS with vancomycin and bromocresol green) for lactobacilli $\mathrm{i}^{20}$ according to the method described previously $\mathrm{y}^{4}$.

Biopsy samples were washed three times by shaking gently in sterile $0.8 \%$ sodium chloride with cysteine- $\mathrm{HCl}(0.1 \%)$. Biopsy samples were homogenised in $0.5 \mathrm{ml} 0.8 \%$ sodium chloride with cysteine- $\mathrm{HCl}(0.1 \%)\left(10^{-1}\right)$ by a sterile tissue grinder (No. 43950, ICN Flow Biomedicals NVSA, Asse-Relegem, Belgium). Forty $\mu \mathrm{l}$ of this solution was diluted in $0.8 \%$ sodium chloride with cysteine- $\mathrm{HCl}(0.1 \%)\left(10^{-2}\right)$. After homogenisation, $50 \mu \mathrm{l}$ of both dilutions were inoculated on the agar plates described above.

Blood agar and eosin-methylene blue agar plates were incubated aerobically at $37^{\circ} \mathrm{C}$ for 24 hours. KF- streptococcus agar plates were incubated aerobically at $42^{\circ} \mathrm{C}$ for 48 hours. Fastidious anaerobic, Bile-esculine, Egg yolk, Rogosa and $\angle A M V A B$ agar plates were incubated anaerobically at $37^{\circ} \mathrm{C}$ for 48 hours after inoculation. Colony forming units (CFU) were counted and expressed as log colony forming units per gram faeces (log CFU/g faeces) or per biopsy sample 
(log CFU/biopsy). The prevalence of bacteria culturable in faecal and biopsy samples has been calculated. Mean mucosal bacterial concentrations were calculated if the bacteria were present in more than five biopsy samples. To compare the bacterial concentrations of faecal to mucosal samples, the CFU were expressed as log CFU per mg protein.

\section{Identification of lactobacilli}

From each LAMVAB agar plate four colonies from the outer ring with the appearance of lactobacilli were isolated and purified on blood agar plates. Isolates were frozen at $-80^{\circ} \mathrm{C}$ for molecular identification of $L$. plantarum $299 \mathrm{~V}$ using randomly amplified polymorphic DNA (RAPD), eventually confirmed with restriction enzyme analysis (REA) according to the method described by Johansson et al. ${ }^{21,22}$.

\section{Bacterial enzyme activities}

The B-glucosidase and B-glucuronidase activities were analysed aerobically. Homogenised faecal samples were diluted (1:1) in $0.1 \mathrm{M} \mathrm{PBS}\left(\mathrm{pH} 6.8,5-7^{\circ} \mathrm{C}\right)$, sonicated for one minute on ice and subsequently centrifuged at $3000 \mathrm{rpm}$ during 15 minutes at $4^{\circ} \mathrm{C}$. The supernatant was dried under vacuum during 75 minutes (Savant speedvac plus Sc 210A) and was used for the assessment of the $\beta$-glucosidase and $\beta$-glucuronidase activities as described previously ${ }^{4}$.

\section{Statistical analyses}

Statistical evaluation of changes within groups was carried out using the nonparametric Wilcoxon signed-rank test. The Mann-Whitney U-test was used for comparison between probiotic and placebo group. The Chi-square test was used to compare prevalence of bacteria countable in biopsy samples between probiotic and placebo group and between rectum and ascending coion biopsies. A p-value below 0.05 was considered to be statistically significant.

\section{Results}

Twenty-nine patients completed the study: 15 in the probiotic group (10 male and 5 female, mean age $57.5 \pm 10.9$ years) and 14 in the placebo group (6 male and 8 female, mean age $56.3 \pm 10.2$ years). One participant did not start with the study because of personal reasons and was excluded. After colonoscopy, 13 patients had been diagnosed with bowel abnormalities such as polyps (6 probiotic, 4 placebo), diverticula (2 probiotic) and an irritated mucosa characterised by red spots (1 placebo). Based on the questionnaires, the compliance to the consumption of the drinks was $98 \%$ in the probiotic and $99 \%$ in the placebo group. No side effects were reported during consumption of either the probiotic or placebo drinks. No significant differences in defaecation frequency or faeces consistency scores could be observed between probiotic 
and placebo group before and after consumption or within groups over time (table 5.1).

Table 5.1 Defaecation frequency per day and faeces consistency scores (scale 1: hard lumps to 7: watery diarrhoea) before and after the consumption of the probiotic or placebo drink (median and range).

\begin{tabular}{lcccc}
\hline & \multicolumn{2}{c}{ Probiotic } & \multicolumn{2}{c}{ Placebo } \\
& before & after & before & After \\
\hline Frequency & $1.0(1-4)$ & $1.0(0-5)$ & $1.5(0-5)$ & $2.0(0-6)$ \\
Consistency & $4.0(2-6)$ & $5.0(3-7)$ & $4.5(1-6)$ & $4.5(1-6)$ \\
\hline
\end{tabular}

\section{Effects of L. plantarum 299v on the lactobacilli}

Before start of the study, L. plantarum $299 \mathrm{v}$ could be identified in faecal samples of two persons from the placebo group but in none from the probiotic group. After the consumption of the probiotic drinks, a significant increase in the faecal concentration of lactic acid bacteria $(p=0.009)$ and lactobacilli $(p=0.002)$ were observed (table 5.2) reaching levels of log $7.1 \mathrm{CFU} / \mathrm{g}$ faeces. Moreover, $L$. plantarum $299 \mathrm{v}$ could be identified in faecal samples of 10 out of the 11 probiotic-treated persons, in whom lactobacilli were isolated, while $L$. plantarum $299 \mathrm{v}$ could not be identified anymore in the placebo-treated persons. The person, in whom L. plantarum 299v was not isolated after probiotic consumption, did not demonstrate an increase in the faecal concentration of lactobacilli either.

Furthermore, lactobacilli could be cultured in three rectal biopsies and in two ascending colon biopsies of three probiotic-treated persons, but in none of the placebo group. Of these lactobacilli, L. plantarum $299 \mathrm{v}$ was identified in the rectal biopsies of two probiotic-treated patients but not in the ascending collon biopsies of these patients.

\section{Effects of L. plantarum 299v on the bacterial composition}

In addition to the lactobacilli increase, the concentration of clostridia increased significantly $(p=0.0048$ ) in faecal samples in the probiotic but not in the placebo group. No other changes in the bacterial concentrations of the faecal samples were observed after either probiotic or placebo consumption. Percentages of faecal samples in which pre-defined bacteria could be counted, were high and ranged from $79 \%$ to $100 \%$ (figure 5.1 ). Intake of L. plantarum $299 \mathrm{v}$ did not influence faecal B-glucosidase and B-glucuronidase activities significantly (table 5.3). 
Table 5.2 Concentrations of bacteria (log CFU/gram faeces), before and after the consumption of the probiotic or placebo drink (mean \pm SEM).

\begin{tabular}{|c|c|c|}
\hline & Before & After \\
\hline \multicolumn{3}{|c|}{ Total aerobic flora } \\
\hline Probiotic & $6.7 \pm 0.3$ & $7.1 \pm 0.2$ \\
\hline Placebo & $6.7 \pm 0.1$ & $6.7 \pm 0.2$ \\
\hline \multicolumn{3}{|l|}{ E.coli } \\
\hline Probiotic & $6.0 \pm 0.3$ & $6.6 \pm 0.3$ \\
\hline Placebo & $5.9 \pm 0.3$ & $6.2 \pm 0.2$ \\
\hline \multicolumn{3}{|l|}{ Enterococci } \\
\hline Probiotic & $4.4 \pm 0.4$ & $4.0 \pm 0.5$ \\
\hline Placebo & $4.0 \pm 0.3$ & $3.7 \pm 0.5$ \\
\hline \multicolumn{3}{|c|}{ Total anaerobic flora } \\
\hline Probiotic & $8.6 \pm 0.3$ & $8.3 \pm 0.4$ \\
\hline Placebo & $8.1 \pm 0.3$ & $8.3 \pm 0.3$ \\
\hline \multicolumn{3}{|c|}{ Bacteroides spp. } \\
\hline Probiotic & $6.1 \pm 0.3$ & $5.7 \pm 0.4$ \\
\hline Placebo & $6.5 \pm 0.2$ & $6.2 \pm 0.3$ \\
\hline \multicolumn{3}{|l|}{ Clastridia } \\
\hline Probiotic & $4.3 \pm 0.2$ & $4.7 \pm 0.2^{a}$ \\
\hline Placebo & $3.9 \pm 0.3$ & $4.3 \pm 0.2$ \\
\hline \multicolumn{3}{|c|}{ Lactic acid bacteria } \\
\hline Probiatic & $5.7 \pm 0.4$ & $7.1 \pm 0.4^{\text {a1 }}$ \\
\hline Placebo & $5.2 \pm 0.4$ & $5.4 \pm 0.3$ \\
\hline \multicolumn{3}{|l|}{ Lactobacill: } \\
\hline Probiotic & $5.0 \pm 0.4$ & $7.1 \pm 0.3^{a}$ \\
\hline Placebo & $4.8 \pm 0.2$ & $4.3 \pm 0.3$ \\
\hline
\end{tabular}

${ }^{\circ}$ statistically significant difference $(p<0.05)$ before and after probiotic intake.

In biopsy samples, enterococci, clostridia, lactic acid bacteria and lactobacilli were cultured in relatively few biopsies $(0-31 \%)$ (figure 5.1$)$. Percentages of biopsy samples in which bacteria were cultured, did not differ significantly between probiotic and placebo group. The mean concentrations of mucosal bacteria, calculated of the bacterial subspecies present in at least five biopsy samples, are expressed in table 5.4. A significant increase $(p=0.019)$ in total anaerobic bacteria in rectal biopsy samples between probiotic and placebo group were found after consumption of the drinks. No other significant differences were observed in bacterial concentrations between probiotic and placebo group. 


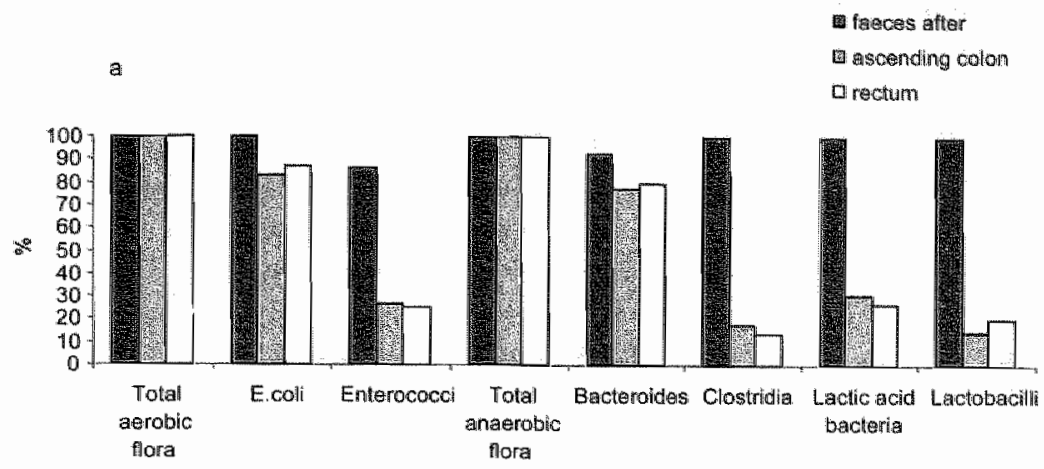

b

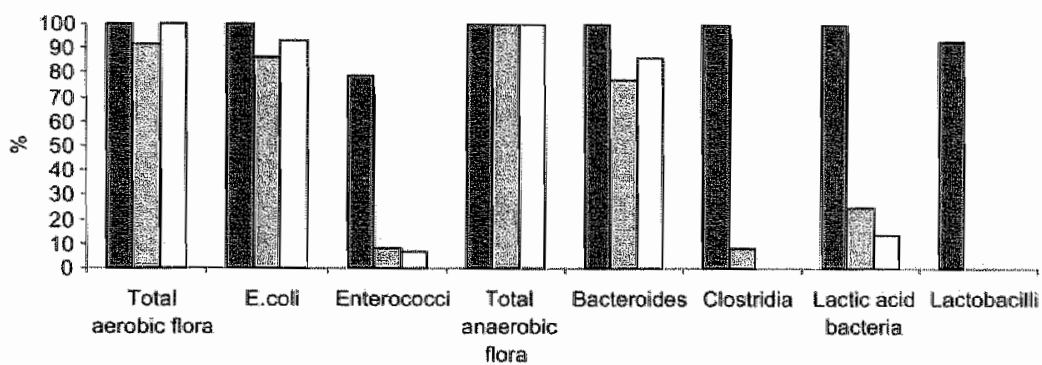

Figure 5.1 Prevalence of bacteria culturable in faecal samples and rectum and ascending colon samples in the probiotic $(n=15)$ (a) and placebo $(n=14)(b)$ group.

Table 5.3 B-glucosidase (mg/60 min/g faeces) and B-glucuronidase (mg/30 min/g faeces) activities before andi after probiotic or placebo consumption (mean \pm SEM).

\begin{tabular}{lcccc}
\hline & \multicolumn{2}{c}{ Probiotic } & \multicolumn{2}{c}{ Placebo } \\
& before & after & before & after \\
\hline B-glucosidase & $1.23 \pm 0.29$ & $0.99 \pm 0.16$ & $1.06 \pm 0.27$ & $1.23 \pm 0.25$ \\
B-glucuronidase & $0.86 \pm 0.38$ & $0.87 \pm 0.34$ & $0.87 \pm 0.22$ & $0.96 \pm 0.30$ \\
\hline
\end{tabular}


Table 5.4. Concentrations of bacteria (log CFU/biopsy) in rectum and ascending colon biopsies after probiotic and placebo consumption (mean \pm SEM).

\begin{tabular}{|c|c|c|}
\hline & Rectum & Ascending colon \\
\hline \multicolumn{3}{|c|}{ Total aerobic flora } \\
\hline Probiotic & $3.9 \pm 0.3$ & $3.9 \pm 0.3$ \\
\hline Placebo & $3.7 \pm 0.3$ & $3.6 \pm 0.3$ \\
\hline \multicolumn{3}{|l|}{ E. coli } \\
\hline Probiotic & $3.8 \pm 0.3$ & $3.9 \pm 0.4$ \\
\hline Placebo & $3.4 \pm 0.3$ & $4.0 \pm 0.3$ \\
\hline \multicolumn{3}{|c|}{ Total anaerobic flora } \\
\hline Problotic & $4.5 \pm 0.3^{3}$ & $4.3 \pm 0.3$ \\
\hline Placebo & $3.3 \pm 0.3^{\mathrm{m}}$ & $3.9 \pm 0.3$ \\
\hline \multicolumn{3}{|c|}{ Bacteroides spp. } \\
\hline Problotic & $2.6 \pm 0.3$ & $3.4 \pm 0.4$ \\
\hline Placebo & $3.0 \pm 0.3$ & $3.4 \pm 0.3$ \\
\hline
\end{tabular}

statistically significant difference $(p<0.05)$ between probiotic and placebo group.

\section{Comparisons of the prevalence and the bacterial concentrations}

Comparing rectum to ascending colon biopsies, prevalence and concentrations of mucosal bacteria did not differ significantly.

Comparing the prevalence of bacteria of the faecal samples to that of the rectum and the ascending colon biopsies, demonstrated that the prevalence of enterococci, clostridia, lactic acid bacteria and lactobacilli was significantly lower in the rectal as well as the ascending colon biopsies compared to that in faecal samples collected from both probiotic and placebo-treated patients.

\section{Discussion}

To our knowledge, this is the first study investigating the effects of the probiotic L. plantarum $299 \mathrm{v}$ on both the faecal and mucosal bacterial composition in order to gain further insight in the possible modes of action of probiotics. Moreover, the bacterial composition of faecal versus mucosal samples and of rectum versus ascending colon biopsy samples has been compared.

\section{Effects of L. plantarum 299v on the lactobacilli}

After L. plantarum $299 \mathrm{v}$ consumption, the faecal concentration of lactic acid bacteria and lactobacilli increased significantly and L. plantarum $299 \mathrm{v}$ could be recovered in faecal samples in the majority of persons from the probiotictreated group, indicating that the probiotic strain survives passage through the gastrointestinal tract. In mucosal samples, L. plantarum $299 \mathrm{v}$ was also detected but to a minor degree. Although an in vitro and animal study demonstrated that L. plantarum $299 \mathrm{~V}$ can adhere to epithelial cells by mannose-specific binding sites competing with $E$. coli ${ }^{7}$, the present study did not support an extensive colonisation of $L$. plantarum $299 \mathrm{v}$ in the mucosa. In 
contrast, in a study performed in Sweden, L. plantarum $299 \mathrm{v}$ could be recovered from jejunum and rectum biopsies in 11 of the 13 participants, even 11 days after cessation of a 10 days treatment period ${ }^{11}$. Differences in the colonisation of $L$. plantarum $299 \mathrm{v}$ between the Swedish and the present study might be due to differences in bowel cleansing or biopsy handling but also due to host factors (mucus composition, intake of nutrients), which could be different in the two populations. Interestingly, the probiotic strain L. plantarum $299 \mathrm{v}$ used in the studies has been isolated from Swedish persons and it is possible that the Swedish population is more susceptible for colonisation of this strain. Because of these inconsistencies in the colonisation results, the mucosal adherence of $L$. plantarum $299 \mathrm{v}$ needs further study.

Moreover, the increase in the concentration of faecal lactobacilli is $1 \log$ CFU/g faeces smaller compared to previous studies with healthy volunteers, although the same daily dose $\left(10^{11} \mathrm{CFU} /\right.$ day $)$ has been administered ${ }^{4,23}$. This difference cannot be explained by the inclusion of patients, of whom 13 patients have been diagnosed with abnormalities during the colonoscopy, as comparison of the faecal bacterial concentrations between patients with or without abnormality did not show any significant difference (data not shown). In addition, no significant difference in the defaecation frequency and faeces consistency scores could be seen comparing the patients to the healthy volunteers (data not shown). The smaller increase in lactobacilli after L. plantarum $299 \mathrm{v}$ intake might also be due to differences in age as the participants in the present study were older (mean age: $\mathbf{5 6 . 9}$ years) compared to the healthy volunteers (mean

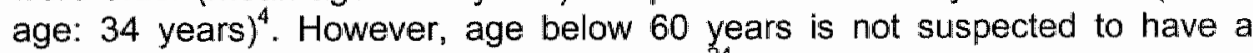
major influence on the bacterial composition ${ }^{24}$.

\section{Effects of L. plantarum 299v on the bacterial composition}

Probiotic intake led to an increase in the faecal concentration of clostridia. This increase could be beneficial if non-pathogenic clostridia subspecies increased, dominating potentially pathogenic clostridia subspecies. However, previous studies including healthy volunteers did not demonstrate changes in the concentration of clostridia after $L$. plantarum $299 \mathrm{v}$ intake, while a significant decrease in sulphate-reducing clostridia has been shown in one Swedish study including healthy volunteers ${ }^{3,4,23}$. A recent study by Langlands et al. observed changes in the composition of clostridia subspecies after prebiotic intake. However, no changes in the concentration were noticed ${ }^{12}$. Further insight is warranted in the effect of $L$. plantarum $299 \mathrm{v}$ on clostridia subspecies.

In the present study, L. plantarum $299 \mathrm{v}$ intake did alter the mucosal bacterial concentrations to a minor extent as the concentration of total anaerobic bacteria in the rectal biopsies increased compared to the placebo group. Unfortunately, no pre-treatment data were available due to ethical problems. In a previous study, no increase in the mucosal concentration of total anaerobic bacteria was shown after 10 days consumption of $L$. plantarum $299 \mathrm{v}^{11}$. In future intervention trials, biopsies should be collected before as well as after probiotic 
intake to get more insight in the possible changes of mucosal bacterial concentrations.

\section{Comparisons of the prevalence and the bacterial concentrations}

The prevalences and the bacterial concentrations detected in the biopsies from ascending colon and rectum were comparable. This indicates that in future studies culturing of rectal biopsy samples will be sufficient to study the probiotic effects on the intestinal mucosal flora. Although the mucosal concentrations found in the present study are difficult to compare to previously described concentrations, as they were expressed in different units (CFU/biopsy, per gram, or per $\mu$ l biopsy dilution), the mucosal bacterial concentrations and prevalence found in the present study seemed to be low compared to previous studies $^{9,12.15}$. This might be due to the bowel cleansing procedure prior to colonoscopy, to differences in handling of the biopsies and/or the use of different culture media. However, the effect of bowel cleansing is expected to be limited as in a previous study performed by our group, bowel cleansing did not significantly affect the intestinal flora of faecal samples. Moreover, Schultsz et al. demonstrated that bacterial concentrations in rectal biopsies did not differ after bowel cleansing compared to preparation by an enema ${ }^{18}$. Comparing the effects of different bowel cleansing procedures on the faecal and mucosal flora will be interesting but is hampered as not all the previous studies described the procedure precisely ${ }^{45,17,18}$.

Moreover, in the present study gently washing of the biopsies was performed to remove contaminating flora and to study the adherent mucosal flora. Previous studies showed that washing of the biopsies did not systematically result in lower bacterial concentrations and prevalence ${ }^{11,15-17}$.

Mucosal concentrations might be difficult to interpret, as the localisation of mucosal bacteria is still controversial. On the one hand, bacteria are shown to be present in the epithelial cells, without having contact with the faecal stream $^{17}$. On the other hand, bacteria have been abserved within or at the luminal side of the mucus layer ${ }^{18,25}$. In such a situation, washing and handling of the biopsies may have a major impact on the bacterial culture results.

The prevalence of bacteria found in biopsies was lower compared to those of the faecal samples, indicating that both types of samples need to be collected in studying potential effects of intervention (drug, nutrition) on the intestinal flora. Unfortunately, comparison of the bacterial concentrations of biopsies versus faecal samples was not possible, as the biopsies could not be weighed under strictly anaerobic conditions without disturbing the mucus layer. However, based on data from previous studies, the biopsy weight is expected to be around $10 \mathrm{mg}^{15}$. If the mucosal concentrations would be expressed based on such weight, lower mucosal concentrations would be calculated compared to the faecal concentrations. This will be in accordance with results from previous studies ${ }^{26-28}$. 
The bacterial concentrations described in the present study were based on culture results. However, more than $50 \%$ of the bacteria in the gastrointestinal tract cannot be cultured or are not yet identified ${ }^{5.29 .30}$. Polymerase chain reaction (PCR) in combination with DGGE will be an additive tool to compare the faecal and mucosal bacterial composition by producing molecular 'bacterial fingerprints" of the individual dominant flora ${ }^{31,32}$. Based on DGGE results, Zoetendal et al. have shown that the bacterial composition found in biopsy samples collected from different locations in the colon was comparable, but significantly different from the bacterial composition found in faecal samples. This is in line with the results found in the present study ${ }^{9}$.

In conclusion, the present study demonstrated that the probiotic $L$. plantarum $299 \mathrm{v}$ survives passage through the gastrointestinal tract. Moreover, the probiotic strain colonised the colonic mucosa to a minor extent. No changes in prevalence and bacterial concentrations between rectum and ascending colon were observed, which suggests that analysis of rectal biopsies might be sufficient in future studies. Prevalence of bacteria in the biopsy samples was lower compared to that of faecal samples, indicating that collection of both samples is necessary to investigate the effects of probiotics on the bacterial composition of the large bowel. Investigating factors that influence the adherence of bacteria to the mucosa might be interesting in view of the mechanisms that modulate intestinal bacteria in health and disease. 


\section{References}

1. Havenaar R, Ten Brink B, Huis in 't Velld J. Selection of strains for probiotic use. In: Chapmann and Hall, ed. Probiotics, The scientific basis. London; 1992:209-224.

2. Goossens $D$, Jonkers $D$, Stobberingh $E$, van den Bogaard $A$, Russel $M$, Stockbrugger $R$. Probiotics in gastroenterology indications and future perspectives. Scand I Gastroenteroll Suppl 2003;239:15-23.

3. Johansson $M$, Nobaek $S$, Berggren $A$, et al. Survival of Lactobacillus plantarum DSM 9843 (299v), and effect on the short-chain fatty acid content of faeces after ingestion of a rose-hip drink with fermented oats. Int $J$ Food Microbioll 1998;42: 29-38.

4. Goossens D, Jonkers D, Russel $M$, Stobberingh $E$, Van Den Bogaard A, Stockbrugger $R$. The effect of Lactobacillus plantarum $299 \mathrm{v}$ on the bacterial composition and metabolic activity in faeces of healthy volunteers: a placebocontrolled studly on the onset and duration of effects. Aliment Pharmacol Ther 2003; 18:495-505.

5. Tannock G, Munro K, Harmsen $H$, Welling G, Smart $J$, Gopal P. Analysis of the fecal microflora of human subjects consuming a probiotic product containing Lactobacillus rhamnosus DR20. Appl Environ Microbiol 2000;66:2578-88.

6. Spanhaak S. Havenaar R, Schaafsma G. The effect of consumption of milk fermented by Lactobacillus casei strain Shirota on the intestinal microflora and immune parameters in humans. Eur $\mathrm{J}$ Clin Nutr 1998;52:899-907.

7. Adlerberth $I$, Ahrne $S$, Johansson $M$, Molin $G$, Hanson $L$, Wold A. A mannosespecific adherence mechanism in Lactobacillus plantarum conferring binding to the human colonic cell line HT-29. Appl Environ Microbiol 1996;62:2244-51.

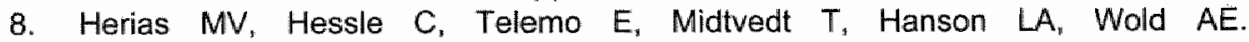
Immunomodulatory effects of Lactobacillus plantarum colonizing the intestine of gnolobiotic rats. Clin Exp Immunol 1999;116:283-90.

9. Zoetendal EG, von Wright $A$, Vilpponen-Salmela $T$, Ben-Amor $K$, Akikermans AD, de Vos WM. Mucosa-associated bacteria in the human gastrointestinal tract are uniformly distributed along the colon and differ from the community recovered from feces. Appl Environ Microbiol 2002;68:3401-7.

10. Alander $M_{3}$ Korpela $R$, Saxelin $M$, Vilpponen-Salmela $T$, Mattila-Sandholm $T$, von Wright A. Recovery of Lactobacillus rhamnosus GG from human colonic biopsies. Lett Appl Microbiol 1997;24:361-4.

11. Johansson $M_{*}$ Molin $G$, Jeppsson $B$, Nobaek $S$, Ahrne $S$, Bengmark $S$. Administration of different Lactobacillus strains in fermented oatmeal soup: in vivo colonization of human intestinal mucosa and effect on the indigenous flora. Appl Environ Microbiol 1993;59:15-20.

12. Langlands $S J$, Hopkins $M J$, Coleman $N$, Cummings $\mathrm{JH}$. Prebiotic carbohydrates modify the mucosa associated microflora of the human large bowel. Gut 2004; $53: 1610-6$.

13. Macfarlane GT, Gibson GR, Cummings JH. Comparison of fermentation reactions in different regions of the human colon. J Appl Bacteriol 1992;72:57-64.

14. Nielsen DS, Moller PL, Rosenfeldt V. Paerregaard A, Michaelsen KF, Jakobsen M. Case study of the distribution of mucosa-assaciated Bifidobacterium species, Lactobacillus species, and other lactic acid bacteria in the human colon. Appl Environ Microbiol 2003;69:7545-8.

15. Poxton $\| R$, Brown $R$, Sawyerr A, Ferguson A. Mucosa-associated bacterial flora of the human colon. J Med Microbiol 1997;46:85-91. 
16. Ott $S$, Musfeldt $M$, Wenderoth $D$, et al. Reduction in diversity of the colonic mucosa associated bacteriall microflora in patients with active inflammatory bowel disease. Gut 2004;53:685-93.

17. Swidsinski $A$, Ladhoff $A$, Pernthaller $A$, et al. Mucosal flora in inflammatory bowel disease. Gastroenterology 2002;122;44-54.

18. Schultsz C, Van Den Berg FM, Ten Kate FW. Tytgat GN, Dankert J. The intestinal mucus layer from patients with inflammatory bowel disease harbors high numbers of bacteria compared with controls. Gastroenterology 1999;117:1089-97.

19. O'Donnell $L$, Virjee J, Heaton $K$. Detection of pseudodiarrhoea by simple clinical assessment of intestinal transit rate. BMJ 1990;300:439-40.

20. Hartemink $R$, Domenech VR, Rombouts FM. LAMVAB-a new selective medium for the isolation of lactobacilli from faeces. J Microbiol Meth 1997;29:77-84.

21. Johansson M, Quednau M, Molin G. Ahrne S. Randomly amplified polymorphic DNA (RAPD) for rapid typing of Lactobacillus plantarum strains. Lett Appl Microbiol 1995;21:155-9.

22. Johansson $M$, Quednau $M$, Ahrne $S$, Molin $G$. Classification of Lactobacillus plantarum by restriction endonuclease analysis of total chromosomal DNA using conventionall agarose gel electrophoresis. Int J Syst Bacteriol 1995;45:670-5.

23. Goossens D, Jonkers D, Russel $M$, et al. Survival of the probiotic, L. plantarum $299 \mathrm{v}$ and its effects on the faecal bacterial flora, with and without gastric acid inhibition. Dig Liver Dis 2005;37:44-50.

24. Mitsuoka T. Intestinal flora and aging. Nutr Rev 1992;50:438-46.

25. Waaij van der $L$, Harmsen $H$, Madjipour $M$, et al. Bacterial population analysis of human colon and terminal ileum biopsies with $16 \mathrm{~S}$ rRNA-based fluorescent probes: commensal bacteria live in suspension and have no direct contact with epithelial cellis. Inflamm Bowel Dis 2005;11:865-71.

26. Linskens RK, Huijsdens XW, Savelkoul PH, Vandenbroucke-Grauls CM, Meuwissen SG. The bacterial flora in inflammatory bowel disease: current insights in pathogenesis and the influence of antibiotics and probiotics. Scand $J$ Gastroenterol Suppl 2001;234:29-40.

27. Hudson M, Hill M, Elliott $P$, Berghouse L, Burnham W, Lennard-Jones J. The microbial flora of the rectal mucosa and faeces of patients with Crohn's disease before and during antimicrobial chemotherapy. J Med Microbiol 1984;18:335-45.

28. Marteau P, Pochart P, Dore J, Bera-Maillet $C_{\text {" Bernalier A }}$ Corthier $G$. Comparative study of bacterial groups within the human cecal and fecal microbiota. Appl Environ Microbiol 2001;67:4939-42.

29. Zoetendal $E G$, Akkermans $A D$, de Vos WM. Temperature gradient gel electrophoresis analysis of 16S rRNA from human fecal samples reveals stable and host-specific communities of active bacteria. Appl Environ Microbiol 1998;64:3854-9.

30. Suau $A$, Bonnet $R$, Sutren $M$, et al. Direct analysis of genes encoding $16 S$ rRNA from complex communities reveals many novel molecular species within the human gut. Appl Environ Microbiol 1999;65:4799-807.

31. Muyzer $G$, de Waal EC, Uitterlinden AG. Profiling of complex microbial populations by denaturing gradient gel electrophoresis analysis of polymerase chain reactionamplified genes coding for 16S rRNA. Appl Environ Microbiol 1993;59:695-700.

32. Muyzer G, Smalla K. Application of denaturing gradient gel electrophoresis (DGGE) and temperature gradient gel electrophoresis (TGGE) in microbial ecology. Antonie Van Leeuwenhoek 1998;73:127-41. 


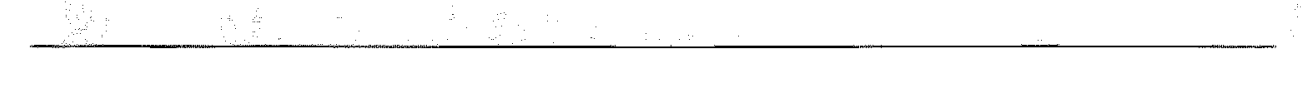

98 


\section{Chapter 6}

The faecal and mucosal bacterial composition of patients with inactive UC: can it be changed by L. plantarum 299v?

D. Goossens, D. Jonkers, E. Stobberingh, G. Molin, S. Ahrné, M. Russel, R. Stockbrügger 


\section{Abstract}

\section{Introduction}

The intestinal flora of patients with ulcerative colitis (UC) is considered to be different from that of healthy persons. Moreover, beneficial effects of probiatics have been found in UC. In this study, the faecal bacterial composition of inactive UC patients was compared to that of healthy controls, and the effects of the probiotic $L$. plantanum $299 \mathrm{v}$ on the faecal and mucosal bacterial composition and faecal metabolites were examined.

\section{Methods}

Bacteriological culture results of faecal samples of thirty-one inactive UC patients on a stable dose of maintenance therapy were compared to those of 20 healthy controls. In a randomised placebocontrolled study design, patients consumed a dirink with or without L. plantarum $299 \mathrm{v}$ $\left(10^{11} \mathrm{CFU} / d a y\right)$ during four weeks. Faecal samples were collected before and after consumption. In a subgroup of patients, rectal biopsies were collected after consumption. Concentrations and prevalence of faecal and mucosal bacteria as well as faecal enzyme activities, short chain fatty acids (SCFA) and endotoxin concentrations were analysed. Moreover, temporal temperature gel electrophoresis (ITGE) was performed to compare the molecular 'fingerprints' of the dominant bacteria present in rectal biopsies of the probiatic versus the placeboutreated UC patients.

\section{Results}

Faecal bacterial concentrations (log CFU per mg protein) were lower in UC patients than in healthy controls, being significant for total anaerobic bacteria $(7.6 \pm 0.1$ vs. $8.2 \pm 0.1)$. Bacteroides spp. $(5.1 \pm 0.3$ vs. $6.6 \pm 0.2)$ and lactic acid bacteria (2.6 0.3 vs. $5.5 \pm 0.5)$. However, the prevalence of faecal bacteria was comparable in UC patients and healthy controls except for $E$. coli (70 vs. $95 \%$. $\mathrm{p}<0.05 \%$

L. plantarum $299 \mathrm{v}$ intake resulted in a significant increase in the faecal concentration of lactobacilli and lactic acid bacteria and in a reduction of the mucosal prevalence of Bacteroides spp. However, L. plantarum $299 \mathrm{w}$ intake did not influence significantly other faecal and mucosal bacterial concentrations and mucosal bacterial 'fingerprints' nor the enzyme activities, SCFA and endotoxin concentrations.

\section{Conclusions}

Comparing UC patients to healthy controls, differences in faecal bacterial composition were observed, which could be a consequence of either the disease and/or its treatment. As intake of L. plantarum $299 \mathrm{v}$ did only partly change the bacterial composition, more studies are warranted to investigate other modes of action of probiotics such as modulation of the immune system. 


\section{Introduction}

Ulcerative colitis (UC) is a chronic inflammatory disease of the colon and/or rectum and belongs to the group of inflammatory bowel diseases (IBD). Although the aetiology of UC is still unknown, genetic, microbiological, immunological and environmental factors are thought to be involved in the pathogenesis ${ }^{1}$. It is hypothesised that UC is the result of an exaggerated intestinal host response against commensal intestinal bacteria or their components $^{2}$. Experimental animal models demonstrated that intestinal bacteria trigger chronic intestinal inflammation as the presence of these bacteria is required for the development of spontaneous colitis in $\mathrm{IL}-10$ deficient mice and in rats transgenic for the human HLA-B27 gene ${ }^{3-5}$. Furthermore, a role of intestinal bacteria in influencing colitis has been confirmed in several clinical observations: inflamed sites of the colon in UC patients comprise the highest number of bacteria, and antibiotic treatment results in decreased disease activity in acute UC patients ${ }^{6-9}$.

Some studies suggested that the intestinal bacterial composition of active and inactive UC patients might be different from that of healthy controls. Both an increase and a decrease in anaerobic bacterial counts (Bacteroides spp., lactobacilli, clostridia, eubacteria and bifidobacteria) and aerobic bacterial counts (enterobacteriaceae) have been described in faecal and mucosal samples of active UC patients compared to inactive patients and to healthy controls $^{10-15}$. In contrast, Giaffer et al. did not demonstrate a difference in the concentration of faecal anaerobic bacteria comparing active to inactive UC patients ${ }^{16}$. Studies investigating the bacterial composition of UC patients differ in their design. Some studies compared the bacterial composition to controls, while others did not ${ }^{11,12}$. These controls were healthy volunteers ${ }^{10,16}$ or non-IBD patients ${ }^{13-15}$. Several studies did not register disease activity ${ }^{14,15}$ or the use of the medication ${ }^{12,14,15}$ including antibiotics ${ }^{10,11}$. Moreover, other studies did not investigate the bacterial composition quantitatively ${ }^{12-15}$.

The concentrations of some intestinal bacteria, such as Bacteroides spp. and enterobacteriaceae, as well as some bacterial components such as lipopolysaccharides (LPS) were higher in the mucosa of UC patients compared to healthy controls ${ }^{14,17}$. These bacteria and bacterial products can translocate through the mucosa as the permeability of the mucosa in UC patients was found to be increased ${ }^{7.18}$. This higher mucosal permeability may be related to a deficient butyrate oxidation ${ }^{19-21}$ and a reduced mucus production ${ }^{22-24}$ caused by increased bacterial enzyme activities (glucosidases and sulphatases) ${ }^{25,26}$. Metabolic products such as bacterial enzymes, short chain fatty acids (SCFA) and LPS concentrations appear to be useful indicators to study changes in the bacterial composition in UC patients but are still not investigated in studies comparing the bacterial composition of UC patients to that of healthy controls. 
Probiotics are defined as "mono or mixed cultures of live micro-organisms which, when applied to animal or man, beneficially affect the host by improving the properties of the indigenous flora" ${ }^{m}$. As the intestinal flora is suspected to play an important role in the pathogenesis of $U C$, changing this flora by probiotics may have a beneficial therapeutic effect. Three clinical studies have investigated the effect of the probiotic Escherichia coli strain Nissle 1917 versus mesalazine in UC patients with inactive disease and found a similar relapse rate in the treatment groups suggesting that probictics could be an alternative maintenance therapy $y^{20-30}$ "In an uncontrolled study, a multispecies probiotic preparation (VSL\#3) was also found to have potential as maintenance therapy ${ }^{31}$. However, most probiotic studies only focused on clinical outcome without investigating the possible modes of action of these probiotics or suffered from methodological limitations such as low numbers of patients included, a heterogeneous population included and the lack of a randomised placebo-controlled design.

The monospecies probiotic Lactobacillus plantarum $299 \mathrm{v}$ has been found to reduce colitis in rats and IL-10 deficient mice ${ }^{32-35}$. In addition, several studies have shown that $L$. plantarum $299 \mathrm{v}$ survived passage through the gastrointestinal tract and can adhere to mucosal cells $\mathrm{s}^{32,36-38}$. Consequently, this bacterium is a good candidate to study the effects of a probiotic on the intestinal bacterial composition and the metabolic activity of UC patients.

In this study, the faecal bacterial composition of inactive UC patients was compared to that of healthy controls, and in these UC patients the effect of the probiotic $L$. plantarum $299 \mathrm{v}$ on the intestinal bacterial composition in faecal and in mucosal samples as well as on faecal metabolites was investigated by a placebo-controlled double-blind design.

\section{Methods}

\section{Subjects}

Thirty-one UC patients of the South Limburg IBD registry ${ }^{39}$ were asked to participate in the study. Patients had a well-defined diagnosis of UC established by endoscopic, radiologic and/or histologic criteria and had inactive disease confirmed by a Clinical Activity Index (CAI) below $10^{40}$. Patients known with other pre-existing bowel diseases including irritable bowel syndrome, diverticullar disease, cancer and bowel resection were excluded. Only patients receiving mesalazine or sulfasalazine with or without azathioprine as maintenance therapy were included in the study. The selected patients used this medication for at least 8 weeks prior to inclusion and were on a stable dose for at least 4 weeks prior to inclusion and remained so during the study period. The use of enemas, gastric acid inhibition, laxantia or antibiotics was not allowed during the 4 weeks before inclusion as well as during the study while 
the consumption of prebiotics and probiotics was not allowed for at least 2 weeks before inclusion as well as during the study period. The study was approved by the Medical Ethics Committee of the University Hospital Maastricht and was performed in accordance with the Declaration of Helsinki. All participants had given written informed consent.

\section{Comparison of UC patients and healthy volunteers}

Culture results of the faecal samples of the UC patients before start of probiotic or placebo consumption were compared to the results of a previously performed study in which 20 healthy volunteers were enrolled and in which the handling of the faecal samples and bacteriological culture methods used were simillar ${ }^{41}$.

\section{Study design}

The study was randomised, placebo-controlled and double-blind with a fourweek treatment period. During the treatment period, participants consumed 200 $\mathrm{ml}(100 \mathrm{ml}$ in the morning and $100 \mathrm{ml}$ in the evening) of an oatmeal fermented drink without (placebo) or with (probiotic) L. plantarum 299v $\left(10^{9} \mathrm{CFU} / \mathrm{ml}\right)$. The two types of drinks were indistinguishable in colour, smell and taste.

Two faecal samples were collected: one before start of treatment and one on the last day of the treatment period. At each time of faeces collection, the patients also completed questionnaires regarding the use of medication, disease activity, side effects, compliance with regard to the consumption of the drinks, and bowel habits (defaecation frequency and faeces consistency score according to the Bristol $\mathrm{scale}^{42}$ ). All patients were asked to undergo a protoscopy at the end of the treatment period in order to collect two rectal biopsies. A subgroup of patients $(n=13)$ agreed to undergo the proctoscopy. Patients were excluded from the analyses if the drinks were consumed for less than 6 days per week based on the information of the questionnaire. Patients were asked to continue their usual dietary habits during the study period.

\section{Microbiological analyses}

Faecal samples ( \pm 20 gram) were collected in a sterile container, brought to the laboratory within 12 hours after defaecation, and were divided into three parts. Five grams were diluted (1:4) in $20 \mathrm{ml}$ peptone water with cysteine $(2.1 \mathrm{mM})$ and glycerol $(37 \%)$ and homogenised with an ultra-turrax (IKA®), Sigma-Aldrich Chemie B.V., Zwijndrecht, The Netherlands) for 1 minute. Half a $\mathrm{ml}$ was used immediately for bacteriological culture while the remaining part was frozen at $-20^{\circ} \mathrm{C}$ for the determination of $B$-glucosidase and $B$-glucuronidase activities and SCFA concentrations. Ten grams were centrifuged at $4^{\circ} \mathrm{C}$ for 2 hours at $25.000 \mathrm{~g}$ to obtain faecal water, which was frozen at $-80^{\circ} \mathrm{C}$ for determination of the endotoxin concentration. The remaining undiluted faeces was frozen at $-20^{\circ} \mathrm{C}$ for additional analyses. 
In a subgroup of patients, two rectal biopsy samples were collected during a proctoscopy. These patients had to take an enema (Klistier ${ }^{\circledR}$. Fresenius Kabi, Bad Homburg, Germany) to clean the rectum half an hour prior to the proctoscopy. Biopsy samples were taken with a sterile biopsy forceps. Biospy samples for culture were collected in $1 \mathrm{ml}$ sterile $0.8 \%$ saline with $0.1 \%$ cysteine- $\mathrm{HCl}$ and were processed immediately. Biopsy samples for temporal temperature gel electrophoresis (TTGE) analysis were collected in TE-buffer $(10 \mathrm{mM}$ Tris- $\mathrm{HCl}$ and $1 \mathrm{mM}$ EDTA at $\mathrm{pH} 8,0)$ and frozen immediately at $-80^{\circ} \mathrm{C}$ until further analysis.

\section{Culture}

Ten-fold serial dilutions of the faecal samples $\left(10^{-1}-10^{-6}\right)$ were made in physiological saline $(0.9 \%)$ and $40 \mu \mathrm{l}$ were inoculated using a spiral plater (Eddy Jet v1.2, IUL-instruments, Barcelona, Spain) on the following agar plates: Blood agar plates (Oxoid $\mathrm{CM} 271$, Basingstoke, UK) for total (facultative) aerobic bacteria, Eosin-methylene blue agar plates (Oxoid CM69, Basingstoke, UK) for enterobacteriaceae, KF-streptococcus agar plates (Oxoid CM701, Basingstoke. UK) for enterococci, Fastidious anaerobic agar plates (Lab M LabGo, Lancashire BI9, 6AU, UK) for total (facultative) anaerobic bacteria, Bile-esculine agar plates (Becton Dickinson 287920, La Pont de Claix, France) for Bacteroides spp., Egg Yolk agar plates for clostridia, Rogosa agar plates (Oxoid CM627, Basingstoke, UK) for lactic acid bacteria and LAMVAB (lactobacillus anaerobic MRS with vancomycin and bromocresol green) for lactobacilli ${ }^{43}$ according to the method described previously ${ }^{41}$.

Biopsy samples collected were washed three times in sterile $0.8 \%$ sodium chloride with cysteine- $\mathrm{HCl}(0.1 \%)$ and were homogenised in $0.5 \mathrm{ml} 0.8 \%$ sodium chloride with cysteine- $\mathrm{HCl}(0.1 \%)$ using a sterile tissue grinder $\left(10^{-1}\right)$ (No. 43950, ICN Flow Biomedicals NVSA, Asse-Relegem, Belgium). Forty $\mu$ l of this solution was further diluted $\left(10^{-2}\right)$ and $50 \mu$ of both biopsy dilutions $\left(10^{-1}\right.$ and $10^{-2}$ ) were inoculated on the agar plates described above using glass spatula.

Colony forming units (CFU) were counted and expressed as log CFU per mg protein (log CFU/mg protein) for the faecal samples or per biopsy sample (log CFU/biopsy).

\section{Protein analysis}

Homogenised faecal samples were diluted $(1: 99)$ in $0.1 \mathrm{M}$ PBS $\left(\mathrm{pH} 6.8,5-7^{\circ} \mathrm{C}\right)$ and added to BioRad Assay Protein Dye Reagent (1:1). After 30 minutes, the absorbance was read at $595 \mathrm{~nm}$. Concentrations of proteins were calculated from a standard curve for proteins ranging from 0 to $120 \mu \mathrm{g} / \mathrm{ml}$ and were expressed, after correction for dilution, as $\mathrm{mg}$ protein per gram faeces. 


\section{TTGE analysis}

Temporal temperature gel electrophoresis (TTGE) was performed to compare the molecular 'fingerprints' of the dominant bacteria present in rectal biopsies of the probiotic versus placebo-treated UC patients. After thawing on ice, the biopsies were centrifuged and resuspended in $10 \mu \mathrm{l}$ proteinase $\mathrm{K}$ and $190 \mu \mathrm{l}$ of buffer G2 (Qiagen, Hilden Germany). UV-treated glass beads were added to the biopsy samples and samples were heated at $56^{\circ} \mathrm{C}$ for 4 hours and subsequently shaken on a mixer for 30 minutes at $4^{\circ} \mathrm{C}$. Thereafter, DNA was extracted using the BioRobot EZI DNA isolation kit (Qiagen, Hilden, Germany) according to the instructions by the manufacturer.

The eluted DNA was used in PCR reactions amplifying the entire 16S rRNAgene using the primers ENV1 (5'-AGA GTT TGA TII TGG CTC AG-3') and ENV2 (5'-CGG ITA CCT TGT TAC GAC TT-3') ${ }^{44}$. These PCR-products were used as templates in the TTGE-PCR.

For TTGE-PCR amplification, 16S rDNA primers P5 (5"-gc AAC GCG AAG AAC CTT AC-3') (gc=gc-clamp according to Heuer et al. ${ }^{45}$ ) and P6 (5'-CGG TGT GTA CAA GGC CCG GGA ACG-3') flanking the variable V3, V4 and V5 regions were used ${ }^{46}$. The PCR-conditions and TTGE-electrophoresis were run as previously described by Monstein et $a l^{47}$. The TTGE-results were compared by band based analyses using Dice coefficient and UPGMA for clustering using the computer program BioNumerics (Applied Maths, Sint-Martens-Laten, Belgium). In order to see if there were any differences between probiotic and placebo group, the similarity of the patterns were calculated numerically.

\section{Bacterial enzyme activities}

The B-glucosidase and B-glucuronidlase activities were analysed aerobically. Homogenised faecal samples were diluted (1:1) in $0.1 \mathrm{M}$ PBS $\left(\mathrm{pH} 6.8,5-7^{\circ} \mathrm{C}\right)$, sonicated for 1 minute on ice and subsequently centrifuged at $3000 \mathrm{rpm}$ during 15 minutes at $4^{\circ} \mathrm{C}$. The supernatant was dried under vacuum during 75 minutes (Savant speedvac plus Sc 210A) and was used for the assessment of the $\beta$-glucosidase and $\beta$-glucuronidase activities as described previously ${ }^{41}$.

\section{Short chain fatty acid assay}

Short chain fatty acid (SCFA) concentrations were measured in the faeces using gas-liquid chromatography (GLC). The GLC system consisted of a DANI 8521-a gas chromatograph equipped with flame ionisation detector in conjunction with Maestro software (Chrompack, Middelburg. Holland) for calculations. The chromatographic column used, was WCOT fused silica $25 \mathrm{~m} \times$ $0.32 \mathrm{~mm}$ id, coated with FFAP-CB df 0.3 and was used in an isotherm mode at $140^{\circ} \mathrm{C}$. The injector and detector temperature were $270^{\circ} \mathrm{C}$. The injection type was split with a ratio of 1:50. Helium was used as carrier gas, with a head pressure of 0.8 bar. One $\mathrm{ml} \mathrm{HCl}$ with heptanoic acid (internal standard, $10 \mathrm{mmol} / \mathrm{I})$ was added to $1 \mathrm{ml}$ of the diluted faecal samples to form free fatty acids. SCFA were extracted with $2 \mathrm{ml}$ of diethyl ether. One $\mu \mathrm{l}$ of the diethyl 
ether extract was injected for measurement. Concentrations of SCFA were determined in mmol/g faeces after correction for dilution ${ }^{48}$.

\section{Endotoxin assay}

The bacterial endotoxin concentration (i.e. LPS concentration) was determined in faecal water using the microtechnique of the Limulus amoebocyte lysate test (Endosafe, end point chromogenic analysis endochrome test kit, Charles River, Kent, UK). Pyrogen-free water was used to dilute the faecal water samples, to dissolve the solutions and as negative control. The analysis was performed according to the manufacturer's instructions under pyrogen-free conditions. The range of the assay in which endotoxin concentration can be detected was between $1.25 \times 10^{-3}$ and $0.1 \mathrm{ng} / \mathrm{ml}$. The mean value of faecal endotoxin was expressed as $\log \mathrm{ng}$ endotoxin per $\mathrm{ml}$ faecal water.

\section{Statistical analyses}

The non-parametric Mann-Whitney U-test was used for comparison between UC patients and healthy controls and between probiotic and placebo group while the non-parametric Wilcoxon signed-rank test was used for the statistical evaluation of changes of faecal bacterial concentrations and metabolites within groups. Mucosal bacterial concentrations of the probiotic and placebo subjects were statistically compared using the non-parametric Mann-Whitney U-test. A p-value below 0.05 was considered to be statistically significant.

\section{Results}

\section{UC patients characteristics}

Thirty-one UC patients were enrolled in the study and 27 UC patients completed the study: 13 in the probiotic (median 46 (range 35-67) yrs, $54 \%$ male) and 14 in the placebo group (median 50 (range 33-73) yrs, 64\% male) No significant differences in age and gender were observed between the probiotic and placebo group. Four patients did not complete the study (2 probiotic and 2 placebo group) due to bowel complaints. Inactive disease was present in all patients at inclusion and at the end of the study period. Thirteen patients agreed to undergo a proctoscopy for the collection of rectal biopsies: 5 in the probiotic (median 57 (range 43-67) yrs, 60\% male) and 8 in the placebo group (median 50 (range 33-73) yrs, 63\% male).

In the probiotic group, 11 patients used maintenance therapy for UC: sulfasalazine $(n=2)$, mesalazine $(n=7)$ and azathioprine in combination with sulfasalazine or mesalazine $(n=2)$. In the placebo group, 13 patients were on maintenance therapy: sulfasalazine $(n=4)$, mesalazine $(n=5)$ and azathioprine in combination with sulfasalazine or mesalazine $(n=4)$. The use of different types of maintenance therapy was equally distributed in the probiotic and the 
placebo group. Moreover, dose and type of medication did not change during the study period.

Median defaecation frequency of UC patients in this study was twice per day while the median faeces consistency score was 5 according to the Bristol scale (defined as 'soft blubs') indicating that the UC patients had loose faecal samples. No significant differences were observed in defaecation frequency and faeces consistency scores between probiotic and placebo group before or after consumption or within groups over time (table 6.1).

Table 6.1 Defaecation frequency and faeces consistency scores according to the Bristol scale (from 1: hard lumps, to 7 : watery diarrhoea) before and after consumption of probiotic or placebo drinks (median and range).

\begin{tabular}{lcccc} 
& \multicolumn{2}{c}{ Probiotic } & \multicolumn{2}{c}{ Placebo } \\
& before & after & before & after \\
\hline Consistency & $4.0(4-7)$ & $4.5(3-7)$ & $5.0(2-7)$ & $5.0(4-7)$ \\
Frequency & $2.0(1-7)$ & $2.0(0-4)$ & $2.0(0-10)$ & $3.0(0-6)$ \\
\hline
\end{tabular}

\section{Baseline comparison of UC patients and healthy volunteers}

Faecall culture results found in this study were compared to the results of 20 healthy volunteers included in a previous study using the same method of collection of the faecal samples and of bacterial culture ${ }^{4 \cdot 1}$. These healthy volunteers were significantly younger compared to the UC patients $(32(20-57)$ versus $50(33-73)$ years, $p<0.05)$ while no significant difference in gender was observed ( $45 \%$ versus $59 \%$ male).

The median defaecation frequency $(2(0-10)$ versus $1(0-2), p=0.005)$ and faeces consistency score $(5(2-7)$ versus $4(2-6), p=0.002)$ were significantly different in the UC patients compared to the healthy volunteers indicating that inactive UC patients had more frequent and more loose stools. To correct for the differences in faeces consistency, faecal bacterial concentrations were calculated per mg protein (table 6.2).

In the UC patients, faecal concentrations of total anaerobic bacteria, Bacteroides spp. and lactic acid bacteria were significantly lower compared to those of the healthy volunteers. Prevalence of bacteria in faecal samples was comparable in UC patients to healthy controls, except for $E$. coli (70 versus $95 \%, p<0.05$ ) (table 6.3).

Comparison of the faecal bacterial concentrations found in this study in relation to the type of maintenance medication did not show significant differences, with the exception of the concentration of enterococci, which was significantly lower in patients using mesalazine $(p=0.032)$ compared to patients not taking maintenance therapy ( $\log 2.9 \pm 0.4$ versus $4.6 \pm 0.7 \mathrm{CFU} / \mathrm{g}$ faeces). 
Tabile 6.2 Concentrations of faecal bacteria (log CFUimg protein) in UC patients $(n=31$ ) and healthy volunteers $(n=20)$ before probiotic or placebo consumption (mean $\pm S E M$ ).

\begin{tabular}{lcc}
\hline & UC patients & Healthy wolunteers \\
\hline Total aerobic flora & $5.5 \pm 0.2$ & $5.3 \pm 0.2$ \\
E.coli & $4.3 \pm 0.4$ & $4.7 \pm 0.3$ \\
Entlerococci & $2.8 \pm 0.4$ & $2.9 \pm 0.2$ \\
& & \\
Total anaerobic flora & $7.6 \pm 0.1^{\text {a }}$ & $8.2 \pm 0.1$ \\
Bacteroides spp. & $5.1 \pm 0.3^{\text {a }}$ & $6.6 \pm 0.2$ \\
Closinidia & $2.5 \pm 0.2$ & $2.5 \pm 0.3$ \\
Lactic acid bacteria & $2.6 \pm 0.3^{\text {a }}$ & $5.5 \pm 0.5$ \\
Lactobacilli & $2.8 \pm 0.3$ & $3.5 \pm 0.3$ \\
\hline
\end{tabular}

at statistically significant difference $(p<0.05)$ between $U C$ patients and healthy volunteers.

Table 6.3 Percentages of faecal samples of UC patients and healthy volunteers in which specific bacteria could be cultured.

\begin{tabular}{lcc}
\hline & UC patients & Healthy volunteers \\
\hline Total aerobic flora & $97 \%$ & $100 \%$ \\
Ecolf & $70 \%{ }^{*}$ & $95 \%$ \\
Enterococci & $77 \%$ & $95 \%$ \\
& & \\
Total anaerobic flora & $100 \%$ & $100 \%$ \\
Bacteroides spp. & $94 \%$ & $100 \%$ \\
Clostridia & $81 \%$ & $80 \%$ \\
Lactic acid bacteria & $66 \%$ & $90 \%$ \\
Lactobacilli & $90 \%$ & $100 \%$ \\
\hline
\end{tabular}

gstatistically significant difference $(p<0.05)$ between $U C$ palients and healthy volunteers.

\section{Effect of $L$. plantarum $299 \mathrm{v}$ on culture results}

Culture results of the UC patients before and after probiotic or placebo consumption are shown in table 6.4. Before start of the treatment period, the concentration of total aerobic bacteria was significantly lower in the probiotic group compared to the placebo group while the other bacterial concentrations were comparable in both groups.

At the last day of $L$. plantarum $299 \mathrm{v}$ intake, a significant increase in the faecal number of lactic acid bacteria $(p=0.012)$ and lactobacilli was observed $(p=0.005)$ (table 6.4), reaching mean levels up to log $5.6 \pm 0.2 \mathrm{CFU} / \mathrm{mg}$ protein. No other changes in faecal bacterial concentrations were observed after $L$. plantarum $299 \mathrm{v}$ or placebo intake.

The mucosal prevalence (i.e. percentage of persons with culture positive biopsies) after the treatment period is shown in figure 6.1. The prevalence of total anaerobic bacteria was $100 \%$, while total aerobic bacteria, lactic acid bacteria, lactobacilli and $E$. coli were cultured in lower prevalences in both 
groups (14-63\%). Enterococci and Bacteroides spp. were not cultured in the probiotic-treated group while Bacteroides spp. was detected in $63 \%$ of the biopsy samples collected in the placebo group. Clostridia was not cultured in both the probiotic-treated and the placebo-treated group.

The mean concentrations of mucosal bacteria are shown in table 6.5. In general, the concentration of bacteria cultured from rectal biopsies was relatively low (ranging from log 1.0 to $4.7 \mathrm{CFU} / \mathrm{biopsy}$ ). The mucosal concentration of total anaerobic bacteria was significantly lower in the probiotic compared to the placebo group $(p=0.019)$ after consumption.

Table 6.4 Concentrations of faecal bacteria (log CFU/mg protein) before and after consumption of probiotic or placebo drinks (mean \pm SEM).

\begin{tabular}{lcccc}
\hline & \multicolumn{2}{c}{ Probiotic } & \multicolumn{2}{c}{ Placebo } \\
& before & after & before & after \\
\hline Total aerobic flora & $5.2 \pm 0.3^{\mathrm{a}}$ & $5.9 \pm 0.3$ & $5.8 \pm 0.1^{\mathrm{a}}$ & $5.6 \pm 0.2$ \\
E.coli & $3.6 \pm 0.6$ & $3.8 \pm 0.5$ & $4.9 \pm 0.5$ & $4.8 \pm 0.5$ \\
Enterococci & $2.5 \pm 0.6$ & $2.4 \pm 0.5$ & $3.0 \pm 0.5$ & $3.0 \pm 0.5$ \\
& & & & \\
Total anaerobic flora & $7.5 \pm 0.2$ & $7.3 \pm 0.3$ & $7.6 \pm 0.2$ & $7.2 \pm 0.5$ \\
Bacteroides spp. & $4.8 \pm 0.5$ & $5.0 \pm 0.6$ & $5.4 \pm 0.3$ & $4.9 \pm 0.5$ \\
Clostridia & $2.5 \pm 0.3$ & $2.4 \pm 0.4$ & $2.4 \pm 0.3$ & $2.2 \pm 0.3$ \\
Lactic acid bacteria & $2.9 \pm 0.5$ & $5.5 \pm 0.3^{\mathrm{b}}$ & $2.5 \pm 0.3$ & $4.3 \pm 0.5$ \\
Lactobacilli & $2.5 \pm 0.4$ & $5.6 \pm 0.2^{0 .}$ & $3.0 \pm 0.5$ & $3.3 \pm 0.5$ \\
\hline
\end{tabular}

a statistically significant difference $(p<0.05)$ between probiotic and placebo group:

"statistically significant difference $(p<0.05)$ before versus after probiotic intake.

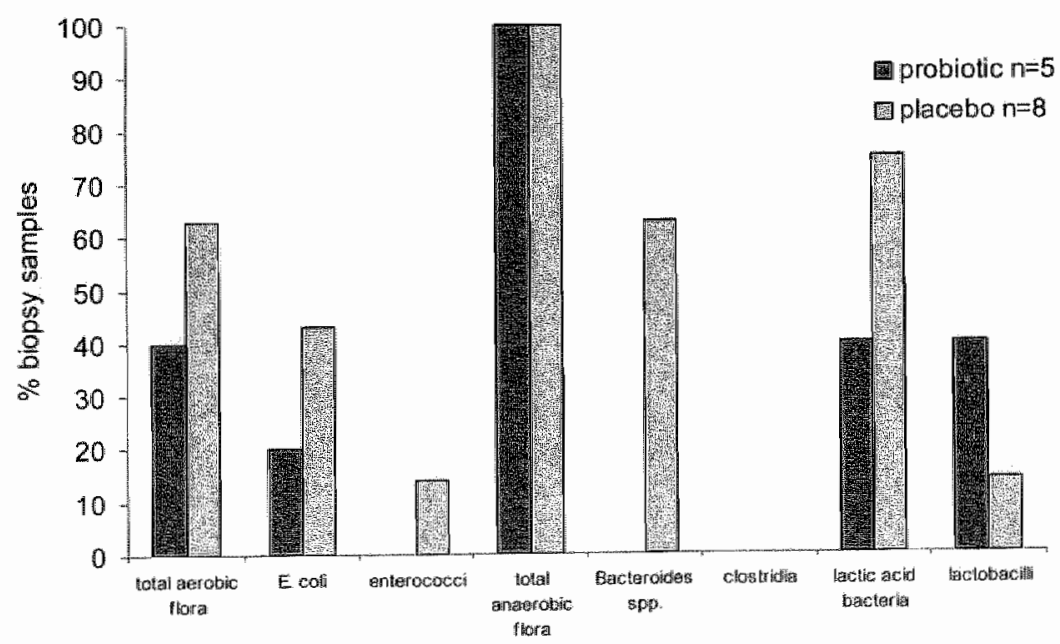

Figure 6.1 Percentages of biopsy samples in which specific bacteria could be cultured after" probiotic and placebo consumption. 
Table 6.5 Mucosal concentration of bacteria (log CFU/biopsy) after probiotic or placebo intake (mean $\mathrm{E}$ SEM) nd. means "not detected".

\begin{tabular}{lcc}
\hline & Probiotic & Placebo \\
\hline Total aerobic flora & $2.8 \pm 1.6$ & $3.5 \pm 0.8$ \\
E.coli & 1.0 & $4.7 \pm 0.8$ \\
Enterococel & n.d. & 2.38 \\
Total annaerobic flora & & \\
Bacteroides spp. & $2.3 \pm 0.4^{\mathrm{a}}$ & $4.0 \pm 0.4^{\mathrm{a}}$ \\
Clostridia & n.d. & $3.2 \pm 0.4$ \\
Lactic acid bacteria & n.d. & $n . \mathrm{d}$. \\
Lactobacilli & $2.0 \pm 0.1$ & $2.2 \pm 0.4$ \\
\hline
\end{tabular}

* statistically significant difference $(\rho<0.05)$ between probiotic and placebo group.

\section{Effect of L. plantarum 299v on bacterial 'fingerprints'}

TTGE banding patterns were available for 12 rectal biopsy samples: 5 from the probiotic and 7 from the placebo group. No significant differences could be found in the similarity patterns comparing these two groups. The samples of the different treatment groups were intermixed and no clustering could be found per group (i.e. probiotic or placebo) (figure 6.2).

$$
\text { Similarity }(\%) \quad \text { TTGE banding pattems }
$$

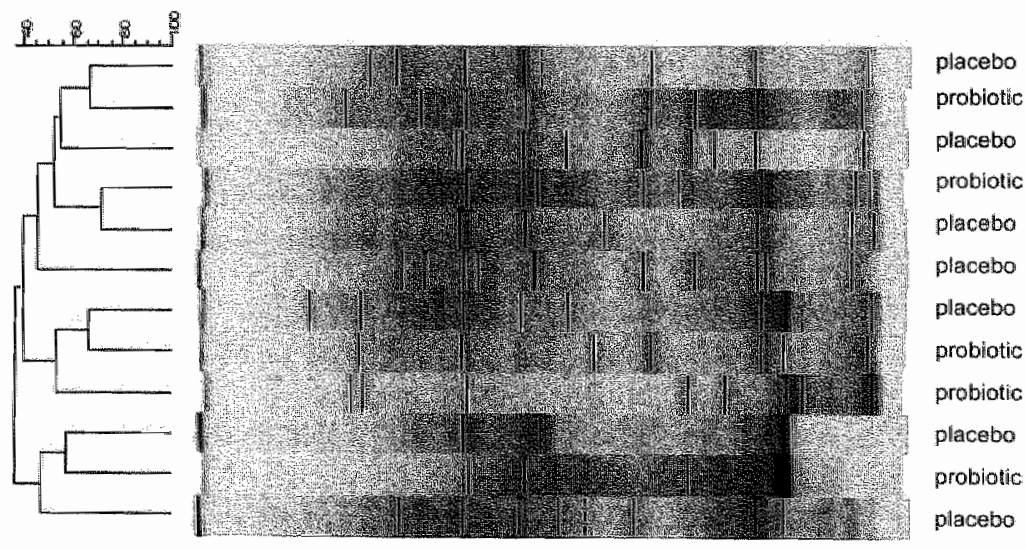

Figure 6.2 TTGE banding patterns of the dominant bacteria in rectal biopsy samples of 5 probiotic and 7 placebo-treated UC patients after clustering analysis. No clustering per treatment group was seen. 
Effect of L. plantarum $299 \mathrm{v}$ on enzyme activities, short chain fatty acid and endotoxin concentrations

Faecal B-glucosidase and $B$-glucuronidase activities did not differ significantly before and after consumption of the drinks in either the probiotic or placebo group, nor within groups over time (table 6.6). SCFA concentrations did not change due to probiotic intake (table 6.7) and no significant differences in bacterial endotoxin concentrations were observed between and within probiotic and placebo group (figure 6.3).

Table 6.6. B-glucosidase (mg/60 min/g faeces) and B-glucuronidase (mg/30 min/g faeces) activities before and after problotic or placebo consumption (mean $\pm S E M$ ).

\begin{tabular}{lcccc}
\hline & \multicolumn{2}{c}{ Probiotic } & \multicolumn{2}{c}{ Placebo } \\
& before & after & before & after \\
\hline B-glucosidase & $0.67 \pm 0.15$ & $0.76 \pm 0.13$ & $0.59 \pm 0.11$ & $0.59 \pm 0.11$ \\
B-glucuronidase & $1.47 \pm 0.37$ & $1.17 \pm 0.25$ & $0.90 \pm 0.22$ & $0.38 \pm 0.11$ \\
\hline
\end{tabular}

Table 6.7 Short chain fatty acid concentrations (mmol/g faeces) measured before and after probiotic or placebo intake (mean \pm SEM).

\begin{tabular}{|c|c|c|}
\hline & Before & After \\
\hline \multicolumn{3}{|l|}{ Acetic acid } \\
\hline Probiotic & $67.7 \pm 7.3$ & $85.2 \pm 11.4$ \\
\hline Placebo & $66.1 \pm 9.3$ & $61.9 \pm 10.6$ \\
\hline \multicolumn{3}{|c|}{ Propionic acid } \\
\hline Probilotic & $20.3 \pm 4.1$ & $21.6 \pm 2.4$ \\
\hline Placebo & $19.1 \pm 2.4$ & $19.4 \pm 3.5$ \\
\hline \multicolumn{3}{|c|}{ Isobutyric acid } \\
\hline Probiotic & $1.46 \pm 0.19$ & $1.53 \pm 0.20$ \\
\hline Placebo & $1.97 \pm 0.50$ & $1.71 \pm 0.30$ \\
\hline \multicolumn{3}{|l|}{ Butyric acid } \\
\hline Problotic & $17.3 \pm 2.4$ & $18.5 \pm 2.5$ \\
\hline Placebo & $23.9 \pm 4.92$ & $24.8 \pm 5.64$ \\
\hline \multicolumn{3}{|c|}{ Isovaleric acid } \\
\hline Probiotic & $1.65 \pm 0.23$ & $1.92 \pm 0.28$ \\
\hline Placebo & $1.99 \pm 0.39$ & $1.80 \pm 0.43$ \\
\hline \multicolumn{3}{|l|}{ Valeric acid } \\
\hline Probiotic & $2.63 \pm 0.52$ & $2.42 \pm 0.29$ \\
\hline Placebo & $2.65 \pm 0.48$ & $2.18 \pm 0.40$ \\
\hline \multicolumn{3}{|c|}{ Isocaproic acid } \\
\hline Probiotic & $0.62 \pm 0.22$ & $0.76 \pm 0.31$ \\
\hline Placebo & $0.81+0.18$ & $0.43 \pm 0.03$ \\
\hline \multicolumn{3}{|l|}{ Caproic acid } \\
\hline Probiotic & $1.34 \pm 0.27$ & $1.38 \pm 0.30$ \\
\hline Placebo & $1.23 \pm 0.11$ & $1.64 \pm 0.45$ \\
\hline
\end{tabular}




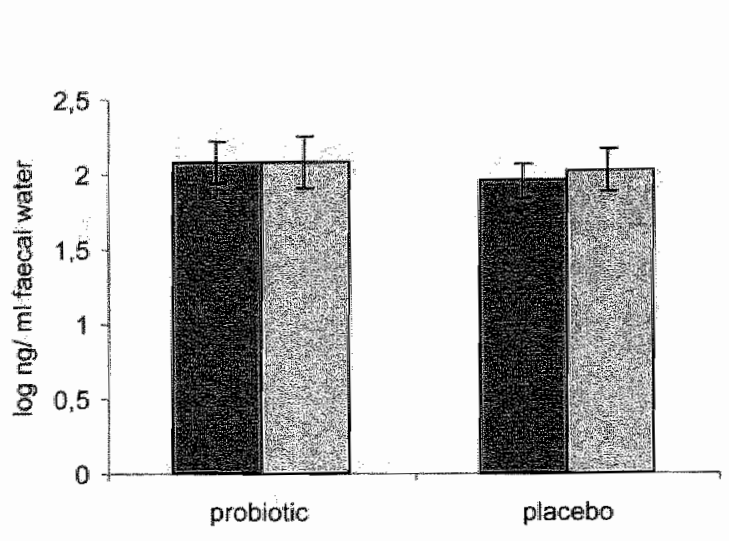

Figure 6.3 Endotoxin concentrations (log $\mathrm{ng} / \mathrm{ml}$ faecal water) before and after probiotic or placebo consumption (mean \pm SEM).

\section{Discussion}

In the present study, it has been demonstrated that the bacterial composition of inactive UC patients is significantly different from that of healthy volunteers, as lower bacterial concentrations of total anaerobic bacteria, Bacteroides spp. and lactic acid bacteria were found in the faecal samples of the UC patients.

Four-weeks treatment of the $U C$ patients with $L$. plantarum $299 \mathrm{~V}$ compensated the low concentration of lactobacilli and lactic acid bacteria, while no effect on other faecal and mucosal bacterial concentrations or metabolites was observed. A remarkable finding was the absence of mucosal Bacteroides spp. in the probiotic-treated group, while they were detected in $63 \%$ of the biopsy samples collected in the placebo group.

The lower bacterial concentrations in both faecal and mucosal samples of the UC patients compared to healthy controls, confirm the results of published studies $^{10,14,15}$. These differences in bacterial concentration could be due to the disease and/or of its treatment as the majority of UC patients included in this study were on maintenance therapy. Sulfasalazine, for instance, is known to decrease the concentration of $E$. coli in inactive UC patients ${ }^{49}$. Comparison of the faecal bacterial concentrations per type of maintenance therapy in this study did not show major differences. However, the subgroups of patients using different types of maintenance therapy were small and a larger study investigating the role of maintenance therapy on the intestinal flora is warranted. Moreover, the UC patients were significantly older compared to the healthy volunteers. Exclusion of the culture results of the three UC patients 
above 60 years did not influence the results (data not shown) indicating that age is not expected to influence the faecal culture results significantly.

L. plantarum $299 \mathrm{v}$ significantly increased the faecal concentration of lactic acid bacteria and lactobacilli but did not affect the other faecal and mucosal bacterial concentrations drastically. These findings were supported by the results of the TTGE analyses as no treatment specific patterns in the dominant bacteria could be found. The significantly lower concentration in the probiotic group of faecal total aerobic bacteria before and mucosal total anaerobic bacteria after $L$. plantarum $299 \mathrm{v}$ intake cannot be explained. Remarkably, there was a clear reduction in the mucosal prevalence of Bacteroides spp. after $L$. plantarum 299v intake. This suppression of Bacteroides spp. by $L$. plantarum $299 \mathrm{~V}$ is potentially beneficial as UC patients have increased concentrations of Bacteroides spp. and increased antibody responses against Bacteroides vulgatus $^{10,14,50,51}$. Further investigation of possible changes in subspecies of Bacteroides as well as the role of host factors in the adhesion of Bacteroides spp. may lead to further insights in the effects of probiotic bacteria on the Bacteroides spp. However, a reduction in the prevalence of Bacteroides spp. due to $L$. plantarum $299 \mathrm{v}$ intake was not seen in a previous study including 29 subjects undergoing polyp control ${ }^{52}$. In the present study, biopsy samples were only collected after the intervention and the number of biopsies collected in the study was small, indicating that collection of more biopsy samples both before as well as after intervention is needed.

The difference in the bacterial composition in UC patients versus healthy controls can be supported by differences in endotoxin concentrations (data not shown), as endotoxin concentrations in UC patients were found to be significantly higher compared to the healthy controls ${ }^{41}$. A higher endotoxin level suggests a higher release of cell wall components of Gram-negative bacteria such as $E$. col/ $i^{77,53,54}$. However, the faecal bacterial concentration of $E$. coli was decreased in the UC patients compared to healthy controls in the present study suggesting that the increased faecal endotoxin concentration is either based on non-viable $E$. coli, or on other Gram-negative bacteria ${ }^{17,53,54}$.

Comparing the bacterial composition in the mucosa between UC patients and healthy volunteers would be of additional value but for ethical and practical reasons biopsy samples were not collected in the healthy persons in the present study. However, in a previous study the mucosal bacterial composition of subjects undergoing polyp controll was analysed ${ }^{52}$. Compared to these results, UC patients had a lower prevalence in the mucosa of bacteria, especially of $E$. coli (probiotic group $20 \%$ versus $87 \%$ and in the placebo group $43 \%$ versus $93 \%$ ) indicating that also the mucosal bacterial composition is different in UC patients compared to healthy controls. An explanation for this low mucosal prevalence may be changes in the mucosa or shorter transit times in the UC patients resulting in lower colonisation rates of mucosal bacteria ${ }^{55-57}$. The present study did not demonstrate drastic changes in the bacterial composition due to $L$. plantarum $299 \mathrm{v}$ intake. This is in line to previous studies, 
which observed only an increment in the faecal concentrations of the bacteria, which were given as probiotic strain ${ }^{31,58}$. Several clinical trials showed a potential role of probiotic bacteria , for instance as maintenance therapy in IBD patients $^{28-3,59}$.

The effects of $L$. plantarum $299 \mathrm{v}$ on the immune system were not investigated in the present study, although modulation of the immune system can be another mode of action and may be of benefit for UC patients as they have an altered immune response (exaggerated $T$ helper 2 response and overproduction of $\mathbb{I L}-4$ and $\mathbb{L}-5)^{4,60-62}$. Animal studies showed the immunomodulating properties of several probiotic strains such as L. plantarum, Lactobacillus salivarius and Bifidobacterium infantis and a recent trial demonstrated clinical improvement of UC patients after an immunomodulating therapy by Trichuris suis ${ }^{32,53-69}$. The immunomodulating properties of probiotics need to be studied in future.

In conclusion, this study showed that inactive UC patients differed in faecal bacterial composition from healthy controls. Intake of the probiotic $L$, plantarum 299v during four weeks significantly increased the concentration of lactobacilli. More well-designed and controlled studies are required to investigate the role of intestinal bacteria in UC and to investigate the potential of L. plantarum $299 \mathrm{~V}$ as treatment. In such studies, the intake of medication has to be considered because of possible confounding. Moreover, other possible modes of action of probiotics need to be studied such as the influence on the immune system. 


\section{References}

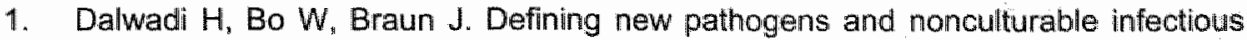
agents associated with inflammatory bowel disease. Cur Opinion in Gastroenterol 2000; 16:56-9.

2. Elson $\mathrm{CO}$. Commensal bacteria as targets in Crohn's disease. Gastroenterology 2000;119:254-7.

3. Sellon RK, Tonkonogy $\mathrm{S}$, Schultz $\mathrm{M}$, et al. Resident enteric bacteria are necessary for development of spontaneous colitis and immune system activation in interleukin-10-deficient mice. Infect Immun 1998;66:5224-31.

4. Sartor RB. The role of luminal bacteria in colitis: more than an antigenic drive. Eur $J$ Clin Invest 1998;28:1027-9.

5. Rath $\mathrm{HC}_{1}$ Herfarth $\mathrm{HH}_{3}$ Ikeda JS, et al. Normal luminal bacteria, especially Bacteroides species, mediate chronic colitis, gastritis, and arthritis in HLAB27/human beta2 microglobulin transgenic rats. J Clin Invest 1996;98:945-53.

6. Gionchetti $P$, Rizello $F$, Venturi $A_{*}$ et al. Review-Antibiotic treatment in inflammatory bowel disease: rifaximin, a new possible approach. Eur Review for Medical and Pharmacol Sciences 1999;3:27-30.

7. Campieri M, Gionchetti P. Probiotics in inflammatory bowel disease: new insight to pathogenesis or a possible therapeutic alternative? Gastroenterology 1999;116:1246-9.

8. Linskens RK, Huijsdens XW, Savelkoul PH, Vandenbroucke-Grauls CM, Meuwissen SG. The bacterial flora in inflammatory bowel disease: current insights in pathogenesis and the influence of antibiotics and probiotics. Scand $J$ Gastroenterol Suppl 2001;234:29-40.

9. Burke DA, Axon AT, Clayden SA, Dixon MF, Johnston D, Lacey RW. The efficacy of tobramycin in the treatment of ulcerative colitis. Aliment Pharmacol Ther $1990: 4: 123-9$

10. Fabia $R$, Ar"Rajab $A_{4}$ Johansson ML, et al. Impairment of bacterial flora in human ulcerative colitis and experimental colitis in the rat. Digestion 1993;54:248-55.

11. Hartley MG, Hudson MJ, Swarbrick ET, et al. The rectal mucosa-associated microflora in patients with ulcerative colitis. J Med Microbiol 1992;36:96-103.

12. Bullock NR, Booth JC, Gibson GR. Comparative composition of bacteria in the human intestinal microflora during remission and active ulcerative colitis. Curr Issues Intest Microbiol 2004;5:59-64.

13. Ott $S$, Musfeldt $M$, Wenderoth $D$, et al. Reduction in diversity of the colonic mucosa associated bacterial microflora in patients with active inflammatory bowel disease. Gut 2004,53:685-93.

14. Swidsinski $A_{\text {, Ladhoff }} A_{1}$ Pernthaler $A_{0}$ et all. Mucosal flora in inflammatory bowel disease. Gastroenterology 2002;122:44-54.

15. Schuitsz C, Van Den Berg FM, Ten Kate FW, Tytgat $G N$, Dankert J. The intestinal mucus layer from patients with inflammatory bowel disease harbors high numbers of bacteria compared with controls. Gastroenterology 1999;117:1089-97.

16. Giaffer $M H$, Holdsworth $C D$. Duerden Bl. The assessment of faecal flora in patients with inflammatory bowel disease by a simplified bacteriological technique. J Med Microbiol $1991 ; 35: 238-43$.

17. Caradonna L, Amati $L$, Magrone $T$, Pellegrino NM, Jirillo E, Caccavo D. Enteric bacteria, lipopolysaccharides and related cytokines in inflammatory bowel disease: biological and clinical significance. J Endotoxin Res 2000;6:205-14. 
18. Liu $Y$, van Kruiningen $H J$, West $A B$, Cartun RW, Cortot $A$, Colombel JF. Immunocytochemical evidence of Listeria, Escherichia coli, and Streptococcus antigens in Crohr's disease. Gastroenterology 1995;108:1396-404.

19. Agarwal VP, Schimmel EM. Diversion colitis: a nutritional deficiency syndrome? Nutr Rev $1989 ; 47: 257-61$.

20. Roediger. WE. The starved colon-diminished mucosal nutrition diminished absorption, and colitis. Dis Colon Rectum 1990;33:858-62.

21. Roediger WE. The colonic epithelium in ulcerative colitis: an energy-deficiency disease? Lancet 1980;2:712-5.

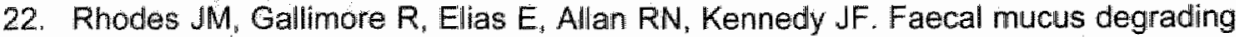
glycosidases in ulcerative colitis and Crohn's disease. Gut 1985;26:761-5.

23. Raouf AH, Tsai HH. Parker N. Hoffman J, Walker RJ, Rhodes JM. Sulphation of colonic and rectal mucin in inflammatory bowel disease: reduced sulphation of rectal mucus in ulcerative collitis. Clin Sci 1992;83:623-6.

24. Tsail HH, Dwarakanath AD, Hart CA, Milton JD, Rhodes JM. Increased faecal mucin sulphatase activity in ulcerative colitis: a potential target for treatment. Gut 1995;36:570-6.

25. Dwarakanath $A D$, Campbell BJ, Tsai HH, Sunderland D, Hart CA, Rhodes JM. Faecal mucinase activity assessed in inflammatory bowel disease using $14 \mathrm{C}$ threonine labelled mucin substrate. Gut 1995;37:58-62.

26. Rafii F, Ruseler-Van Embden JG, van Lieshout LM. Changes in bacterial enzymes and PCR profiles of fecal bacteria from a patient with ulcerative colitis before and after antimicrobial treatments. Dig Dis Sci 1999;44:637-42.

27. Havenaar $R$, Ten Brink $B_{n}$ Huis in "t Veld J. Selection of strains for probiotic use. In: Chapmann and Hall, ed. Probiotics, The scientific basis. London, 1992:209-24.

28. Rembacken BJ, Snelling AM, Hawkey PM, Chalmers DM, Axon AT. Nonpathogenic Escherichia coli versus mesalazine for the treatment of ulcerative colitis: a randomised trial. Lancet 1999;354:635-9.

29. Kruis W, Schutz E, Fric P, Fixa B, Judmaier G, Stotte M. Double-blind comparison of an oral Escherichia coli preparation and mesalazine in maintaining remission of ulcerative colitis. Aliment Pharmacol Ther 1997;11:853-8.

30. Kruis $W$, Fric $P$, Pokrotnieks $J$, et al. Maintaining remission of ulcerative colitis with the probiotic Escherichia coli Nissle 1917 is as effective as with standard mesalazine. Gut 2004;53:1617-23.

31. Venturi A, Gionchetti P, Rizzello F, et al. Impact on the composition of the faecal flora by a new probiotic preparation: preliminary data on maintenance treatment of patients with ulcerative coilitis. Aliment Pharmacol Ther 1999:13:1103-8.

32. Mao $Y_{\text {, Nobaek }} S$, Kasravi $B$, et al. The effects of Lactobacillus strains and oat fiber on methotrexate- induced enterocolitis in rats. Gastroenterology 1996;111:334-44.

33. Schultz M, Veltkamp C, Dielemans LA, Wyrick PB, Tonkonogy SL, Sartor RB. Continuous feeding of Lactobacillus plantarum attenuates established colitis in interleukin-10 deficient mices. Gastroenterology 1998;114:A1081.

34. Schultz M, Veltkamp C, Dieleman LA, et al. Lactobacillus plantarum $299 \mathrm{~V}$ in the treatment and prevention of spontaneous colitis in interleukin-10-deficient mice. Inflamm Bowel Dis 2002;8:71-80.

35. Madsen KL, Doyle JS, Jewell LD, Tavernini MM, Fedorak RN. Lactobacillus species prevents colitis in interleukin 10 gene-dleficient mice. Gastroenterology $1999 ; 116: 1107-14$ 
36. Johansson $M$, Nobaek $S$, Berggren $A$, et al. Survival of Lactobacillus plantarum DSM $9843(299 \mathrm{v})$, and effect on the short-chain fatty acid content of faeces after ingestion of a rose-hip drink with fermented oats. Int J Food Microbiol 1998;42: 29-38.

37. Adlerberth 1, Ahrne $S$, Johansson M, Molin G, Hanson L, Wold A. A mannosespecific adherence mechanism in Lactobacillus plantarum conferring binding to the human colonic cell line HT-29. Appl Environ Microbiol 1996;62:2244-51.

38. Goossens D, Jonkers D, Russel M, et al. Survival of the probiotic, L. plantarum $299 \mathrm{v}$ and its effects on the faecal bacterial flora, with and without gastric acid inhibition. Dig Liver Dis 2005;37:44-50.

39. Russel MG, Dorant $E$, Volovics $A$, et al. High incidence of inflammatory bowel disease in The Netherlands: results of a prospective study. The South Limburg IBD Study Group. Dis Colon Rectum 1998;41:33-40.

40. Lichtiger $S$, Present $\mathrm{DH}$, Kornbluth $\mathrm{A}$, et al. Cyclosporine in severe ulcerative colitis refractory to steroid therapy. N Engl J Med 1994:26:1841-5.

41. Goossens $D$, Jonkers $D$, Russel $M$, Stobberingh $E_{\text {, Van }}$ Den Bogaard $A_{\text {, }}$ Stockbrugger $R$. The effect of Lactobacillus plantarum $299 \mathrm{v}$ on the bacterial composition and metabolic activity in faeces of healthy volunteers: a placebocontrolled study on the onset and duration of effects. Aliment Pharmacol Ther 2003; 18:495-505.

42. O'Donnell L, Virjee J, Heaton K. Detection of pseudodiarrhoea by simple clinical assessment of intestinal transit rate. BMJ 1990;300:439-40.

43. Hartemink R, Domenech VR, Rombouts FM. LAMVAB-a new selective medium for the isolation of lactobacilli from faeces. J Microbiol Methods 1997;29:77-84.

4.4. Olsson $C_{1}$ Ahrne $S$, Pettersson B, Molin $G$. The bacterial flora of fresh and chillstored pork: analysis by cloning and sequencing of $16 \mathrm{~S}$ rRNA genes. Int J Food Microbiol 2003;83:245-52.

45. Heuer $H$, Kresk M, Baker P, Smalla K, Wellignton EMH. Analysis of Actinomycete communities by specific amplification of genes encoding 16S rRNA and gelelectrophoretic separation in denaturing gradients. Appl Environ Microbiol 1997;63:954-64.

46. Gray MW, Sankoff $D$, Cedergren RJ. On the evolutionary descent of organisms and organells: a global phylogeny based on a highly conserved structural core in the small subunit ribosomal RNA. Nucleic Acid Res 1984:12:5837-52.

47. Monstein $H-J$, Olsson $C_{4}$ Nilisson I, Grahn $N$, Benoni C. Ahrné S. Multiple displacement amplification of DNA from human colon and rectum biopsies: Bacterial profiling and identification of Helicobacter pylorl-DNA by means of $16 \mathrm{~S}$ rDNA-based TTGE and pyrosequencing analysis. Microbiol Methods. 2005; $63: 239-47$.

48. van den Bogaard $A E_{n}$ Hazen MJ, van Boven CP. Quantitative gas chromatographic analysis of volatile fatty acids in spent culture media and body fluids. $J$ Clin Microbiol 1986;23:523-30.

49. Hartley MG, Hudson MJ, Swarbrick ET, Grace RH, Gent AE, Hellier MD. Sulphasalazine treatment and the colorectal mucosa-associated flora in ulcerative colitis. Aliment Pharmacol Ther 1996;10:157-63.

50. Matsuda $H$. Fujuyama $Y$, Andoh A, Ushijima $T$, Kajinami $T$, Bamba $T$. Characterization of antibody responses against rectal mucosa-associated bacterial flora in patients with ulcerative colitis. J Gastroen Hepatol 2000;15:61-8.

51. Poxton $\mathbb{R}$, Brown $R$, Sawyerr $A$, Ferguson $A$. Mucosa-associated bacterial flora of the human colon. J Med Microbiol 1997;46:85-91. 
52. Goossens $D$, Jonkers $D$, Russel $M$, Stobberingh $E$, Stockbrügger $R$. The effect of a probiotic with L. plantarum $299 \mathrm{v}$ on the bacterial composition in faeces and mucosal biopsies of rectum and ascending colon. Aliment Pharmacol Ther $2006 ; 23: 255-63$.

53. Wyatt $J$, Oberhuber $G$, Pongratz $S$, et al. Increased gastric and intestinal permeability in patients with Crohn's disease. Am J Gastroenterol 1997:92:1891-6.

54. Wellmann W, Fink PC, Benner F, Sichmidt FW. Endotoxaemia in active Crohn's disease. Treatment with whole gut irrigalion and 5-aminosalicylic acid. Gut 1986;27:814-20.

55. Pullan RD, Thomas GA, Rhodes $M$, et al. Thickness of adherent mucus gel on colonic mucosa in humans and its relevance to colitis. Gut 1994;35:353-9.

56. McCormick DA, Horton LW, Mee AS. Mucin depletion in inflammatory bowel disease. J Clin Pathol 1990;43:143-6.

57. Rhodes JM. Colonic mucus and ulcerative colitis. Gut 1997;40:807-8.

58. Spanhaak $S$, Havenaar $R$, Schaafsma $G$. The effect of consumption of milk fermented by Lactobacillus casei strain Shirota on the intestinal microflora and immune parameters in humans. Eur $₫$ Clin Nutr 1998;52:899-907.

59. Guslandi M. Probiotics for chronic intestinal disorders. Am J Gastroenterol 2003;98:520-1.

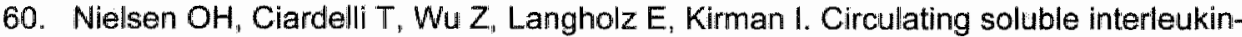
2 receptor alpha and beta chain in inflammatory bowel disease. Am $J$ Gastroenterol 1995;90:1301-6.

61. Elson CO, Sartor RB, Tennyson GS, Riddell RH. Experimental models of inflammatory bowel disease. Gastroenterology 1995;109:1344-67.

62. Podolsky DK. Inflammatory bowel disease. N Engl J Med 1991;325:1008-16.

63. Sartor RB. Therapeutic manipulation of the enteric microflora in inflammatory bowel diseases: antibiotics, probiotics, and prebiotics. Gastroenterology 2004;126: 1620-33.

64. Ulisse S. Gionchetti P, D'Alo S, et al. Expression of cytokines, inducible nitric oxide synthase, and matrix metalloproteinases in pouchitis: effects of probiotic treatment. Am J Gastroenterol 2001;96:2691-9.

65. McCarthy J, O'Mahony L, O'Callaghan $L$, et al. Double blind, placebo controlled trial of two probiotic strains in interleukin 10 knockout mice and mechanistic link with cytokine balance. Gut 2003:52:975-80.

66. Pathmakanthan $\mathrm{S}$, Li CK, Cowle J, Hawkey CJ. Lactobacillus plantarum 299: beneficial in vitro immunomodulation in cells extracted from inflamed human colon. $J$ Gastroenterol Hepatol 2004;19:166-73.

67. Borruel N. Carol $M$, Casellas $F$, et al. Increased mucosal turnour necrosis factor alpha production in Crohn's disease can be downregulated ex vivo by probiotic bacteria. Gut 2002;51:659-64.

68. Herias MV. Hessile C. Telemo E, Midtvedt T, Hanson LA, Woid AE. Immunomodulatory effects of Lactobacillus plantarum colonizing the intestine of gnotobiotic rats. Clin Exp Immunol 1999;116:283-90.

69. Summers RW, Elliatt DE, Qadir K, Urban JF, Thompson R, Weinstock JV. Trichuris suis seems to be safe and possibly effective in the treatment of inflammatory bowel disease. Am J Gastroenterol 2003;98:2034-41. 
Chapter 7

General discussion and conclusions 


\section{Introduction}

Results of probiotic trials are encouraging for the promotion of general health but also as alternative or supplementary therapy for various gastrointestinal diseases, in which the intestinal flora may be disturbed (chapter 1). However, results of well-designed blinded placebo-controlled probiotic studies, also focusing on possible modes of actions, have to be awaited, before rational recommendations about the use of probiotics can be done (chapter 1). One of the potential modes of action is the replacement of intestinal bacteria by the probiotic strains and the modulation of the bacterial metabolic activities.

In this thesis, five double-blind placebo-controlled studies have been described, focusing on the effects of the probiotic L. plantarum $299 \mathrm{v}$ on the composition of the faecal and mucosal intestinal flora and on faecal metabolic activities, in healthy subjects with a 'normal' flora as well as in patients with intestinal disorders with a potentially disturbed flora.

\section{Effect of L. plantarum 299v on faecal lactobacilli}

All studies described in this thesis showed that oral application of $L$. plantarum $299 \mathrm{v}$ significantly increased the concentration of lactobacilli (table 7.1) and documented the good survival of $L$. plantarum $299 \mathrm{v}$ in the gastrointestinal tract. This survival was irrespective of gastric acidity, as pharmacological increment of the intragastric $\mathrm{pH}$ did not result in an increase in the faecal lactobacilli concentration (chapter 3 ). One week after start of the probiotic drinks, $L$. plantarum $299 \mathrm{v}$ could be identified in the faecal samples, paralleling the increase in the concentration of lactobacilli (chapter 2). One week after cessation of $L$. olantarum $299 \mathrm{v}$, the lactobacilli concentration decreased and $L$. plantarum 299 could not be identified anymore in the faecal samples from the probiotic group demonstrating that no prolonged colonisation was achieved (chapter 2).

Table 7.1 Concentration of lactobacill (log CFU/g faeces) before, during and after L. plantarum $299 \mathrm{v}$ intake (daily dose $10^{11}$ CFU) in the five studies described in this thesis (mean $\pm S E M)$. n.m. means "not measured".

\begin{tabular}{lccc}
\hline & before & last day of intake 4 weeks after cessation \\
\hline Chapter 2 (healthy volunteers) & $4.6 \pm 0.3$ & $8.1 \pm 0.1$ & $4.4 \pm 0.4$ \\
Chapter 3 (healthy volunteers tpantoprazole) & $4.4 \pm 0.3$ & $7.9 \pm 0.1$ & $4.4 \pm 0.3$ \\
Chapter 4 (bowel cleansing) & $4.7 \pm 0.5$ & $6.8 \pm 0.3$ & $4.6 \pm 0.4$ \\
Chapter 5 (controls for polyps) & $5.0 \pm 0.4$ & $7.1 \pm 0.3$ & n.m. \\
Chapter 6 (UC patients) & $3.4 \pm 0.4$ & $7.1 \pm 0.2$ & n.m. \\
\hline
\end{tabular}

The increase in lactobacilli concentration found in the five present studies ranged from log 2.1 to $3.7 \mathrm{CFU} / \mathrm{g}$ faeces and was lowest in the subjects undergoing polyp control (chapter 5) and in the patients who underwent bowel 
cleansing (chapter 4) and was highest in the UC patients (chapter 6) (table 7.1). The magnitude of the increase seems to be influenced by the pretreatment concentration: a lower pre-treatment concentration was accompanied by a higher increase. Such a low pre-treatment concentration can be caused by the disease or medication used and compensation can be beneficial, although the exact clinical importance still needs to be determined.

The magnitude of the increase in the concentration of lactobacilli was high compared to results from previous studies using L. plantarum $299 \mathrm{v}$, Lactobacillus rhamnosus DR20 and Lactobacillus caseistrain Shirota (increase of $\log 0.4,0.6$ and $1.3 \mathrm{CFU} / \mathrm{g}$ faeces, respectively $)^{1-3}$, which could be due to the probiotic strain used in the present studies and/or to the consumption of relatively high concentrations (daily dose $10^{11} \mathrm{CFU}$ ).

The present studies demonstrated that L. plantarum $299 \mathrm{v}$ could not be identified anymore in faecal samples collected after cessation of the probiotic drinks. In contrast, a study performed in Sweden showed that $L$. plantarum $299 \mathrm{v}$ was still present in faecal samples in five of 26 healthy volunteers one week after cessation ${ }^{1}$. The prolonged survival of $L$. plantarum $299 \mathrm{v}$ in the Swedish study might be due to a higher susceptibility to colonise L. plantarum $299 \mathrm{v}$ in Swedes, as the probiotic strain originally was isolated from this population. Host factors such as the mucus composition may also play a role in the colonisation. In addition, isolation of lactobacilli from faecal samples differed between the present studies and the Swedish one as in the present studies four lactobacilli have been isolated from the outer ring of the LAMVAB plates after inoculation with a spiral plater representing the dominant lactobacilli flora, while in the Swedish study lactobacilli with the appearance of $L$. plantarum $299 \mathrm{v}$ have been isolated from Rogosa agar plates?

\section{Effect of L. plantarum 299v on other faecal bacteria}

Intake of $L$. plantarum $299 \mathrm{v}$ did not influence other faecal bacteria with the exception of small increases ( $<\log 1 \mathrm{CFU} / \mathrm{g}$ faeces) in total aerobic bacteria (chapter 3) and clostridia (chapter 5). An explanation for these differences could not be found. However, the clinical importance of these small changes is questionable, especially as the variation of the conventional culture method is $\log 0.5 \mathrm{CFU} / \mathrm{g}$ faeces.

In line with the culture results, no changes in the molecular 'fingerprints' based on the denaturating gradient gel electrophoresis (DGGE) analyses of the dominant faecal flora could be seen due to $L$. plantarum $299 \mathrm{v}$ intake or to bowel cleansing, indicating that the intestinal flora can be considered as relatively stable. In contrast, studies described in the literature observed changes in the composition of the intestinal flora after the intake of antibiotics, sulfasalazine or after major changes in diet (such as a switch to a vegetarian diet $)^{4-7}$. Recently, a study demonstrated that intake of the antibiotic amoxycillin 
drastically affected the composition of the dominant faecal flora ${ }^{8}$. These changes in the bacterial composition might be due to selective suppression of bacteria versus total non-selective washing out such as bowel cleansing.

\section{Effect of L. plantarum $299 \mathrm{v}$ on mucosal bacteria}

The consumption of $L$. plantarum $299 \mathrm{v}$ did not significantly influence the concentration or prevalence of lactobacilli in biopsies (chapter 5,6 ). L. plantarum $299 \mathrm{v}$ could not be identified in the colon ascendens biopsies and only in two of the 15 rectum biopsies collected in the subjects undergoing polyp control (chapter 5), indicating that L. plantarum 299v did only colonise the mucosa of these patients to a minor degree. It has been shown in in vitro studies and in gnotobiotic rats that $L$. plantarum $299 \mathrm{v}$ competes with $E$. coli for mannose-specific receptors for adherence $e^{9,10}$. However, a decrease in the mucosal concentration of $E$. coliwas not seen in the present studies (chapter 5 , $6)$.

Remarkably, L. plantarum 299v decreased the prevalence of Bacteroides spp. in the mucosa of UC patients (chapter 6). This decrease can be beneficial, as UC patients are known to have enhanced Bacteroides spp. concentrations ${ }^{11-13}$. However, this decrease was not seen in the subjects undergoing polyp control or in faecal samples (chapter 5 ). Investigation of the effect of $L$. plantarum $299 \mathrm{v}$ intake on the subspecies of Bacteroides is needed.

Furthermore, the intake of $L$. plantarum $299 \mathrm{v}$ did not change other mucosal bacterial prevalences or concentrations and molecular 'fingerprints' of the dominant bacteria in rectal biopsies, except for the concentration of total anaerobic bacteria, that became significantly higher in the subjects undergoing polyp control (chapter 5) and significantly lower in the UC patients after L. plantarum 299v intake (chapter 6 ). This difference may be due to differences in bowel cleansing (total bowel cleansing (chapter 5) versus enema (chapter 6 ). However, it has been demonstrated in chapter 4 that bowel cleansing did not change the faecal bacterial composition significantly based on culture as well as on molecular results.

Comparing the mucosal prevalence and concentrations after $L$. plantarum $299 \mathrm{v}$ intake in subjects undergoing polyp control versus UC patients (chapter 5,6 ) showed that both prevalence and concentrations of most bacterial species tend to be lower in the UC patients (figure 7.1). This lower mucosal prevalence found, may be caused by differences in the UC patients in the mucus composition, the metabolic activity or the intestinal transit time ${ }^{14-16}$. A thinner mucus layer has been reported in UC patients possibly resulting in less adherence sites for bacteria ${ }^{17,18}$. However, bacterial prevalences and concentrations found in chapter 5 and 6 have not been compared statistically as the number of collected biopsies was small. 


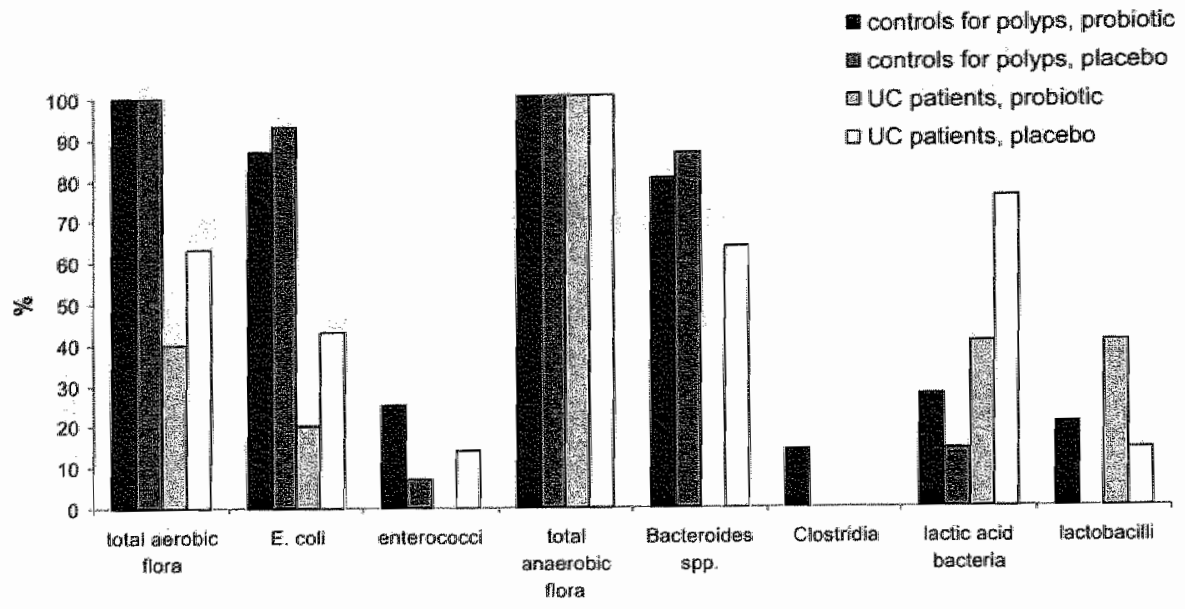

Figure 7.1 Prevalence of mucosal bacteria in rectal biopsies collected from subjects undergoing polyp control (chapter 5) and inactive UC patients (chapter 6)

Lower bacterial prevalences were found in biopsy samples compared to faecal samples supporting the idea that host and/or bacterial factors are responsible for a selective adherence of bacteria to the mucosa. More insight into this selection process will be interesting in view of future attempts to modulate the intestinal flora. These differences between mucosal and faecal samples indicate that an analysis of both types of sample is needed to give further insight in the effects of probiotics on the bacterial composition (chapter 5,6 ). The study described in chapter 5 demonstrated that the bacterial composition of colon ascendens biopsies is comparable to rectum biopsies indicating that analysis of rectum biopsies seems to be sufficient to study effects of probiotics on the intestinal mucosal flora in a non-inflamed colon. The collection of rectum biopsies only is more preferable because of practical and ethical reasons and because intensive bowel cleansing is not needed prior to biopsy collection. However, the comparison of the bacterial composition in colon ascendens and rectum biopsies in the present studies has only been based on culture results and molecular analyses might be of additional value.

It is difficult to compare the mucosal results of the present studies to results found in the literature, as in those studies the samples were handled and processed differently. For example, some investigations washed the biopsies $^{13,19,20}$, while others did not ${ }^{12,21,22}$. However, comparing the culture results, washing of the biopsy samples did not systematically result in lower bacterial concentrations and prevalence. Furthermore, the bacterial concentrations have in different studies been expressed in different units: log CFU/biopsy, $\log$ CFU/g tissue, log CFU/ $\mu$ l biopsy dilution or log CFU/mg protein. Protein concentrations in biopsy samples have been analysed in the 
study including subjects undergoing polyp control (chapter 5) but were below the detection level in the majority of the samples.

\section{Effect of L. plantarum $299 \mathrm{v}$ on faecal metabolic activity}

Consumption of L. plantarum $299 \mathrm{v}$ did not significantly influence B-glucosidase and B-glucuronidase activities (chapter 2, 5, 6), endotoxin concentrations (chapter 2,6), SCFA concentrations in faeces (chapter 2, 3,6), or the $\mathrm{pH}$ of faecal water (chapter 2, 3). Nor did L. plantarum $299 \mathrm{v}$ intake influence defaecation frequency and faeces consistency scores according to the Bristol scale in the five studies.

An increase in SCFA concentrations due to L. plantarum $299 \mathrm{v}$ intake could probably not be found because SCFAs are excreted in the faeces for only $5 \%$ suggesting that an increase in SCFA production may result in an increase in absorption and not in excretion ${ }^{23}$. Furthermore, higher amounts of carbohydrates are present in the proximal compared to the distal colon, increasing the bacterial fermentation as well as the production of SCFA possibly more proximal. For this reason, measuring SCFA concentrations both proximal and distal in the mucosa will give further insight in the effects of $L$. plantarum $299 \mathrm{~V}$.

The SCFA concentration before treatment did not differ comparing the two healthy volunteer populations (chapter 2,3 ). Unfortunately, the pre-treatment SCFA concentrations and also the enzyme activities found in the healthy volunteers could not be compared to the results found in the UC patients because of variation in the methods and the use of new equipment in the course of the studies. However, pre-treatment endotoxin concentrations found in healthy volunteers (chapter 2) could be compared to the UC patients (chapter 6) and showed a significantly higher concentration in the UC patients (UC: $\log 2.0 \pm 0.1$ versus healthy volunteers: $1.5 \pm 0.03 \mathrm{ng} / \mathrm{ml}$ faecal water, $p=0.003$ ). This is probably caused by a higher release of cell wall components of Gram-negative bacteria.

In literature, changes in metabolic activities after probiotic intake are described in healthy volunteers such as a decrease as well as an increase in $\beta$ glucosidase activity, 2.24, and an increase in acetic and propionic acid after probiotic consumption ${ }^{1}$. However, some of these studies used other probiotic strains such as $L$. casei and $L$. acidophilus, which may be the reason of these different results compared to the studies described in this thesis.

In the present studies a subset of metabolites have been investigated based on results described in the literature. Measuring other microflora-associated characteristics such as cholesterol metabolism, transformation of bilirubin, trypsin activity, degradation of $B$-aspartylglycine and the degradation of mucin 
may give further insight in the effects of $L$. plantarum $299 \mathrm{v}$ on the metabolic activity of the faecal flora ${ }^{25}$.

\section{Comparison of pre-treatment faecal bacterial concentrations}

Faecal samples collected in the five studies were handled in a similar way and similar culture methods were used, which allows a comparison of the pretreatment concentrations (table 7.2).

Table 7.2 Pre-treatment concentrations of bacteria (log CFU/g faeces) cultured before probiotic or placebo intake (mean \pm SEM)

\begin{tabular}{|c|c|c|c|c|c|}
\hline & $\begin{array}{c}\text { Healthy } \\
\text { volunteers } \\
\text { (chapter 2) }\end{array}$ & $\begin{array}{c}\text { Healthy } \\
\text { volunteers } \\
+ \text { pantoprazole } \\
\text { (chapter 3) }\end{array}$ & $\begin{array}{c}\text { Bowel } \\
\text { cleansing } \\
\text { (chapter 4) }\end{array}$ & $\begin{array}{c}\text { Contrals for } \\
\text { pollyps } \\
\text { (chapter 5) }\end{array}$ & (chapter 6) \\
\hline Total aerobic flora & $7.0 \pm 0.2$ & $7.2 \pm 0.2^{2}$ & $6.7 \pm 0.2$ & $6.7 \pm 0.2$ & $6.8 \pm 0.2$ \\
\hline Ex coli & $6.1 \pm 0.3$ & $6.8 \pm 0.2^{6}$ & $6.2 \pm 0.3$ & $6.0 \pm 0.2$ & $5.2 \pm 0.4$ \\
\hline Enterococad & $4.4 \pm 0.3^{d}$ & $4.7 \pm 0.3^{c}$ & $3.7 \pm 0.3$ & $4.3 \pm 0.2$ & $3.8 \pm 0.3$ \\
\hline Total anaerobic flora & $9.8 \pm 0.1^{\circ}$ & $9.6 \pm 0.1^{\circ}$ & $8.3 \pm 0.3$ & $8.4 \pm 0.2$ & $9.0 \pm 0.4$ \\
\hline Bacteroides spp. & $8.2 \pm 0.2^{\Theta}$ & $7.7 \pm 0.2^{\mathrm{a}}$ & $5.9 \pm 0.4$ & $6.3 \pm 0.2$ & $6.4 \pm 0.3$ \\
\hline Clostridia & $4.1 \pm 0.3$ & $5.0 \pm 0.2^{t}$ & $4.4 \pm 0.2$ & $4.2 \pm 0.1$ & $3.7 \pm 0.2$ \\
\hline Lactic acid bacteria & $7.1 \pm 0.5^{\mathrm{e}}$ & $6.4 \pm 0.4^{\circ}$ & $5.1 \pm 0.3$ & $5.5 \pm 0.3$ & $3.4 \pm 0.2$ \\
\hline Lactobacilli & $5.1 \pm 0.3^{\text {dl }}$ & $4.5 \pm 0.2$ & $4.9 \pm 0.4^{\mathrm{d}}$ & $4.9 \pm 0.2$ & $4.0 \pm 0.3$ \\
\hline
\end{tabular}

a significant increase compared to controls for polyps and patients bowel cleansing

- significant increase compared to controls for polyps and UC patients

- significant increase compared to patients bowel cleansing and UC patients

al significant increase compared to UC patients

- significant increase compared to controls for polyps, patients bowell cleansing and UC patients

1 significant increase compared to healthy volunteers (chapter 2), controls for polyps, patients bowel cleansing and UC patients

significant increase compared to controls for polyps

Comparison of the bacterial concentrations of the two studies that included healthy volunteers demonstrated similar pre-treatment bacterial concentrations with the exception of the concentration of clostridia, which was significantly higher in the subjects who took pantoprazole or placebo in addition to the probiotic (chapter 3). These two populations are comparable concerning gender, age and bowel habits (defaecation frequency and faeces consistency scores) (chapter 2, 3). However, the studies including patients (chapter 4, 5, 6) are different compared to the healthy volunteers studies concerning age (healthy volunteers were younger) and bowel habits (patients had more loose faecal samples). Comparison of the pre-treatment bacterial concentrations between the healthy volunteers and the patient populations demonstrated that healthy volunteers have significantly higher concentrations for almost all 
bacteria (table 7.2). Remarkably are the low pre-treatment bacterial concentrations found in the UC patients compared to the healthy volunteers as well as to the other patient populations. As the UC patients had significantly more loose faecal samples, the concentrations were corrected for dilution (log CFU/mg protein)(chapter 6). After this correction, the concentrations were still significantly lower, which indicates that disease and/or medication used may influence the bacterial concentrations found. More insight in the bacterial composition and the role of the intestinal flora in UC is still warranted.

The pre-treatment faecal bacterial concentrations found in the present studies including healthy volunteers were comparable to the results described in the literature ${ }^{1-3}$, except for the concentration of lactobacilli, which was significantly lower in our studies ${ }^{1,2}$. This lower concentration might be due to the use of a more selective LAMVAB agar plate versus the less selective Rogosa agar plate mostly used $^{1-3}$, as Rogosa agar plates also support the growth of other acidresistant bacteria, such as bifidobacteria, corynebacteria and enterococci ${ }^{26}$. Moreover, studies described in this thesis cultured the bacteria quantitatively using a spiral plater whilst several previous studies used semi-quantitative methods such as a standard loop method ${ }^{27}$. Finally, differences in bacterial concentrations may be explained by differences in processing as faecal samples were processed within 12 hours after defaecation while in some previous studies the faecal samples were stored in the freezer.

\section{Concluding remarks}

In the present studies bacterial concentrations and prevalence have been based on culture techniques. One of the major disadvantages of this method is that not all bacteria are identified and can be cultured yet. However, conventional culture techniques are well established and frequently used to investigate the bacterial composition quantitatively, making comparisons to results described in the literature possible. The use of molecular techniques such as DGGE, fluorescent in situ hybridisation (FISH) and real-time polymerase chain reaction (PCR) are of additional value to get a more complete picture of the complex microbial ecosystem of bacteria present in the intestine. Disadvantages of these techniques are that also non-viable bacteria will be analysed and that these techniques, with the exception of real-time PCR, are not quantitative ${ }^{3,28}$. Moreover, molecular techniques can be biased as not all intestinal bacteria will lyse and amplify just as easy.

The studies described in this thesis investigated the effect of a monospecies probiotic, $L$. plantarum $299 \mathrm{v}$. Several studies in the literature used different monospecies or even multispecies probiotics. Probiotic strains might operate in different ways and it is unlikely that one single probiotic strain will be (equally) effective for all clinical indications. More studies are warranted to investigate 
modes of action of these different bacterial strains separately or as a multispecies product.

Based on the results described in this thesis, L. plantarum $299 \mathrm{v}$ did not change the intestinal flora profoundly. Apart from affecting the intestinal flora, probiotics may modulate the immune system. Indeed, $L$. plantarum $299 \mathrm{v}$ was found to have immunomodulatory properties such as an increase of serum IgA against E. co/fin gnotobiotic rats after incubation with $E$. coliand L. plantarum $299 v^{10,29}$. Moreover, L. plantarum $299 \mathrm{v}$ has been shown to reduce colitis in IL-10 deficient mice and experimental rats ${ }^{29,30}$ indicating that future studies should also include immunological parameters to get further insight in the immunomodulatory effects of probiotics.

\section{General conclusions}

- The recovery of $L$. plantarum $299 \mathrm{v}$ in faeces is high indicating that $L$. plantarum $299 \mathrm{v}$ survives passage through the gastrointestinal tract.

- Intake of L. plantarum $299 \mathrm{v}$ increased the concentration of lactobacilli in faeces, and has minor influence on other bacterial concentrations or metabolic activity.

- Both faecal and mucosal samples need to be collected to study the effects of $L$. plantarum $299 \mathrm{~V}$ on the intestinal flora.

- UC patients have a significantly different bacterial composition compared to healthy controls. 


\section{References}

1. Johansson M, Nobaek $S$, Berggren $A$, et at. Survival of Lactobacillus plantarum DSM $9843(299 \mathrm{v})$, and effect on the short-chain fatty acid content of faeces after ingestion of a rose-hip drink with fermented oats. Int J Food Microbiol 1998;42: 29-38.

2. Spanhaak $S$, Havenaar $R$, Schaafsma $G$. The effect of consumption of milk fermented by Lactobacillus casei strain Shirota on the intestinal microflora and immune parameters in humans. Eur J Clin Nutr 1998;52:899-907.

3. Tannock G. Munro K, Harmsen H, Welling G, Smart J, Gopal P. Analysis of the fecal microflora of human subjects consuming a probiotic product containing Lactobacillus rhamnosus DR20. Appl Environ Microbiol 2000;66:2578-88.

4. Danielsson D, Kjellander $J$ Jarnerot $G$. The effect of metronidazole and sulfasalazine on the fecal flora in patients with Crohn's disease. Scand $J$ Gastroenterol 1981:16:183-92.

5. Krook A, Jarnerot $G$, Danielsson D. Clinical effect of metronidazole and sulfasalazine on Crohn's disease in relation to changes in the fecal flora. Scand $\mathrm{J}$ Gastroenterol 1981;16:569-75.

6. Hartley MG, Hudson MJ, Swarbrick ET, Grace RH, Gent AE, Hellier MD. Sulphasalazine treatment and the colorectal mucosa-associated flora in ulcerative colitis. Aliment Pharmacol Ther 1996;10:157-63.

7. Goldin BR, Swenson L, Dwyer J, Sexton M, Gorbach SL. Effect of diet and Lactobacillus acidophilus supplements on human fecal bacterial enzymes. I Natl Cancer Inst 1980;64:255-61.

8. Koning CJM, Jonkers DMAE, Stobberingh EE, Smidt $H$, Stockbrügger RW. Effect of a multispecies probiotic on the composition of the dominant faecal flora in healthy volunteers treated with amoxycillin. United European Gastroenterology Week. Copenhagen, 2005.

9. Adlerberth I, Ahrne $S$, Johansson M, Molin G, Hanson L, Wold A. A mannosespecific adherence mechanism in Lactobacillus plantarum conferring binding to the human colonic cell line HT-29. Appl Environ Microbiol 1996;62:2244-51.

10. Herias MV, Hessle $C$, Telemo $E$, Midtvedt $T$, Hanson LA, Wold AE. Immunomodulatory effects of Lactobacillus plantarum colonizing the intestine of gnotobiotic rats. Clin Exp Immunol 1999;116:283-90.

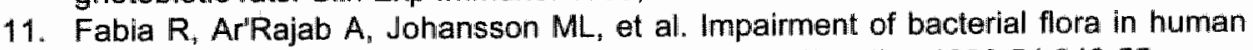
ulcerative colitis and experimental colitis in the rat. Digestion 1993;54:248-55.

12. Poxton IR, Brown $R$, Sawyerr A. Ferguson A. Mucosa-associated bacterial flora of the human colon. J Med Microbiol 1997;46:85-91.

13. Swidsinski $A$, Ladhoff $A$, Pernthaler $A$, et al. Mucosal flora in inflammatory bowel disease. Gastroenterology 2002;122:44-54.

14. Smithson JE, Campbell A, Andrews JM, Milton JD, Pigott R, Jewell DP. Altered expression of mucins throughout the colon in ulcerative colitis. Gut 1997;40:23440.

15. Rafiil $F$, Ruseler-Van Embden JG, van Lieshout LM. Changes in bacterial enzymes and PCR profiles of fecall bacteria from a patient with ulcerative colitis before and after antimicrobial treatments. Dig Dis Sci 1999;44:637-42.

16. Kruis $W$, Kalek HD, Stellaard F, Paumgartner $G$. Altered fecal bile acid pattern in patients with inflammatory bowel disease. Digestion 1986;35:189-98.

17. Shirazi T, Longman RJ, Corfield AP, Probert CS. Mucins and inflammatory bowel disease. Postgrad Med J 2000;76:473-8. 
18. Pulan RD, Thomas GA, Rhodes $M$, et al. Thickness of adherent mucus gel on colonic mucosa in humans and its relevance to colitis. Gut 1994;35:353-9.

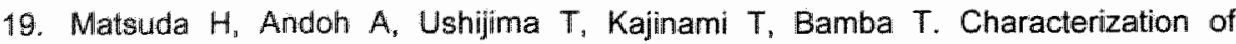
antibody responses against rectal mucosa-associated bacterial flora in patients with ulcerative colitis. I of Gastroent and Hep 2000;15:61-8.

20. Johansson $M$, Molin $G$, Jeppsson $B$, Nobaek $S$, Ahrne $S$, Bengmark $S$. Administration of different Lactobacillus strains in fermented oatmeal soup: in vivo colonization of human intestinal mucosa and effect on the indigenous flora. Appl Environ Microbiol 1993;59:15-20.

21. Ott $S$, Musfeldt $M$, Wenderoth $D$, et al. Reduction in diversity of the colonic mucosa associated bacterial microflora in patients with active inflammatory bowel disease. Gut 2004;53:685-93.

22. Kleessen $B$, Kroesen $A J$, Buhr $H J$, Blaut $M$. Mucosal and invading bacteria in patients with inflammatory bowel disease compared with controls. Scand $J$ Gastroenterol 2002;37:1034-41.

23. Berggren AM, Bjork IME, Nyman EMGL. Short-chain fatty acids content and $\mathrm{pH}$ in caecum of rats given various sources of carbohydrates. J Sci Food Agric $1993 ; 63: 397-406$.

24. Goldin BR, Gorbach SL. The relationship between diet and rat fecal bacterial enzymes implicated in colon cancer. J Natl Cancer Inst 1980;57:371-5.

25. Gustafsson A, Berstad A, Lund-Tonnesen $S$, Midtvedt $T$, Norin $E$. The effect of faecal enema on five microflora-associated characteristics in patients with antibiotic-associated diarrhoea. Scand J Gastroenterol 1999;34:580-6.

26. Hartemink $R_{*}$ Rombouts FM. Comparison of media for the detection of bifidobacteria, lactobacilli and total anaerobes from faecal samples. J Microbiol Methods 1999;36:181-92.

27. Giaffer $\mathrm{MH}$, Holdsworth $\mathrm{CD}$, Duerden $\mathrm{BI}$. The assessment of faecal flora in patients with inflammatory bowel disease by a simplified bacteriological technique. $\mathrm{J}$ Med Microbiol 1991;35:238-43.

28. Suau $A$, Bonnet $R$. Sutren $M$, et al. Direct analysis of genes encoding $16 S$ rRNA from complex communities reveals many novel molecular species within the human gut. Appl Environ Microbiol 1999;65:4799-807.

29. Mao $Y$, Nobaek S, Kasravi B, et al. The effects of Lactabacillus strains and oat fiber on methotrexate- induced enteracolitis in rats. Gastroenterology 1996;111:334-44.

30. Schultz $M$, Veltkamp $C$, Dielemans LA, Wyrick PB, Tonkonogy SL, Sartor RB. Continuous feeding of Lactobacillus plantarum attenuates established colitis in interleukin-10 deficient mices. Gastroenterology 1998;114:A1081. 
Chapter 8

\section{Summary}




\section{Summary}

This thesis describes the effects of the probiotic $L$. plantarum $299 \mathrm{v}$ on the composition of the faecal and mucosal intestinal flora and faecal metabolites in healthy volunteers as well as in patients with a possibly disturbed intestinal flora.

Chapter 1 critically reviews the literature about the effects of probiotics in gastrointestinal disorders such as diarrhoea, inflammatory bowel disease, pouchitis $_{n}$ irritable bowel syndrome, lactose malabsorption, Helicobacter pyiori infection, constipation and colorectal cancer. The composition and functions of the human microflora as well as the environmental factors that might influence this microflora are described. The definition of probiotics and possible modes of actions are also reported. In this chapter, it is postulated that the results of probiotic studies are encouraging although more well-designed placebocontrolled studies with sufficient numbers of clinically well-defined patients are required. More attention should be paid to the onset and duration of probiotic effects, the survival of probiotic strains and the differences between probiotic strains (mono-, versus multispecies). Moreover, the effects of probiotics on the bacterial composition but also on its metabolites need to be studied to get further insight in these possible modes of action.

Finally, this chapter summarizes studies investigating the effects of $L$. plantarum $299 \mathrm{v}$ in vitro, in animal models and in human trials. It can be concluded that $L$. plantarum $299 \mathrm{v}$ is a good candidate to study probiotic effects as this probiotic strain can survive passage through the gastrointestinal tract and is able to adhere to the epithelium via mannose-specific receptors.

In chapter 2 the effects of $L$. plantarum $299 \mathrm{v}$ on the faecal bacterial composition were investigated in healthy volunteers. The bacterial composition was studied by measuring the concentration of bacteria by culture and by measuring metabolic activities such as the enyme activities (1-glucosidase. $\beta$-glucuronidase and azoreductase), the short chain fatty acid concentrations (SCFA), the endotoxin concentrations and the faecal pH. This placebocontrolled study also focused on the onset and the duration of the problotic effects. In summary, L. plantarum $299 \mathrm{v}$ increased the lactobacill concentration significantly but did not have a significant influence on the other faecal bacteria cultured, or on the metabolic activities. The increase in L. plantarum $299 \mathrm{v}$ concentration was noticed within one week after start of problotic intake and disappeared within one week after cessation of intake.

Chapter 3 focuses on the survival of L. plantarum $299 \mathrm{v}$ through the gastrointestinal tract and describes a placebo-controlled double-blind study with healthy volunteers. These healthy persons took a proton pump inhibitor (pantoprazole) to decrease gastric acidity, or a placebo in addition to L. plantarum $299 \mathrm{v}$ intake. Decrement of the gastric acidity might result in a better survival of $L$. plantarum $299 \mathrm{v}$ resulting in a higher faecal lactobacill 
concentration and changes in the faecal metabolic activity (i.e. SCFA concentrations and $\mathrm{pH}$ ). However, the increase in the lactobacilli concentration was in the pantoprazole group as high as in the placebo group and no changes in metabolic activity were seen. Lactobacilli cultured from faecal samples were identified as $L$. plantarum $299 \mathrm{v}$ by molecular analyses. This study demonstrates a good survival of $L$. plantarum $299 \mathrm{v}$ irrespective of the gastric acidity.

In chapter 4 the results of a placebo-controlled double-blind study including patients who had to undergo a bowel cleansing procedure are presented. This study investigated the effects of the bowel cleansing on the faecal bacterial composition and paid special attention to the eventually beneficial effects of L. plantarum $299 \mathrm{v}$ in the recolonisation phase after bowel cleansing. The bacterial composition has been studied quantitatively by culture as well as by denaturating gradient gel electrophoresis producing bacterial molecular 'fingerprints' of the dominant faecal flora.

No major changes were observed in the bacterial composition after the bowel cleansing procedure and therefore it was concluded that the intestinal flora is relatively stable. Probiotic intake increased the faecal concentration of lactobacilli significantly but did not influence other bacterial concentrations or the bacterial composition based on cuiture results and bacterial "fingerprints".

As the bacterial composition found in faecal samples may not represent that of the mucosa, a placebo-controlled study was performed to compare the effects of $L$. plantarum $299 \mathrm{v}$ on the faecal versus mucosal bacterial composition. Moreover, as probiotic effects may differ along the gastrointestinal tract, biopsies have been collected and compared from colon ascendens and rectum (chapter 5). Patients who had to undergo a colonoscopic control for colorectal polyps were included and consumed $L$. plantarum $299 \mathrm{v}$ during two weeks prior to colonoscopy. Intake of L. plantarum $299 \mathrm{v}$ increased the lactobacilli concentration in faecal samples significantly, while $L$. plantarum $299 \mathrm{v}$ could be found sporadically in mucosal samples. The low mucosal prevalence of L. plantarum $299 \mathrm{v}$, which is in contrast to a previously performed study in Sweden, needs further study to get more insight in the possible modes of action of this probiotic strain. The bacterial composition of rectum biopsies did not differ significantly from colon ascendens biopsies suggesting that in future studies, collection of rectal biopsies only may be sufficient to study effects of probiotics on the mucosal intestinal flora. However, the faecal bacterial composition differed significantly from the mucosal bacterial composition as the mucosal prevalence of several aerobic and anaerobic bacteria was significantly lower compared to that found in faecal samples. In future studies both samples need to be collected.

In chapter 6 differences in bacterial composition between inactive UC patients on a stable dose of maintenance therapy and healthy volunteers were compared by culture. Moreover, the effects of L. plantarum $299 \mathrm{v}$ on the 
intestinal flora in faecal and mucosal samples as well as on faecal metabolic activities (enzyme activities, endotoxin concentrations and SCFA concentrations) were studied in these patients. As the UC patients had significantly more loose faecal samples, the bacterial concentration was corrected by expressing the concentrations as log CFU/mg protein in faeces. Faecal bacterial concentrations of UC patients were significantly lower compared to those of the healthy controls. These differences may be due to either the disease or the intake of medication.

Besides the significant increase in the lactobacillii concentration in faecal samples after $L$. plantarum $299 \mathrm{v}$ intake, no other changes in the bacterial composition of faecal samples or rectal biopsies could be observed based on culture and temporal temperature gel electrophoresis. Nor did L. plantarum $299 \mathrm{v}$ intake change metabolic products in faecall samples significantly. Remarkably, Bacteroides spp. was not present in mucosal samples in the probiotic group while the prevalence was relatively high in the placebo group indicating that probiotic intake might reduce Bacteroides spp. prevalence in the mucosa of UC patients, which can be beneficial for these patients. As the intake of $L$. plantarum $299 \mathrm{v}$ did not profoundly change the bacterial composition, more studies are warranted to investigate other modes of action of probiotics such as modulating the immune system.

In conclusion, this thesis shows that intake of $L$. plantarum $299 \mathrm{v}$ increased the lactobacilli concentration of faecal samples significantly. The clinical consequence of the increase in lactobacilli requires further study. No other changes in the faecal bacterial concentrations or bacterial 'fingerprints' were seen after $L$. plantarum $299 \mathrm{v}$ intake. No changes in metabolic activities were measured in faecal samples, or in the bacterial composition of mucosal samples comparing probiotic to placebo group. As L. plantarum $299 \mathrm{v}$ did not change the intestinal flora in the five studies described in this thesis, the bacterial composition can be regarded as relatively stable. However, this thesis also demonstrates that the bacterial composition of UC patients is significantly different from healthy persons.

The modes of acting of $L$. plantarum $299 \mathrm{v}$ in the gastrointestinal tract meed further study focusing on the mucosal adherence, the influences on the mucosal metabolic activities and the effects on the immune system. 
Samenvatting 


\section{Samenvatting}

Dit proefschrift beschrijft de effecten van het probioticum $L$. plantarum $299 \mathrm{v}$ op de samenstelling van de faecale en mucosale darmflora en faecale metabolieten van gezonde vrijwilligers en patiënten met een mogelijk verstoorde darmflora.

Hoofdstuk 1 geeft een kritisch overzicht van de literatuur die bekend is over de effecten van probiotica in gastro-intestinale ziekten zoals diarree, inflammatoire darmziekten, pouchitis, prikkelbare darm syndroom, lactose malabsorptie, Helicobacter pylori infectie, constipatie en colorectale kanker. De samensteiling en de functies van de humane microflora en de omgevingsfactoren die deze microflora kunnen beïnvloeden, worden beschreven. De definitie van probiotica en de mogelijke werkingsmechanismen daarvan komen ook aan de orde. In dit hoofdstuk wordt geconcludeerd dat de resultaten van probioticum-onderzoek bemoedigend zijn, hoewel meer goed opgezette placebo-gecontroleerde studies met voldoende aantallen goed geselecteerde patiënten noodzakelijk zijn. Daarnaast zou aandacht besteed moeten worden aan de aanvang en duur van probioticum-effecten, de overleving van probioticumstammen en het verschil in effecten van verschillende probioticumstammen (mono-, versus multispecies). Bovendien zouden de effecten van probiotica op de intestinale bacteriële samenstelling, maar ook op de metabolieten bestudeerd dienen te worden om een beter inzicht te krijgen in de mogelijke werkingsmechanismen. Dit hoofdstuk eindigt met een overzicht van in vitro, dier-, en humane studies die de effecten van Lactobacillus plantarum $299 \mathrm{v}$ beschrijven. Er wordt geconcludeerd dat $L$. plantarum $299 \mathrm{v}$ een goede kandidaat kan zijn om probioticum-effecten te bestuderen aangezien deze probioticumstam passage door het maagdarmkanaal kan overleven en in staat is om te hechten aan het epitheel via mannose-specifieke receptoren.

Hoofdstuk 2 beschrijft de effecten van L. plantarum 299v op de faecale bacteriële samenstelling van gezonde vrijwilligers. De bacteriële samenstelling is onderzocht door de concentraties van bacteriën vast te stellen met behulp van kweek en door de metabole activiteit te bepalen aan de hand van enzymactiviteiten ( $\beta$-glucosidase, $\beta$-glucuronidase en azoreductase), alsmede concentraties van korte keten vetzuren (KKVZ) en endotoxinen en de $\mathrm{pH}$ in faeces. In deze placebo-gecontroleerde studie is tevens de aanvang en de duur van de effecten van het probioticum onderzocht. Samenvattend kan gezegd worden dat $L$. plantarum $299 \mathrm{v}$ de concentratie van lactobacilli significant laat stijgen, maar geen significant effect heeft op de overige bacteriën gekweekt in de faecesmonsters, noch op de metabole activiteiten. De stijging van de concentratie van $L$. plantarum $299 \mathrm{v}$ was reeds zichtbaar binnen een week na de start van probioticum inname en verdween binnen een week nadat gestopt was met het probioticum. 
Hoofdstuk 3 richt zich op de overleving van L. plantarum $299 \mathrm{v}$ in het maagdarmkanaal en beschrijft een placebo-gecontroleerde studie met gezonde vrijwilligers. Deze gezonde personen namen een maagzuurremmer (pantoprazol) in om de zuurgraad in de maag te laten dalen, of een placebo naast de inname van $L$. plantarum 299v. Daling van de zuurgraad in de maag zou kunnen leiden tot een betere overleving van $L$. plantarum $299 \mathrm{v}$, wat weer resulteert in een hogere concentratie van lactobacilli in de faecesmonsters en veranderingen in de metabole activiteiten (zoals KKVZ-concentraties en $\mathrm{pH}$ ). De stijging in de concentratie van lactobacilli was echter in the pantoprazolgroep even hoog als in de placebo-groep en veranderingen in de metabole activiteiten werden niet waargenomen. Lactobacilli gekweekt uit de faecesmonsters werden geidentificeerd als L. plantarum $299 \mathrm{v}$ met behulp van moleculaire technieken. Deze studie toont een goede overleving aan van L. plantarum $299 \mathrm{v}$, onafhankelijk van de zuurgraad in de maag.

Hoofdstuk 4 presenteert de resultaten van een placebo-gecontroleerde dubbelblinde studie, waarin patiënten werden geïncludeerd die een lavage dienden te ondergaan. Deze studie onderzocht de effecten van deze lavage op de bacteriesamenstelling in de faeces en onderzocht of toediening van L. plantarum $299 \mathrm{v}$ de herkolonisatie na lavage gunstig kon beïnvloeden. De bacteriesamenstelling is kwantitatief bestudeerd met behulp van kweek, maar ook met behulp van 'denaturating gradient gel electrophoresis' (DGGE), waarbij bacteriële moleculaire bandenpatronen van de dominante faecale flora worden gemaakt.

Er werden geen significante veranderingen waargenomen in de bacteriële samenstelling na de lavage en zodoende is er geconcludeerd dat de intestinale flora relatief stabiel is. Inname van probiotica verhoogde de faecale concentratie van lactobacilli significant, maar beïnvloedde de andere bacteriële concentraties of samenstelling niet.

Aangezien de bacteriële samenstelling gemeten in de faeces zou kunnen verschillen vain de samenstelling gemeten in de mucosa, is een placebogecontroleerde studie uitgevoerd waarin de effecten van $L$. plantarum $299 \mathrm{v}$ op zowel de faecale als de mucosale bacteriesamenstelling werden bestudeerd (hoofdstuk 5). Aangezien de effecten van probiotica op verschillende plaatsen in het maagdarmkanaal zouden kunnen variëren, zijn biopten verzameld en vergeleken in zowel colon ascendens als rectum. Patiënten die een colonoscopie dienden te ondergaan ter controle voor colorectale poliepen, werden geïncludeerd en namen $L$. plantarum $299 \mathrm{v}$ gedurende twee weken vóór de colonoscopie. Door de inname van L. plantarum $299 \mathrm{v}$ steeg de concentratie van de lactobacilli in de faeces significant, terwijl $L$. plantarum $299 \mathrm{v}$ slechts sporadisch in de mucosale biopten geïdentificeerd kon worden. De lage prevalentie van L. plantarum $299 \mathrm{~V}$ in de mucosa is niet in lijn met eerder onderzoek uitgevoerd in Zweden, en zal verder onderzocht dienen te worden om meer inzicht te krijgen in de mogelijke werkingsmechanismen van deze probioticumstam. 
De bacteriële samenstelling van de rectumbiopten bepaald middels kweek verschilde niet significant van de samenstelling in biopten van colon ascendens, wat aantoont dat het verzamelen van alteen rectumbiopten voldoende zou zijn om de effecten van probiotica op de mucosale intestinale flora te bestuderen. De faecale bacteriële samenstelling verschilde wel significant van de mucosale samenstelling aangezien de prevalentie van verscheidene aërobe en anaërobe bacteriën in de mucosa significant lager was dan de prevalentie in de faeces. In toekomstige studies zullen beide monsters verzameld dienen te worden.

In hoofdstuk 6 is de bacteriële samenstelling van de faeces van patiënten met colitis ulcerosa (CU) in een inactieve fase en op een stabiele onderhoudsdosering vergeleken met die van gezonde vrijwilligers met behulp van kweek. Vervolgens is in de CU patiënten het effect bestudeerd van L. plantarum $299 \mathrm{v}$ op de intestinale flora in de faeces en in de mucosa evenals op metabole activiteiten gemeten in faecesmonsters (enzymactiviteit, endotoxinen concentraties, KKVZ-concentraties). Omdat de $\mathrm{CU}$ patiënten minder consistente faeces hadden, werden de bacteriële concentraties gecorrigeerd voor verdunning en uitgedrukt in log kolonie vormende eenheden per $\mathrm{mg}$ eiwit in de faeces.

Faecale bacteriële concentraties gemeten in de CU patiënten waren significant lager in vergelijking met de concentraties gemeten in gezonde vrijwilligers. Deze verschillen kunnen veroorzaakt zijn door de ziekte of door de inname van medicijnen.

Naast de significante stijging in de concentratie van lactobacilli in de faecesmonsters, werden geen andere verschillen gemeten in de bacteriële samenstelling van faeces of biopten na de inname van L. plantarum $299 \mathrm{v}$. Deze resultaten zijn gebaseerd op zowel kweek als op moleculaire technieken. Ook veranderde de inname van $L$. plantarum $299 \mathrm{v}$ de metabole activiteiten in de faeces niet.

Opvallend is dat Bacteroides spp. niet aanwezig waren in de mucosale monsters van de CU patiënten in de probioticum-groep, terwijl de prevalentie relatief hoog was in de placebo-groep. Dat zou erop kurnen duidem dat L. plantarum $299 \mathrm{v}$ de prevalentie van Bacteroides spp. in de mucosa van CU patiënten kan verlagen, wat gunstig kan zijn voor deze patiënten. Aangezien de inname van L. plantarum $299 \mathrm{v}$ geen duidelijke verandering laat zien in de bacteriële samenstelling, zijn meer studies nodig om mogelijk andere werkingsmechanismen van probiotica, zoals het beïnvloeden van het immuunsysteem, te bestuderen.

Dit proefschrift toont dat de inname van $L$. plantarum $299 \mathrm{v}$ de concentratie van lactobacilli in faeces van gezonde vrijwilligers als ook van mensen van wie de darmflora mogelijk verstoord is, significant verhoogt. De klinische relevantie van deze stijging dient echter nader onderzocht te worden. Inname van L. plantarum $299 \mathrm{v}$ toont geen andere veranderingen in de bacteriële concentraties of in de bacterièle bandenpatronen, gemeten in de 
faecesmonsters. Bij vergelijking van de probioticum-groep met de placebogroep werden er ook geen veranderingen gemeten in de metabole activiteiten in de faecesmonsters, of in de bacteriële samenstelling gemeten in de mucosa. Aangezien L. plantarum $299 \mathrm{v}$ de intestinale flora niet lijkt te veranderen, zoals is aangetoond in de vijf onderzoeken beschreven in dit proefschrift, kan de bacteriële samenstelling als relatief stabiel worden beschouwd. Dit proefschrift toont echter een significant verschil in de bacteriële samenstelling indien $\mathrm{CU}$ patiënten worden vergeleken met gezonde personen.

Het werkingsmechanisme van L. plantarum $299 \mathrm{v}$ in het maagdarmkanaal dient verder onderzocht te worden, waarbij aandacht besteed zou moeten worden aan de hechting van de probioticumstam aan de mucosa, de invloed op de metabole activiteiten in de mucosa en de effecten op het immuunsysteem. 
Dankwoord 


\section{Dankwoord}

Dit boekje had hier nooit gelegen zonder de hulp van veel personen. Deze personen wil ik graag bedanken.

Allereerst wil ik mijn promotor Reinhoid Stockbrügger bedanken voor de begeleiding van dit probioticum-project op de afdeling Gastroenterologie. Uw kennis en scherpe inzicht hielden mij altijd alert binmen de "probiotica-wereld". In de eindfase heb ik veel kunnen leren van uw kritische doch waardevolle opmerkingen. Hartelijk dank voor de begeleiding.

Mijn co-promoteren wil ik bedanken. Daisy Jonkers, jij bent mijn dagelijkse begeleider geweest en hebt me steeds op het juiste spoor weten te houden. Alle labresultaten hebben we samen doorgenomen, de protocollen uitgediept, presentaties voor congressen voorbereid en tenslotte alle artikelen gecorrigeerd en dat altijd met veel enthousiasme en precisie. Ik hoop dat je nog veel interessante onderzoeken zult opzetten en onderzoekers blijft begeleiden op de afdeling. Jammer dat we nu geen buurvrouwen meer zijn.

Maurice Russel, jouw begeleiding in de eerste fase van mijn promotie heb ik als nuttig en leerzaam ervaren. De begeleiding is beperkt geworden na je verhuizing, maar toch wil ik je bedanken voor het blijven becommentariëren van mijn artikelen.

Vervolgens wil ik Ellen Stobberingh bedanken. Natuurlijk omdat ik alle analyses op het lab bacteriologie research mocht uitvoeren, maar ook voor het meedenken bij de studies, het bespreken van de bevindingen en het becommentariëren van mijn artikelen. Jouw aanwijzigen waren nuttig en heb ik altijd gewaardeerd.

Dan heeft Ton van den Bogaard mij de eerste twee jaren de nodige probioticaartikelen toegeschoven en was actief betrokken bij het project. Helaas werd onze samenwerking na twee jaar abrupt beëindigd. Een gemis, niet alleen voor dit project maar voor de hele afdeling.

Ton Mestrom en de verpleegkundigen van de endoscopie-afdeling wil ik bedanken voor hun hulp bij het verzamelen van de biopten in de juiste buisjes. Ik wil in het bijzonder de artsen bedanken die voor dit onderzoek tijdens het scopiëren extra biopten hebben verzameld of tijdens hun poli de patiënten nog eens benadrukten dat er een interessant project gaande was. lets wat niet altijd makkelijk was bij een hoge werkdruk.

Math Hazen en Jacqueline Maes van het CPV will ik bedanken voor de begeleiding bij het bepalen van de SCFA-concentraties. Het bleef spannend al die pieken.

Jildou Sijbrandij wil ik bedanken voor de hulp die zij mij bood bij de statistische analyses.

Het lab moleculaire microbiologie van de Wageningen Universiteit, in het bijzonder Elaine Vaughan, Hauke Smidt en Hans Heilig, wil ik bedanken voor de gasturijheid om mij binnen twee maanden de DGGE-techniek aan te leren 
en de samples van één studie door te laten meten. Het was makkelijk aanschuiven bij deze zeer geïnteresseerde groep onderzoekers.

I would like to thank the persons working at Probi AB in Sweden who were very interested in this project and with whom I had scientific discussions about the results. My special thanks are for Goran Molin, Siv Arhné and his laboratory personnel. All the analyses to identify $L$. plantarum $299 \mathrm{v}$ were done by his group as well as the molecular analyses described in chapter 6 . I would also like to thank Monica Molin at Probi AB for sending me all the batches with study products and for the blinding of the studies.

Alle vrijwilligers en patiënten wil ik bedanken voor hun deelname aan de onderzoeken. Zij hebben immers de vragenlijsten ingevuld, de ontlastingsmonsters verzameld en de scopiën ondergaan.

Ook mijn huidige werkgever Numico Research B.V. wil ik bedanken omdat mij de kans is gegeven dit onderzoek af te ronden.

Mijn collega's van de afdeling Gastroenterologie wil ik bedanken voor de prettige samenwerking. Mietsie Tijssens en Elly Mares van het secretariaat wil ik bedanken voor hun behulpzaamheid. Tiny Wouters wil ik bedanken voor de lay-out van dit proefschrift. Dan waren er de mede-onderzoekers met wie ik kon lunchen, bijkletsen of gezellig in de stad iets kon eten: Martine, Ingrid, Daisy, Karen, Ardi, Michiel, Mia, Tessa, Fred, Henrike, Steven en Andrea. Het hebben van gezellige collega"s is zo belangrijk.

Mijn collega's van de afdeling Medische Microbiologie wil ik bedanken voor de vele en gezellige uren op het lab. De stagiaires Annemarie, Sandra, Hanne en Tim wil ik bedanken voor de vele lab bepalingen die zij voor mij hebben uitgevoerd. Daarnaast vond ik op de afdeling medische microbiologie een grote groep collega's met wie het niet alleen prettig werken was, maar met wie ik ook samen kon lunchen, in de stad kon eten, dagjes uit mocht beleven en die ik kon treffen in de pub. Wat zou het kaal geweest zijn zonder jullie als collega's .

Gelukkig was er in het weekend ook de nodige afleiding. Vanuit Maastricht heb ik echt alle kanten op gereisd: Aalst, Aalten, Boxtel, Delft "Den Haag, Ede, Elst, Geldrop, Haarlem, Hoogkerk, Hornborga, Nijmegen, Rijswijk, Zuidlaren, Zwolle... Lieve familie en vrienden, ik geniet van alle bezoeken en het gaf mij een goede afleiding.

Dan zijn er mijn twee paranimfen die ik wil bedanken: Karen, jij hebt mijn onderzoek van $A$ tot $Z$ gevolgd. Jij was de tweede probioticum-AlO waardoor we naast elkaar aan de labtafel zaten en elkaars onderzoek overnamen bij afwezigheid. Ik had geen betrouwbaarder en gezelliger persoon kunnen treffen. Samen met jou op het werk was het altijd leuk!

Miriam, met jou heb ik veel 'fasen' samen doorlopen: studie in Nijmegen, AIO in Maastricht en voor de partner Limburg weer verlaten. Daardoor waren mijn verhalen voor jou herkenbaar en andersom. ik ben blij dat jij mijn paranimf wilt zijn. 
Mijn dank gaat uit naar mijn ouders omdat ze mij de kans hebben gegeven te gaan studeren en samen met mijn zus en broer altijd geïnteresseerd zijn gebleven in de voortgang van mijn proefschrift.

Tenslotte wil ik Wim bedanken. Ondanks de grote afstand was je er de afgelopen jaren voor mij altijd en als ik in alle drukte het overzicht kwijt raakte, gaf jij mij rust. Bedankt voor je luisterend oor en vertrouwen. 
Curriculum Vitae 


\section{Curriculum Vitae}

Dominique Anne Marie Goossens is geboren op 5 januari 1976 te Eindhoven. Zij groeide op in Aalst-Waalre en behaalde in 1994 haar WWO diploma aan het Augustinianum te Eindhoven. Vervolgens startte zij met de studie Biomedische Gezondheidswetenschappen aan de Katholieke Universiteit te Nijmegen met als afstudeerrichting Toxicologie. Zij was gedurende een half jaar studente Humane Voeding aan de Wageningen Universiteit. Zij liep stage bij de afdeling Interne Geneeskunde in het Radboud Ziekenhuis te Nijmegen en bij de vakgroep Toxicologie aan de Wageningen Universiteit en behaalde in 1999 haar doctoraal examen. In november 1999 startte zij als assistent in opleiding bij de vakgroep Interne Geneeskunde van de Universiteit Maastricht onder leiding van Prof. Dr. R. Stockbrügger, Dr. D. Jonkers en Dr. M. Russel. In haar promotie-onderzoek werkte zij nauw samen met de afdeling Medische Microbiologie. Sinds 1 september 2005 is zij werkzaam bij Numico Research B.V. 